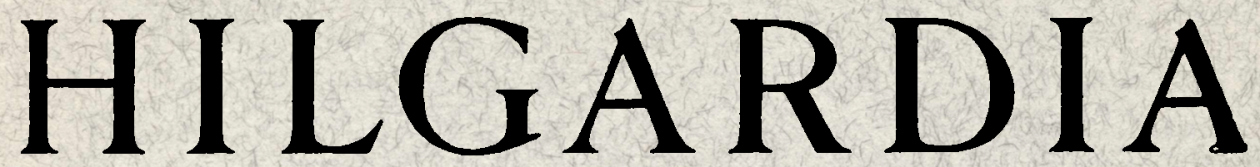

A Journal of Agricultural Science Published by the California Agricultural Experiment Station

\title{
TAXONOMIC STUDY OF CALIFORNIA MEALYBUGS \\ WITH DESCRIPTIONS OF NEW SPECIES \\ (Homoptera: Coccoidea: Pseudococcidae)
}

HOWARD L. MCKENZIE

This ends Volume 29

UNIVERSITY OF CALIFORNIA - BERKELEY, CALIFORNIA 
Introduction

Economic importance

Morphology

Definition of family Pseudococcidae .

Key to genera of North American Pseudococcidae

Genus Chorizococcus McKenzie, new genus .

Chorizococcus abroniae MeKenzie, new species .

Chorizococcus brevicruris MeKenzie, new species

Chorizococcus microporus McKenzie, new species

Chorizococcus peregrinus (Green)

Chorizococcus psoraleae McKenzie, new species

Chorizococcus wilkeyi McKenzie, new species

Genus Heliococcus Sulc

Heliococcus Gddenostomae McKenzie, new species

Genus Humococcus Ferris . . . . . . . . . . . . . . . . . . 709

Humococcus caritus McKenzie, new species.

Humococcus inornatus McKenzie, new species

Genus Phenacoccus Cockerell .

Phenacoccus echeveriae McKenzie, new species .

Phenacoccus graminosus McKenzie, new species.

Phenacoccus lotearum McKenzie, new species

Phenacoccus tibiaegracilis McKenzie, new species.

Pseudococcus importatus McKenzie, new species

Pseudococcus microcirculus McKenzie, new species

Puto acirculus McKenzie, new species .

Puto profusus McKenzie, new species .

Genus Pygmaeococcus McKenzie, new genus . . . . . . . . . . 741

Pygmaeococcus morrisoni McKenzie, new species . . . . . . . . . . . 741

Genus Rhizoecus Künckel d'Herculais . . . . . . . . . . . . . . . . 742

Rhizoecus bituberculatus McKenzie, new species . . . . . . . . . . 743

Rhizeocus eluminatus McKenzie, new species . . . . . . . . . . . . .7747

Rhizoecus pritchardi McKenzie, new species. . . . . . . . . . . . . 749

Rhizoecus sonomae McKenzie, new species . . . . . . . . . . . . 751

Rhizoecus spinosus McKenzie, new species . . . . . . . . . . 753

Genus Spilococcus Ferris . . . . . . . . . . . . . . . . . . 755

Spilococcus cactearum McKenzie, new species . . . . . . . . . . 757

Spilococcus keiferi McKenzie, new species . . . . . . . . . . . 761

Spilococcus parvicirculus McKenzie, new species . . . . . . . . 763

Genus Trionymus Berg . . . . . . . . . . . . . . . . 764

Trionymus haancheni McKenzie, new species . . . . . . . . . . . . 765

Acknowledgments . . . . . . . . . . . . . . . . . . . . . 769

Literature cited . . . . . . . . . . . . . . . . . 770 


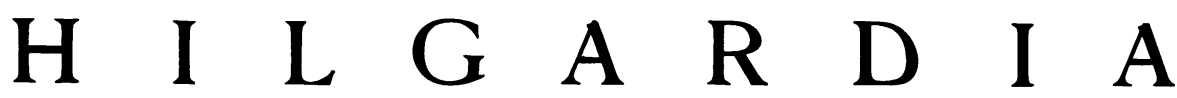

A Journal of Agricultural Science Published by

the California Agricultural Experiment Station

VoL. 29

JUNE, 1960

No. 15

\section{TAXONOMIC STUDY OF CALIFORNIA MEALYBUGS, WITH DESCRIPTIONS OF NEW SPECIES (Homoptera: Coccoidea: Pseudococcidae) ${ }^{1}$}

\author{
HOWARD L. MCKENZIE²
}

\section{INTRODUCTION}

ONE MAY be a little surprised that so many new species of mealybugs, 28 forms herein described, have turned up in California so soon after the late Professor G. F. Ferris' $(1950-53)^{3}$ Atlas of the Scale Insects of North America, the Pseudococcidae, Parts I and II, was completed. This is not surprising, however, when one realizes that Professor Ferris' primary intention was to clarify existing names rather than to describe new species. As a matter of fact, he made no particular search in available material for new species, and much of it was deliberately set aside and omitted from consideration. Certain undescribed species were included in his treatise only because they were involved in the synonymy of other species through misidentifications, or because they would assist in clarifying some group that would otherwise be inadequately considered.

The purpose of the present study is to describe and delineate new California species of mealybugs, and to comment briefly on the taxonomy of other named forms if necessary. Additional undescribed pseudococcid species in the state are a practical certainty and subsequent collections, particularly of those forms occurring underground, will no doubt reveal many of the additional species which will have to be dealt with later on. However, it seems advisable to bring together all of the available information accumulated thus far and to publish this as a contribution to the knowledge of the Pseudococcidae. Later on, these data will be incorporated in a systematic exposition on "California Species of Mealybugs" to appear as a companion piece to the author's recent publication (1956), The Armored Scale Insects of California.

It is also the objective of this study to recast the key to genera of North American Pseudococcidae, as well as to prepare keys to the North American species. This has become necessary because certain new California mealybug genera exhibit morphological characters not provided for in existing keys

${ }^{1}$ Submitted for publication July 1, 1959.

${ }^{2}$ Lecturer in Entomology and Associate Entomologist in the Experiment Station, Davis.

${ }^{3}$ See "References" at end of manuscript. 
presented in Ferris' Atlas. A few comments are given on economic importance mostly of certain subterranean mealybug species.

Much of the material, including the new California pseudococcid species, was found in the extensive collections of the California State Department of Agriculture, Bureau of Entomology, at Sacramento. The writer's position as taxonomist with that organization, for several years prior to his employment with the University of California, gave him access to a considerable amount of mealybug material submitted for identification from various sources throughout the state. Additional material was also found in the Stanford University collection; the United States National Collection of Coccoidea, Washington, D.C.; the University of California, Citrus Experiment Station collection at Riverside; the Los Angeles County Agriculture Commissioner's Office collection at Los Angeles; and in the author's own collection.

\section{ECONOMIC IMPORTANCE}

It was not the intention of the author to mention economic aspects of California mealybugs in this publication, but certain events which have arisen during the course of these taxonomic investigations seem to justify the inclusion.

Members of the Coccoidea family Pseudococcidae are among the most serious pests of plant life. One needs only to mention the devastating effect the citrus mealybug, Planococcus citri (Risso), and the citrophilus mealybus Pseudococcus gahani Green, have had on the citrus industry to make this clear. Specimens of a new species of California mealybug, Phenacoccus graminosus McKenzie, which may be of some economic importance in the state, have also been received from Miss Helen M. Brookes, Coccidologist at the University of Adelaide, Waite Agricultural Research Institute, Adelaide, South Australia. She reports the species in that region infests barley, canarygrass, ryegrass, and wheat. In one instance the mealybugs were living in large colonies among the spikelets of Phalaris tuberosa (bulb canarygrass), feeding on the peduncle rather than on the ovaries. In this case they seem to have been responsible for the failure of many seeds to germinate.

Another California species, Trionymus haancheni McKenzie, described as new in this publication, has reportedly caused economic concern to Haanchen barley in the Tulelake area by producing accumulations of a thick honeydew secretion extensive enough to cause clogging of combine machinery during harvest. Additional comments are made about this damage immediately following the technical description of the mealybug.

Aside from numerous other species of mealybugs feeding aboveground and causing economic concern to commercial, subtropical, and ornamental plants, there appears to be an enormous fauna of subterranean species about which very little is known. Hambleton (1946), in his studies of hypogeic mealybugs, records that two workers, Bünzli (1935) and Weber (1944), have demonstrated the importance of soil-inhabiting mealybugs in the production of certain tropical crops. No less than 10 species of ground mealybugs are associated with ants on roots of Coffea liberica in Dutch Guiana. Apparently, coffee and cacao are infested with so many species of subter- 
ranean mealybugs that it would be reasonable to assume that these insects will be found to play a more important role as pests than has previously been suspected.

Reeent collections of Rhizoecus kondonis Kuwana, on roots of alfalfa, strawberry, and in leaf mold with uncertain plant associations, indicate that this species is more widespread in California than previously supposed, and that it is capable of causing serious economic damage to some of these commercial crops.

Collections of Rhizoecus kondonis Kuwana were made in company with Dr. W. H. Lange of the University of California, during November, 1958, on the roots of alfalfa grown on a ranch eight miles west of Santa Rosa, Sonoma County, California. This mealybug was found aggressively feeding on alfalfa roots and causing extensive brown areas of killed and stunted plants (Plate I, bottom row, right). Recent information (June, 1959) indicates that the alfalfa stand within the affected area has been reduced by approximately 50 per cent.

The land on which this alfalfa was grown was originally planted to Gravenstein apple. In 1929 the orchard was removed, and from that time until the fall of 1950 it was alternately sown to Sudangrass and oats. In 1951 the land was put into alfalfa and left in that crop for three years. Finally the alfalfa was removed, and each year thereafter, until the fall of 1956, the land was sown to oats. In the spring of 1957 it was again put into alfalfa. The alfalfa was grown on alluvial type soil near a creek bed. It was nonirrigated, but subterranean water provided enough moisture to promote sufficient plant growth to justify three or four cuttings annually.

The mealybugs were found to be feeding in great numbers just beneath the soil surface and to depths of more than 38 inches (Plate I, bottom row, left). Small soil samples collected at various depths, i.e., 8 inches, 12 inches, 24 inches, and 36 inches were put into plastic bags and brought into the laboratory. These soil samples were then placed in four separate Berlese funnel traps. The results of mealybugs (nymphs and adults) recovered from the traps are summarized as follows: 8 inches $=3$ specimens; 12 inches $=3$ specimens ; 24 inches $=12$ specimens ; and 36 inches $=23$ specimens. No attempt was made to determine the number of mealybugs per cubic foot of soil in the alfalfa field. It is suspected that alfalfa growing in areas where frequent summer and fall irrigations are practiced may not be so susceptible to attack by this mealybug.

Specimens of this same subterranean mealybug, Rhizoecus kondonis, collected from soil tube cores down to a depth of 6 feet beneath prune trees growing in the Yuba City area, Sutter County, California, were recently brought into the laboratory for identification by Dr. K. Uriu of the University of California, Department of Pomology. According to Dr. Uriu, the orchard from which the mealybugs were taken displayed zinc and potassium deficiency symptoms and, therefore, zinc and potassium plots were established to correct the situation. Apparently, the zinc symptoms were corrected, but the presence of yellow and scorched leaves typical of potassium deficiency was not altered. It is suspected that root injury produced by this mealybug could very likely be the factor in decline of these trees, 

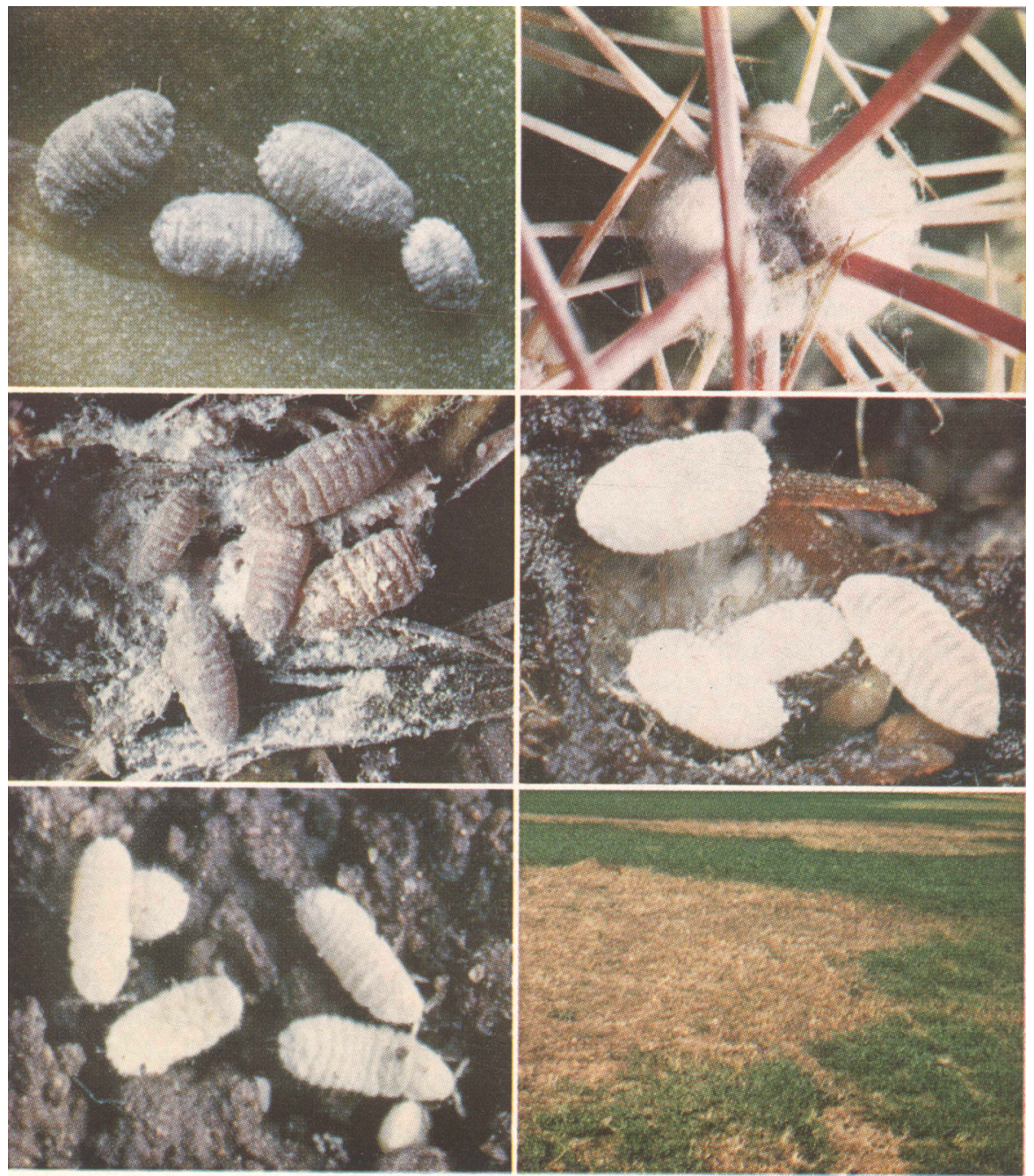

\section{PLATE 1}

Top row. Left: Spilococcus cactearum McKenzie, a cactus-infesting mealybug found in California nurseries; right: white ovisacs of same among cactus spines.

Middle row. Left: Phenacoccus graminosus McKenzie, a grass-infesting mealybug in California; right: Rhizoecus pritchardi McKenzie, a subterranean mealybug infesting roots of maiden-hair fern in California.

Bottom row. Left: Rhizoecus kondonis Kuwana, a ground mealybug infesting alfalfa roots deep in the soil; right: large patches of alfalfa grown in a field near Santa Rosa, California, were killed as a result of the root-feeding activities of this mealybug.

Lower left and upper four illustrations, taken by the author, are photomicrographs (6x-10x enlargement), while photograph on lower right is a field exposure taken by Dr. W. H. Lange of the University of California. 
Preliminary survey indicates that approximately 50 acres of prunes exhibited damage as described above.

This problem of mealybugs on prune roots was brought to the attention of Dr. S. F. Bailey, in charge of University of California investigations on insects attacking deciduous fruits. Dr. Bailey and the author visited the affected prune acreage and took hand-dug soil samples to the 3 -foot level, and soil tube core samples to the 6 -foot level, to ascertain the mealybug population per cubic foot of soil. The infested soil samples were then subjected to Berlese funnel trap treatment to recover the mealybugs. The number of mealybugs (all stages) found per cubic foot of soil at various depths in these samples is recorded as follows: 1-foot level $=1,708 ; 2$-foot level $=$ 1,245 ; and 3 -foot level $=870$. The soil tube core samples taken at the $4-, 5,-$ and 6 -foot levels were not broken up before being put into the Berlese funnel trap; this resulted in the soil hardening and trapping the mealybugs before they could emerge. Mealybugs were, however, observed in all these soil samples before they were dried out.

Hambleton (1946) records subterranean mealybugs commonly found associated with ants, and in their galleries accompanying grass roots, at depths of 8 to 10 inches below the surface. The information recorded above indicates their ability to feed effectively at greater soil depths than heretofore reported.

Rhizoecus kondonis Kuwana also appears to be a pest problem in commercial strawberry plantings. Attacked plants apparently show marked stunting, foliage fading, and devitalization resulting in a commercially nonproductive planting.

\section{MORPHOLOGY}

(Figure 1)

Some fundamental evaluations of certain morphological characteristics of adult female Pseudococcidae have developed as a result of this investigation. Not all morphological details are discussed, only those of systematic importance. Brief comments about these structural characters are recorded under the following headings (see figure 1 for morphological details of Pseudo. coccidae):

\section{Antennae}

The antennae have for a long time been used as a diagnostic character for recognizing mealybug genera, and even for species separation. Earlier pseudococcid descriptions, in fact, placed more emphasis on this structure than on any other physical detail.

It has been noted that in certain genera, exclusive of Rhizoecus and Geococcus where the antennae are noticeably short, small, 5- to 6-segmented and geniculate, the comparative slenderness or stoutness of the normal cylindrical antenna in relation to its length has proved of considerable taxonomic value. This is exemplified in certain species of Chorizococcus McKenzie, herein described as new, and Spilococcus Ferris included in this publication. It is difficult to translate these features into key characters, but they certainly stand out when direct comparison is made. The distance between the base of 


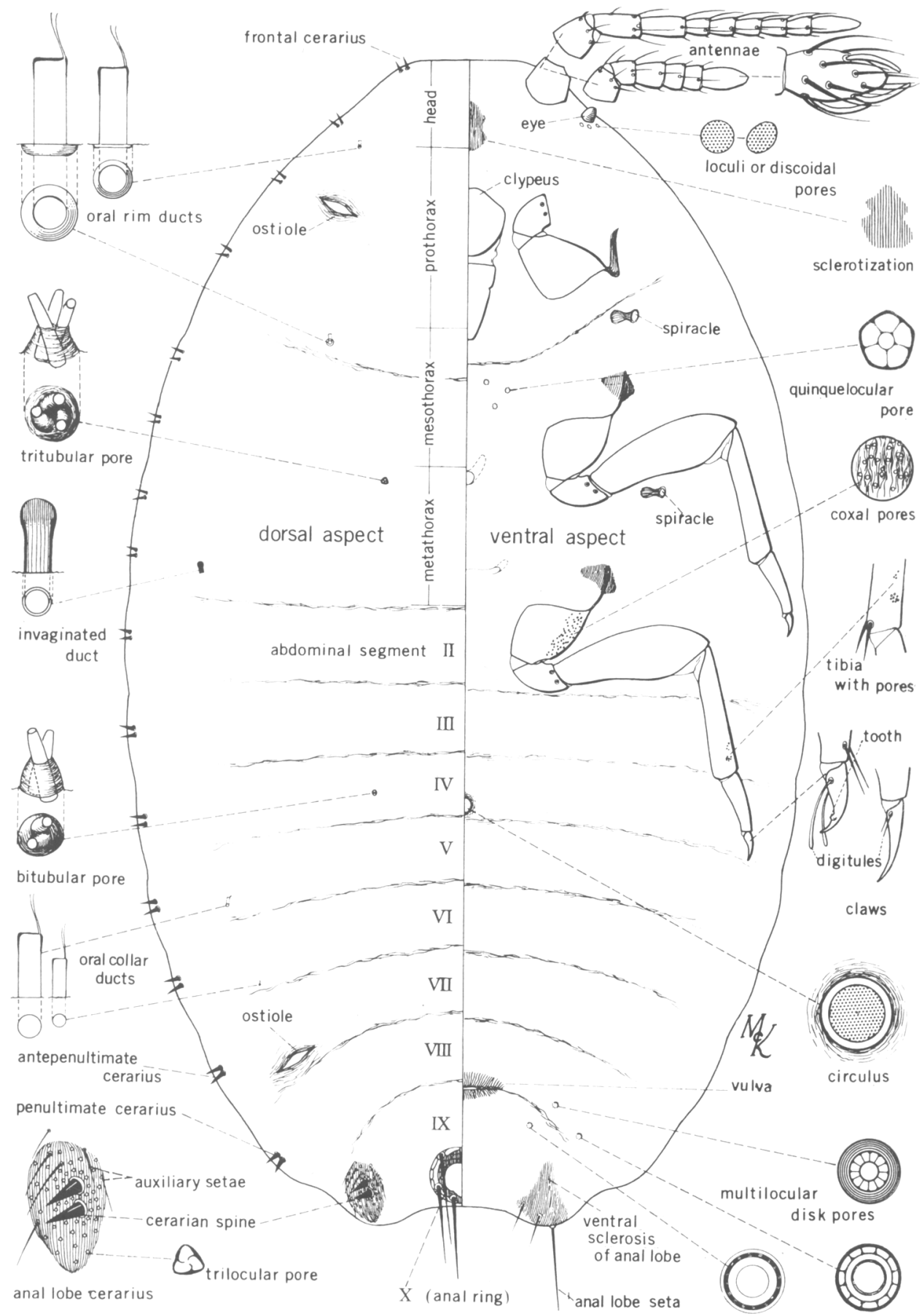

Fig. 1. Generalized and semidiagrammatic drawing representing morphological structures of the mealybug family, Pseudococcidae. 
one antenna and that of the other is of considerable value in separating species, particularly in certain members of Rhizoecus. Perfectly mounted specimens are needed for this comparison.

It has been observed that mealybugs are occasionally so over-treated in mounting, presumably with potassium hydroxide, that the antennal segments may collapse into closely appressed upper and lower planes, giving a shorter appearance than is to be found in a normally cylindrical segment. Most modern mounting procedures, however, tend to avoid such damage.

\section{Eyes}

Most coccidologists have placed little taxonomic emphasis on the eyes of mealybugs. In the author's opinion, however, the presence or absence of eyes in Rhizoecus and related genera has proved to be taxonomically useful.

In certain Pseudococcus species there are tiny loculi or discoidal pores associated with the eyes, and these structures appear to have some taxonomic significance. Additional remarks about these pores are made in the section dealing with pores and ducts.

\section{Mouthparts}

The rostrum or beak is a cone-shaped structure which lies approximately between, and slightly anterior to, the front coxae. As a general rule, the rostrum is approximately one third longer than broad, although in some species it is almost as broad as long. According to Ferris (1950), the anterior sclerotized portion of the mouthparts is the clypeus, including the internal framework of the tentorium, mandibles, and maxillae bases. The clypeus varies in shape from species to species and may, at times, be of taxonomic significance.

The labium appears to be 3-segmented, the basal segment quite small and inconspicuous, comprising a small, sclerotized piece at each side. The labium varies considerably in shape and form, and may be elongate and slender in some species, while in others it is short and broad.

In certain species there appear to be significant differences in shape of both the basal segment and the tip of the rostrum.

Some species exhibit a sclerotized area on the derm just anterior to the clypeus. In some instances, this has been of taxonomic assistance.

\section{Legs}

Considerable taxonomic emphasis has been placed on mealybug legs in the past by certain coccidologists. A principal leg character was considered to be the presence or absence of a denticle or tooth on the plantar surface of the claw. Ferris (1950) in his Atlas on Pseudococcidae, Volume V, states: "This tooth is, at its very highest development, a quite insignificant character, yet it correlates very closely with other characters which in their totality define the genera that may be referred to as the 'phenacoccus series.' It is sometimes extremely small, yet in the course of the experience of preparing this work it has not yet been observed to fail, and it offers a very excellent 'key character' for the recognition of this series of genera." 
Recent developments indicate that this character, although still generally quite helpful in defining members of the genus Phenacoccus, cannot be completely relied upon as exemplifying this group alone. In the case of many species of Chorizococcus McKenzie and Spilococcus Ferris, this tiny denticle or tooth on the claw is present, and it occurs in combination with other characters not at all typical of the Phenacoccus series.

The claws bear two apically spatulate or setose digitules which arise, one on each side, from near claw bases. The digitules may be long or short. If they are long, they may extend to or slightly beyond the tip of the claws and may be either knobbed or setose at apices. Digitules less than half the claw length are usually setose. In certain genera these structures are useful tools especially in species recognition.

The character and arrangement of spines on the legs, particularly those situated along ventral surface of the tarsi and on the tibiae, are often useful characters since they exhibit considerable variation particularly among species of the hypogeic genera. Translucent dots or pores occur on the hind tibiae of quite a few mealybugs. In one species observed, these structures on the apical half of hind tibia appear to have definite significance for species segregation.

In some mealybug forms, each hind coxa bears a cluster of pores at its base, and the area in which these occur is usually wrinkled. The author believes this pore cluster is taxonomically important for differentiating certain species.

The stoutness or slenderness of pseudococcid legs in relation to their length has proved to be of much taxonomic importance in the present studies. These characteristics are difficult to translate into key characters, but they are certainly very useful when direct comparisons are made.

\section{Pores and Ducts}

It is becoming increasingly evident that the types and distribution of the various pores and ducts on the body provide the basic foundation for recognition of species and, in some cases, of genera. The arrangement of these structures, once carefully worked out in illustration, appears as the most important systematic aid yet found in this group of Coccoidea.

Several different types of pores and ducts may be recognized in the Pseudococcidae. A few of the pore types include bitubular and tritubular (sometimes called bi- or tritubular cerores), trilocular, multilocular (sometimes called discoid or genacerores), and quinquelocular.

Still another pore type includes what Borkhsenius (1947 and 1948) calls "discoidal pores" situated near the eyes. The author has observed these structures on both body surfaces in a new species of Pseudococcus described in this publication. These small, round or oval pores have here been designated as loculi or discoidal pores. They may be incorporated within the margin of the eye base, or situated an appreciable distance away from this area, but still recognizably associated with the eye itself. Pores of this kind seem actually to occur in quite a few species, and Borkhsenius has used them, together with other structural characters, to separate certain species of Pseudococcus. The pores are often so very small that they may pass un- 
detected in poorly stained preparations. It is here believed that more taxonomic significance will be placed on this character in the future.

Some of the duct types are designated as invaginated, oral collar, and oral rim. The first type mentioned has been noted on one of the new species of mealybug dealt with in this study. An invaginated duct is rounded or "domeshaped" internally, and apparently exhibits traces of a septum across its inner end (see figure 1).

\section{DEFINITION OF FAMILY PSEUDOCOCCIDAE}

It is advisable at this point to sum up the morphological characteristics which exemplify the mealybug family Pseudococcidae. A definition of the family follows:

Anal ring always present, divided longitudinally into 2 halves, each with single inner and outer rows of angular cells and 3 setae; in a few instances the ring is very much reduced, the sclerotization is slight, and the pores apparently are nearly or completely lacking. Two pairs of dorsal ostioles normally present in the adult female. In some species the number of these structures may be reduced or they may be entirely lacking, thus in some forms the posterior pair is clearly present but anterior pair lacking; in a few forms the ostioles seem to be lacking in the adult, but are present in the first stage. Others lack ostioles in all stages; nevertheless, the totality of their characters places them in this family. Antennae present in adult, normally with from 5 to 9 segments except in a few forms where they are reduced to mere 2-segmented tubercles. Body form normally elongated; legs normally present and usually quite well developed in the adult, sometimes reduced, vestigial, and at times completely lacking in this stage. Body normally with lateral groups of pores and enlarged, conical setae or spines which form cerarii, these at times evident only in anal lobes, sometimes with more, occasionally lacking; normally with pores of the trilocular type present, rarely lacking. Tubular ducts of a distinctive type normally present as cylindrical invaginations in the derm, the tube usually more heavily sclerotized at its opening, and with one side of inner end of tube showing a delicate filamentous prolongation.

Combinations of one or more of these characters will define the few aberrant forms of mealybugs known to exist.

\section{KEY TO GENERA \\ OF NORTH AMERICAN PSEUDOCOCCIDAE}

It is quite obvious that due to our increase in knowledge of California Pseudococcidae there has been a subsequent change in the classificatory status of certain generic categories. This is not unusual and was actually, at least to some degree, anticipated. In order to accommodate two new genera here included, it is desirable to revise Ferris' (1953) key to adult females of North American genera of Pseudococcidae, as presented in his Atlas, Volume VI. A revision of the key is here presented.

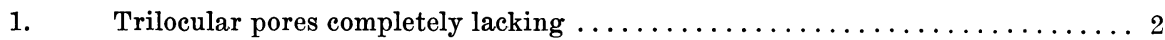

Trilocular pores present at least somewhere on body $\ldots \ldots \ldots \ldots \ldots \ldots \ldots$ 
2 (1). Antennae 9-segmented, claws denticulate; both quinquelocular and multilocular disk pores present .................HETEROCOCCUS Ferris

Antennae 6-segmented, claws without denticle; multilocular disk pores only present

MISERICOCCUS Ferris

3 (1). Dorsum with cerarian spines and some body setae enlarged, stout, and in form of a truncate cone ...............STEMMATOMERINX Ferris Dorsum with cerarian spines conical, and body setae basically lanceolate .... 4

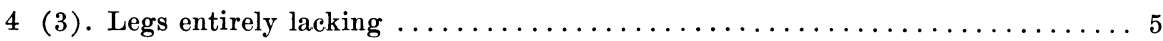

Legs present, though sometimes considerably reduced in size $\ldots \ldots \ldots \ldots \ldots 6$

5 (4). Anal ring completely exposed on dorsal body surface, not at all invaginated, bearing setae which are shorter than diameter of ring itself

PALUDICOCCUS Ferris

Anal ring at least slightly and usually deeply retracted into end of abdomen, bearing setae which are longer than diameter of ring itself

ANTONINA Signoret

6 (4). With at least a few enlarged and elongated tubular ducts, the orifices of which are borne at the apex of sclerotized, projecting tubercles

HELIOCOCCUS Sule

Tubular ducts of this type lacking $\ldots \ldots \ldots \ldots \ldots \ldots \ldots \ldots \ldots \ldots \ldots$

7 (6). Dorsal multilocular disk pores present and arranged in groups of 3 to 6 pores, each group with a tubular duct at its center.PELIOCOCCUS Borkhsenius

Dorsal multilocular disk pores if present not thus arranged, without a

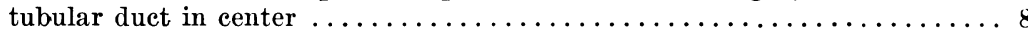

8 (7). Posterior coxa either enlarged and flattened into a plate or area beset with small pores, or coxa normal in size and lying in an enlarged area beset with small pores .................... PSEUDANTONINA Green

Posterior coxa not enlarged into a plate or area beset with small pores, or if normal in size not lying in an area beset with pores $\ldots \ldots \ldots \ldots \ldots \ldots 9$

9 (8). Each cerarius, including those anterior to anal lobe pair, formed upon a sclerotized plate bearing from 6 to 20 , or perhaps even more, enlarged setae or spines ...........................

Cerarii anterior to anal lobe pair, not formed upon a sclerotized plate, if certain cerarii have associated sclerotization these never with more than

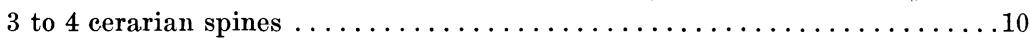

10 (9). Tubular ducts on dorsum comparatively large and conspicuous, with orifice surrounded by a sclerotized area from which there arise 1 or more setae

FERRISIANA Takahashi

Tubular ducts on dorsum with orifice not surrounded by such a sclerotized

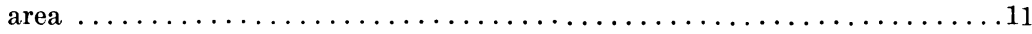

11 (10). Spiracles enlarged, rather heavily sclerotized, with a curved, rather dense band of pores of two kinds across opening of spiracle. ANTONINOIDES Ferris Spiracles not abnormally enlarged, only moderately sclerotized, but without a dense curved band of pores of two kinds across spiracle opening . . . . . . . 12

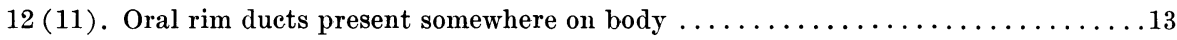

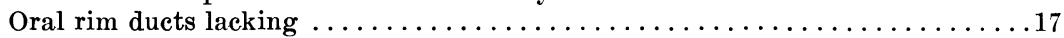

13 (12). Anal ring simplified, abortive, bearing no, or at the most 10 to 12 , cellular

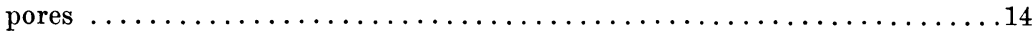

Anal ring well developed, with more than 12 cellular pores . . . . . . . . . 15

14(13). Antennae 8-segmented ................. DISTICHLICOCCUS Ferris Antennae 5- to 7-segmented; part of ............HUMOCOCCUS Ferris

15 (13). With 16 to 17 pairs of cerarii, at least 16 of these possessing small, slender, auxiliary setae in addition to cerarian spines

PSEUDOCOCCUS Westwood

Cerarii number from 0 to 17 , but only anal lobe pair, and at times penultimate cerarii, may possess the small, slender, auxiliary setae ..........16

16(15). With from 0 to 4 pairs of cerarii present .......CHORIZOCOCCUS McKenzie With from 6 to 17 pairs of cerarii present ...........SPILOCOCCUS Ferris 
17 (12). Denticle or tooth, well developed or very tiny, present on the plantar

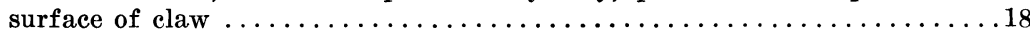

Denticle or tooth lacking on plantar surface of claw $\ldots \ldots \ldots \ldots \ldots \ldots \ldots \ldots 21$

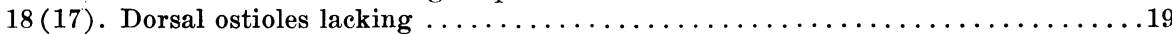

At least posterior pair of ostioles present $\ldots \ldots \ldots \ldots \ldots \ldots \ldots \ldots \ldots \ldots \ldots \ldots \ldots$

$19(18)$. One circulus, or more, present ..............CUCULLOCOCCUS Ferris Circulus lacking .....................EHRHORNIA Ferris

20 (19). Cerarii present only on anal lobes, or completely lacking

AMONOSTHERIUM Morrison and Morrison

Normally with 18 pairs of cerarii, sometimes reduced to 5 or 6 pairs

$P H E N A C O C C U S$ Cockerell

21 (17). Dorsal tubular ducts always with a small adventious cell adjoining the main orifice; anal lobe cerarii always with several conical setae and surrounded by a definite area of sclerotization ........ANISOCOCCUS Ferris

Dorsal tubular ducts never with an adventious cell joined to the main orifice; anal lobe cerarii only rarely with several conical setae contained within a definite sclerotized area, if such an area is present it usually

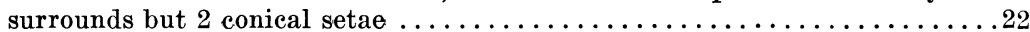

22 (21). The 3 terminal segments of abdomen each with a dorsal sclerotization which extends nearly or quite across the abdomen ...POROCOCCUS Cockerell

Terminal abdominal segments without such dorsal sclerotization ........23

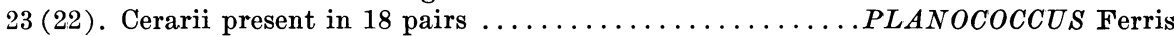

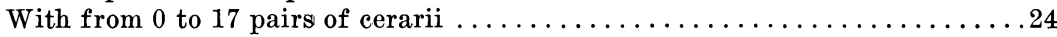

24 (23). Dorsal body setae of the abdomen nearly or quite as large as those of the

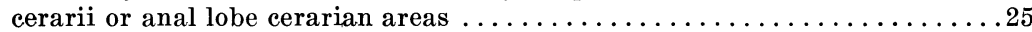

Dorsal body setae slender, smaller in size and form as compared to setae of the cerarii (if cerarii are present) or of the cerarian areas $\ldots \ldots \ldots \ldots 26$

25 (24). Anal lobe cerarii with but 2 stout setae or spines ........NIPAECOCCUS Sulc

Anal lobe cerarii with several stout setae or spines ....HYPOGEOCOCCUS Rau

26 (24). Each spiracle borne within the arms of a crescentic area of sclerotization

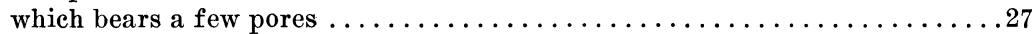

Spiracles with their openings not thus borne within the arms of a crescentic

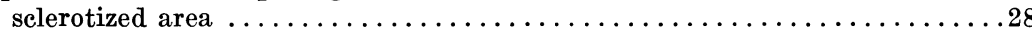

27 (26). Anal ring broadly sclerotized and bearing large setae which are considerably longer than the diameter of the ring itself; posterior dorsal ostioles alone present ....................SYRMOCOCCUS Ferris

Anal ring very narrowly sclerotized and bearing very small setae which are shorter than the diameter of the ring itself; dorsal ostioles entirely lacking ..............................

28 (26). Anal lobe cerarii with at least 5 to 6 , usually many more, conical setae

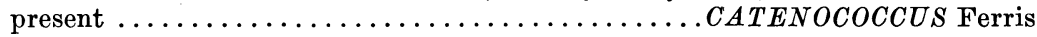

Never with the number of conical setae in anal lobe cerarii, if cerarii are

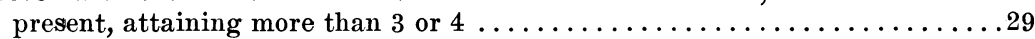

29 (28). Circulus of a distinctive shape, unusually large and more or less hourglass-

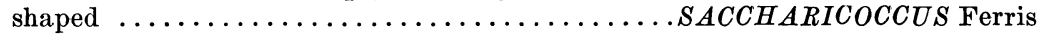

Circulus, if present, not shaped as above $\ldots \ldots \ldots \ldots \ldots \ldots \ldots \ldots \ldots \ldots \ldots \ldots \ldots \ldots$

30 (29). Anal lobes with a very distinct, ventral, narrow, sclerotized bar extending in from the base of the anal lobe seta; anal lobe seta longer than anal

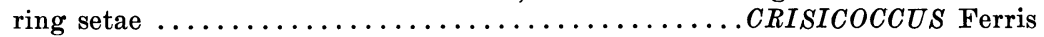

Anal lobes without ventral thickening, or this shaped otherwise if present; anal lobe seta shorter than anal ring setae $\ldots \ldots \ldots \ldots \ldots \ldots \ldots \ldots \ldots \ldots \ldots$

$31(30)$. Anal lobes with their cerarii represented by paired, conical setae .........39

Anal lobes with their cerarii represented by a pair of slender, distinctly paired setae, or with no recognizable cerarii $\ldots \ldots \ldots \ldots \ldots \ldots \ldots \ldots \ldots 2$

32 (31). With invaginated tubular ducts, rounded or dome-shaped at inner end; adult female at maturity extremely small, measuring not more than 0.75 $\mathrm{mm}$ in length ...............................

Tubular ducts variously shaped but not rounded or dome-shaped at inner end; adult female at maturity measuring not less than $1.25 \mathrm{~mm}$ in length....33 
33 (32). Body setae evident in considerable numbers $\ldots \ldots \ldots \ldots \ldots \ldots \ldots \ldots \ldots$

Body setae almost completely lacking, there being apparently only 2 pairs which mark position of anal lobes ............. RADICOCCUS Hambleton

34 (33). Distinctive bi- or tritubular pores present ...RHIZOECUS Künckel d’Herculais

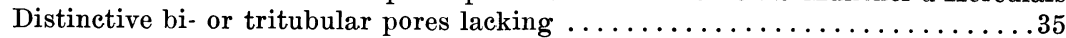

35 (34). Antennae 5-segmented .................. EORHIZOECUS Hambleton

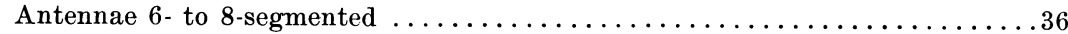

36 (35). Anal ring abortive, simplified, bearing no, or at the most 10 to 12 cellular pores ; part of ........................HUMOCOCCUS Ferris Anal ring well developed, with more than 12 cellular pores ...............37

37 (36). Dorsum without tubular ducts of any kind ..........EURYCOCCUS Ferris Dorsum with tubular ducts, although at times these quite small ...........38

38 (37). At least 1 circulus, usually more, present . . . . . . . . . TRIDISCUS Ferris Circulus lacking $\ldots \ldots \ldots \ldots \ldots \ldots \ldots \ldots \ldots \ldots \ldots \ldots$ CRPPORIPERSIA Cockerell

39 (31). With 6 or more pairs of cerarii present including frontal ones

$D Y S M I C O C C U S$ Ferris

With 5 or fewer pairs of cerarii present including frontal ones . . . . . . . . 40

40 (39). Body form at maturity normally elongate and slender ${ }^{4}$; circulus, if present, always quite small, circular or oval, normally not capable of folding along intersegmental line of segments between which it lies ${ }^{5}$

TRIONYMUS Berg

Body form at maturity broadly oval or rotund; circulus, if present, extending across the fold between the fourth and fifth abdominal seg-

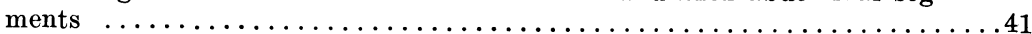

41 (40). Cerarii confined to anal lobe pair ........... At least 4 to 5 pairs of cerarii present on head and thorax ...ORACELLA Ferris

\section{Genus Chorizococcus McKenzie, new genus}

During the course of this investigation it was discovered that, for practical reasons if nothing more, it was necessary to set up a new unit of generic rank to accommodate certain pseudococcid species which have tubular ducts of the oral rim type and reduced numbers of cerarii. There was an evident complication when a species collected on Agave in southern California seemed to key to Eurycoccus in Ferris' Atlas, Volume VI, 1953. Its morphological characteristics showed no cerarii, and the circulus was large and divided by a fold between the fourth and fifth abdominal segments. On the basis of this identification, and because the species was believed to be new, a drawing of it was made for the author by Professor Ferris. Subsequently, this illustration together with mounted examples of the species were sent to Dr. Harold Morrison for comment. Dr. Morrison pointed out that the species had been originally described as a Spilococcus by Ferris in 1953. The results of these observations would seem to justify the erection of a new genus to accommodate this mealybug and 12 other species, all but 5 of which have been previously assigned to other groups. A description of the new genus is here presented.

Generic type. Chorizococcus wilkeyi McKenzie, described as new in this publication, is here designated as type of Chorizococcus McKenzie.

\footnotetext{
${ }^{4}$ Trionymus magnus (Cockerell and Cockerell) is one exception, although its circulus is very small and undivided, and all other characters are typical of Trionymus.

${ }^{5}$ Trionymus haancheni McKenzie, herein described as new, and Trionymus modocensis (Ferris), (just transferred from Dysmicoccus Ferris), are exceptions here, although their body shape and all other features are characteristic Trionymus.
} 
Recognition characters. Length of largest available specimen is about $4.00 \mathrm{~mm}$. Pseudococcidae with a limited number of cerarii on dorsum. Type species with not more than 3 or 4 recognizable pairs of cerarii, or associations of "spines" with triloculars on each side that can be regarded as more or less developed cerarii, anal lobe pair being "complete" cerarii. Each of the latter is made up of 2 conical spines, a slight concentration of trilocular pores around these spines, and in or at the edge of this area 1 or more slender setae obviously associated with the cerarius. Penultimate cerarii with spines usually progressively smaller and more slender, no cerarii on head or thorax, except in 1 species, Chorizococcus irishii (Cockerell), which is doubtfully retained in this genus, and which possesses a frontal pair of cerarii, normally all without accessory setae, except in Chorizococcus microporus McKenzie, herein described as new, which apparently possesses auxiliary setae in penultimate cerarii. Dorsal body setae all small and slender. Tubular ductśs of the oral rim type somewhere present on body. Normally with a few oral collar tubular ducts, except in $C$. irishii (Cockerell). Trilocular pores rather evenly distributed over entire dorsum. Anal ring with 6 setae, these normally about twice as long as the diameter of the ring.

On the ventral side multilocular disk pores present predominantly in midregion of abdomen, from ninth to fourth or fifth abdominal segments. Ventral setae are slender and generally longer than those on dorsum. Trilocular pores are generally distributed over entire venter.

Circulus present or absent, when present extending across the fold between the fourth and fifth abdominal segments. Antennae 6- to 8-segmented. Legs normally well-developed, ranging from rather small, stout, to comparatively long and slender. Hind coxae in some of the species with a cluster of pores at base. Claws with or without a denticle or tooth on plantar surface. Body form at maturity elongate oval to broadly oval.

NOTES. Chorizococcus McKenzie is closely related to Spilococcus Ferris, but differs principally in either completely lacking dorsal cerarii, or having only 1 to 4 pairs present on abdomen (1 aberrant species has a frontal and anal lobe pair only), as compared to 6 to 17 dorsal pairs of cerarii along entire body margin ( 1 exception with 6 to 7 pairs on abdomen) in the lastnamed genus.

It is rather closely related to the monotypical genus Allotrionymus described by Takahashi in 1958. Four paratype specimens of Allotrionymus elongatus Takahashi (genotype), kindly sent to me by Professor Takahashi, exhibit noticeably longer and more slender, flagellate, cerarian spines or setae on cerarii anterior to anal lobes as compared to those of anal lobe cerarii. In Chorizococcus the cerarian spines or setae anterior to anal lobes, while often more slender, are either much shorter or only as long as those of anal lobe cerarii. Allotrionymus also possesses dorsal multilocular disk pores on head, these structures lacking in Chorizococcus. In addition, Allotrionymus appears to have from 5 to possibly 6 or 7 cerarian pairs on abdomen, these quite difficult to discern anterior to antepenultimate pair because cerarian spines are situated farther apart. In this respect Allotrionymus would appear to have closer relationship with Spilococcus Ferris, as interpreted by the present author. 
Chorizococcus appears to have affinities with the genus Atrococcus, established by Goux in 1941. One of the basic characteristics recorded by Goux in his original description of this genus is the black body color which is particularly apparent after death. He also indicated relationship with Amonostherium Morrison and Morrison on this similarity. Specimens of this type, when boiled in potassium hydroxide or lactophenol used in the mounting procedure, turn very dark and the body contents often form into large blue-black globules. The black body color alone differentiates Atrococcus from Chorizococcus.

As previously mentioned, it seems necessary at this time, for practical reasons if nothing more, to set up the new genus, Chorizococcus, to accommodate pseudococcid species which have oral rim tubular ducts and reduced number of cerarii.

The species included in Chorizococcus are listed below. With the exception of the 5 new species herein described, the generic assignments given them, mostly by Ferris (1950-53) in his Atlas, Volumes V and VI, are used to show their previous relationships.

Chorizococcus abroniae McKenzie, herein described as new ; Chorizococcus brevicruris McKenzie, new; Chorizococcus microporus McKenzie, new; Chorizococcus psoraleae McKenzie, new; Chorizococcus wilkeyi McKenzie, new; Distichlicoccus alkalinus (Cockerell); Spilococcus aphyllonis (Cockerell) ; Spilococcus irishii (Cockerell); Spilococcus neomexicanus (Tinsley); Spilococcus reducta Ferris; Trionymus peregrinus (Green); Trionymus rostellum Hoke, and Trionymus shaferi (Hollinger).

A key to North American species of Chorizococcus McKenzie, is here presented.

\section{Key to Chorizococcus Species of North America}

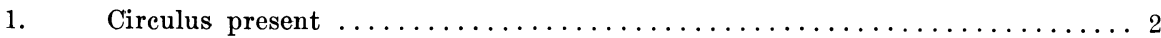

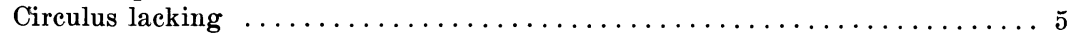

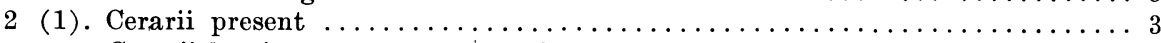

Cerarii lacking, the anal lobes with merely a cluster of slender setae

reducta (Ferris)

3 (2). Abdominal segments 4 to 6 each with 12 or more (usually more) dorsal oral rim ducts; cerarii developed on last two abdominal segments....... 4

Abdominal segments 4 to 6 each with 9 or less (usually less) dorsal oral rim ducts; cerarii confined to anal lobes................ rostellum (Hoke)

4 (3). Dorsum of abdomen with numerous oral rim ducts, each segment, except seventh and ninth, possessing a total of from 20 to 40 such ducts neomexicanus (Tinsley)

Dorsum of abdomen with segments bearing not more than 14 to 16 oral

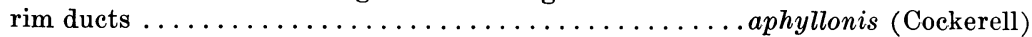

5 (1). Ventral multilocular disk pores present on abdomen.............6

Ventral multilocular disk pores lacking on abdomen......alkalinus (Cockerell)

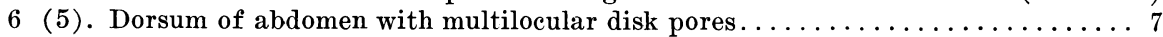

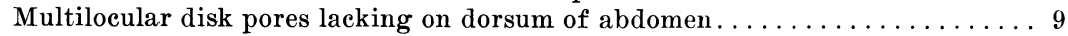

7 (6). Anal lobe cerarii alone present; antennae 6-segmented...... abroniae McKenzie With at least anal lobe and penultimate cerarii present; antennae 8-segmented . 8

8 (7). Dorsal and ventral multilocular disk pores present on head and thorax; associated with succulents ................. brevicruris McKenzie

Dorsal and ventral multilocular disk pores lacking on head and thorax;

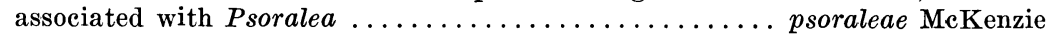




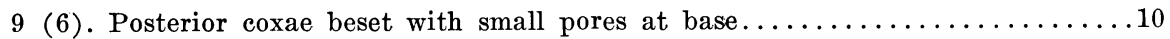

Posterior coxae without translucent pores at base $\ldots \ldots \ldots \ldots \ldots \ldots \ldots \ldots \ldots 11$

10 (9). Oral rim ducts present both dorsally and ventrally on head and thorax

'wilkeyi MeKenzie

Oral rim ducts lacking on dorsal and ventral surfaces of head and thorax shaferi (Hollinger)

11 (9). Frontal pair of cerarii present; entire venter from posterior end to head beset with very numerous tubular ducts of the oral rim type......irishii (Cockerell)

Frontal pair of cerarii lacking; with only a few submarginal oral rim tubulars present on ventral surface of thorax and abdomen. . . . . . . . . . 12

12(11). Multilocular disk pores present ventrally in sternal region of thorax; penultimate cerarii with auxiliary setae...............microporus McKenzie

Multilocular disk pores lacking ventrally in sternal region of thorax; auxiliary setae in penultimate cerarii lacking............. peregrinus (Green)

\section{Chorizococcus abroniae McKenzie, new species}

(Figure 2).

Suggested common name. Abronia mealybug.

Hosts and distribution. Type and paratype females from Abronia maritima (Nyctaginaceae), Corona del Mar, San Diego County, California, August 7, 1935, J. D. Maple, collector. Additional paratypes are available collected on Abronia sp., San Francisco (sand dunes), San Francisco County during August, 1935, by P. C. Ting.

Type material. Holotype female (1 specimen mounted on 1 slide), and 4 paratypes have been deposited in the University of California, Department of Entomology and Parasitology Museum collection at Davis, California; 1 paratype has been placed in the Stanford University Natural History Museum collection at Stanford University, California; and paratypes have been sent to the United States National Collection of Coccoidea at Washington, D.C.

Habit. Presumably occurring exposed on the foliage of the host. No other information is available.

Recognition characters. Length of largest available specimen is about 3.50 $\mathrm{mm}$. On the dorsum the anal lobe cerarii alone are present, these represented by 2 conical spines of approximately the same size, a few slender auxiliary setae, and very few scattered trilocular pores. Infrequently, a single enlarged, conical spine appears in position of penultimate cerarius paired with a slender seta, although the normally associated trilocular pores and auxiliary setae are lacking. Dorsal body setae all small and slender. Dorsum with quite numerous oral rim ducts, these arranged in a single row of as many as 22 across each abdominal segment, except the last, and scattered over the thoracic segments and head. Trilocular pores abundant and distributed evenly over entire dorsum. A few oral collar tubular ducts present along margin of last 4 or 5 abdominal segments. Fifth to eighth abdominal segments including multilocular disk pores, these arranged in rows extending across the segment to lateral margins, with from 8 to 18 pores per segment. Anal ring normal in form and size for the genus, with its 6 setae about twice as long as the greatest diameter of ring.

Ventral side, with numerous multilocular disk pores, these occurring in 10 recognizable rows from the last abdominal segment to the fourth, a few 


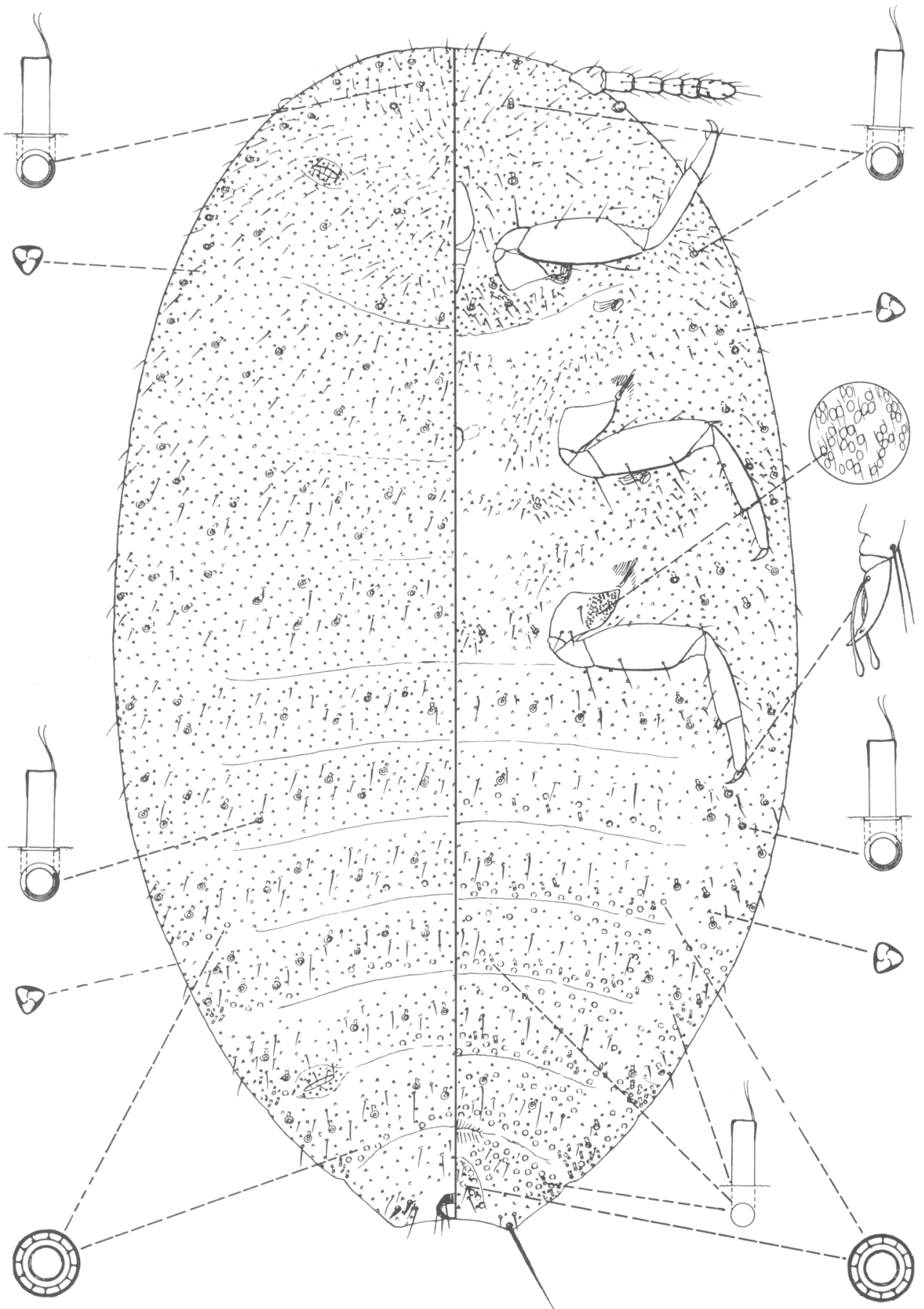

Fig. 2. Chorizococcus abroniae McKenzie, new species, collected on Abronia maritima (Nyctaginaceae), along the coast in both northern and southern California. 
pores situated near margin. Small tubular ducts, of the oral collar type, in same region as multilocular disk pores, appearing more numerous in the lateral areas of the ninth to sixth abdominal segments. Oral rim tubulars of the same size as those of dorsum occur in variable number on a few of the abdominal segments, with apparently more on segment 3, also present in lateral areas of all the segments forward to prothorax and head, and in sternal areas of all thoracic segments. Ventral setae are short and slender although generally slightly longer than those of dorsum. Trilocular pores rather numerous and generally distributed over venter, with a few clear areas showing in sternal region.

Circulus lacking. Antennae proportionately short, 6-segmented, the second, third, and sixth segments longest, fourth and fifth shorter. Legs comparatively short and stout, hind coxae with cluster of pores or ducts at base, and with a small, at times indiscernible, denticle or tooth on claw. Mouthparts short and broad.

NOTES. Chorizococcus abroniae McKenzie shares with $C$. brevicruris McKenzie, herein described as new, the presence of dorsal multilocular disk pores on abdomen. It differs, however, in lacking these pores ventrally on head and thorax, and possessing a 6-segmented antennae as compared to an 8-segmented one in brevicruris. Superficially, it resembles Chorizococcus aphyllonis (Cockerell) in possessing a rather similar arrangement of dorsal and ventral oral rim tubulars, but the presence of dorsal multilocular disk pores on abdomen precludes confusion with that species.

The illustration for this species was made by Professor Ferris. It has been modified by the author to meet certain necessary additions and corrections derived from a study of an extended series.

\section{Chorizococcus brevicruris McKenzie, new species}

(Figure 3)

Suggested common name. Short-legged mealybug.

Hosts and distribution. Holotype female on Caralluma nebrowni (Asclepiadaceae), a succulent plant, taken in quarantine at Honolulu, Hawaii, from California, January 25, 1935 ; collector not indicated.

Type material. Holotype female ( 1 specimen mounted on 1 slide) has been deposited in the United States National Collection of Coccoidea, Washington, D.C. This single example represents the only collection of this mealybug known to date.

Habit. Presumably occurring on the foliage of the host. No other information is available.

Recognition characters. Length of available specimen approximately 2.50 $\mathrm{mm}$. On the dorsum the number of cerarian pairs reduced, with not more than 2 recognizable pairs, these present on last two abdominal segments; penultimate cerarian spines smaller than anal lobe pair; penultimate cerarii without auxiliary setae, both anal lobe and penultimate cerarii with scattered trilocular pores. Dorsal body setae quite numerous, small and slender. Dorsum with quite numerous oral rim ducts, these arranged in a single row of as many as 6 across each abdominal segment, except the last, and scattered over the thoracic segments and head. Trilocular pores abundant and rather 


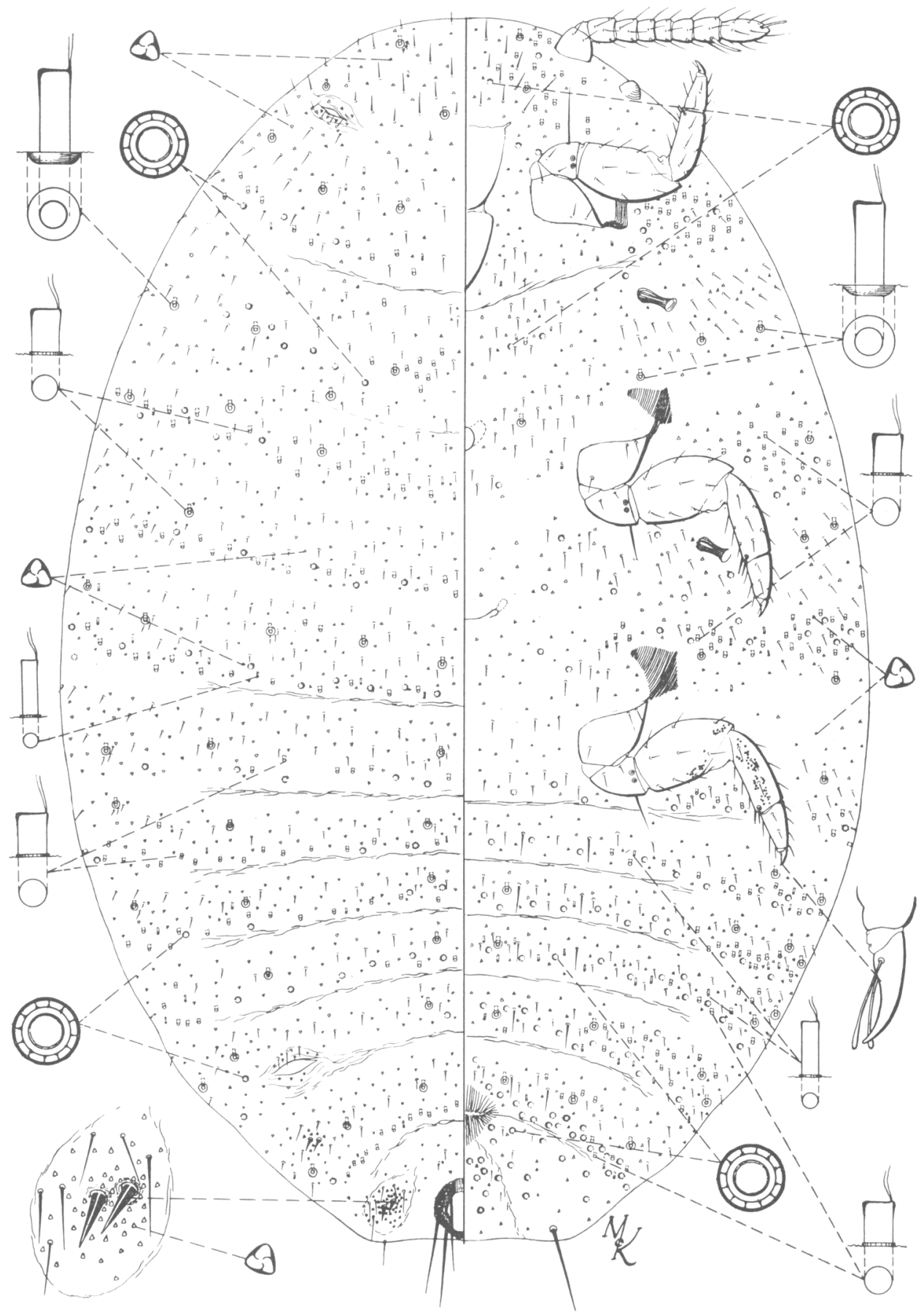

Fig. 3. Chorizococcus brevicruris McKenzie, new species, collected on Caralluma nebrowni (Asclepiadaceae), a succulent plant, taken in quarantine at Honolulu, Hawaii, from California. 
evenly distributed over entire dorsum. Small oral collar tubular ducts of 2 distinct sizes present over entire dorsum. Multilocular disk pores present dorsally on thorax and abdomen, these arranged in rows extending across abdominal segments, except the last, with from 6 to 20 such pores per segment, lacking on head. Anal ring normal in form and size for the genus, with its setae about twice as long as the greatest diameter of ring.

On the ventral side, multilocular disk pores are numerous, occurring on head, thorax, and abdomen, present on all abdominal segments, somewhat scattered on head and thorax; venter with numerous small oral collar tubular ducts of two distinct sizes. Oral rim ducts of the same size as those of dorsum are present, quite noticeably so in lateral areas of abdomen, thorax, and head. Ventral setae numerous, generally slightly longer than those of dorsum, particularly so along median area of abdominal segments. Trilocular pores numerous and generally distributed over venter, with a few clear areas showing particularly on thorax.

Circulus lacking. Antennae relatively short, 8-segmented. Legs comparatively short and stout, hind femur and tibia with small translucent dots or pores. Claws without denticle or tooth on plantar surface. Mouthparts short and broad.

NOTES. This species appears quite closely related to Chorizococcus abroniae McKenzie, herein described as new, but differs from it in possessing both dorsal and ventral multilocular disk pores on head and thorax, these lacking in abroniae; an 8-segmented antenna as compared to a 6-segmented one in abroniae; and shorter and more robust legs in brevicruris as compared to more slender ones in abroniae.

The single type specimen of this species was kindly made available to the author by Dr. Harold Morrison, Coccidologist at Washington, D.C.

\section{Chorizococcus microporus McKenzie, new species}

(Figure 4)

Suggested common name. Succulent mealybug.

Hosts and distribution. Type and paratype females on succulent plant, taken in quarantine at Honolulu, Hawaii, from California, January 25, 1950, T. S. Uyeda, collector (U.S.D.A. \#50-2352; Honolulu \#36,916).

Type material. Holotype female (1 specimen mounted on 1 slide), and 1 paratype have been deposited in the United States National Collection of Coccoidea, Washington, D.C., and 2 paratypes have been included in the University of California, Department of Entomology and Parasitology Museum collection at Davis.

Habit. Presumably occurring exposed on the foliage of the host. No other information is available.

Recognition characters. Length of largest available specimen is approximately $3.00 \mathrm{~mm}$. On the dorsum the number of cerarian pairs reduced, with not more than 2 recognizable pairs, these present on last 2 abdominal segments. Penultimate cerarian spines smaller than anal lobe pair, both anal lobe and penultimate cerarii with auxiliary setae and scattered trilocular pores. Dorsal body setae quite numerous, small and slender. Dorsum with quite numerous oral rim tubular ducts, these arranged in a single row of 


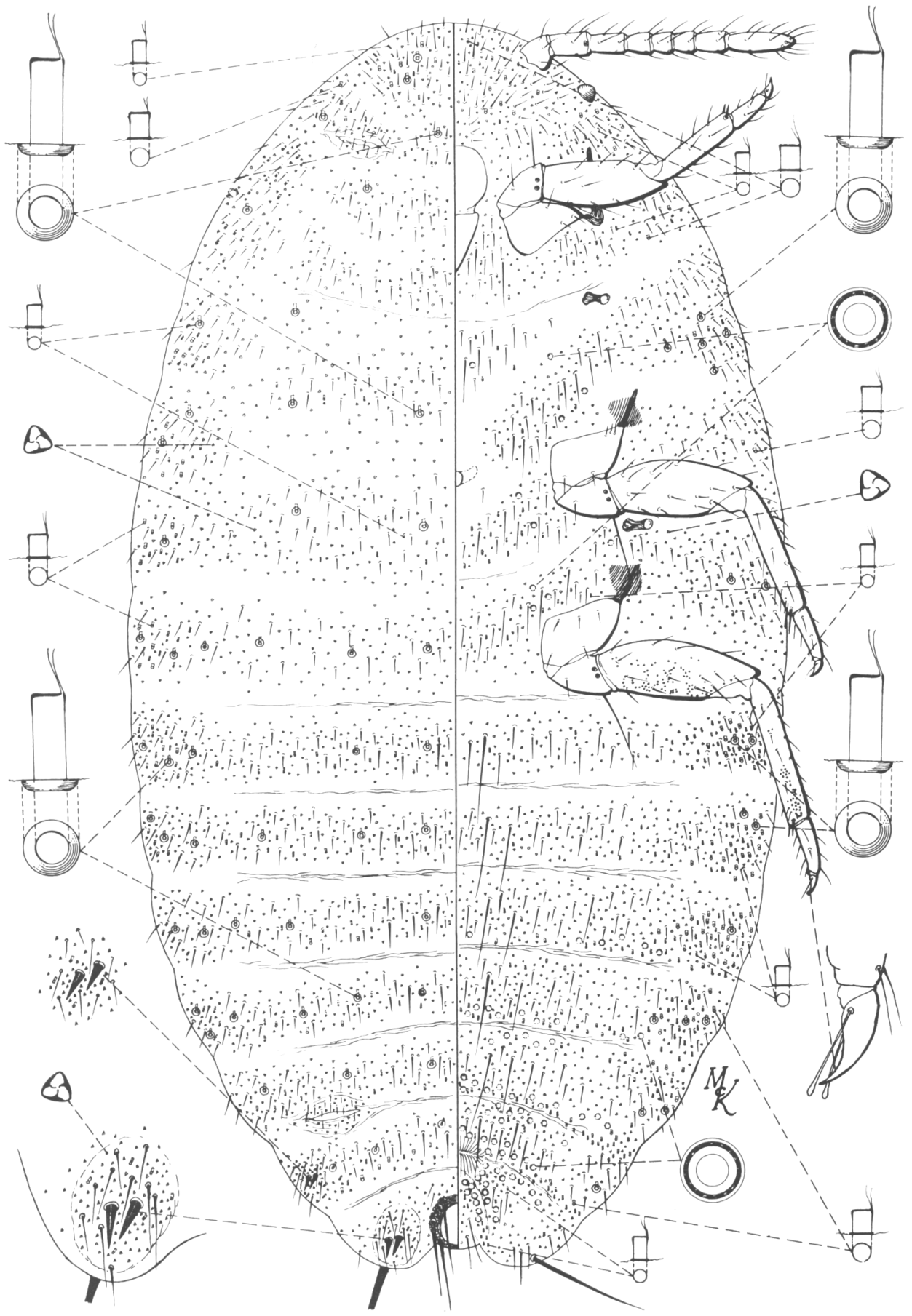

Fig. 4. Chorizococcus microporus McKenzie, new species, collected on succulent plant taken in quarantine at Honolulu, Hawaii, from California. 
as many as 12 across each abdominal segment, except the last, and scattered over the thoracic segments and head. Trilocular pores abundant and evenly distributed over entire dorsum ; small oral collar tubular ducts of 2 distinct sizes present over entire dorsum, particularly noticeable submarginally along body. Anal ring normal in form and size for genus, with its 6 setae about twice as long as the greatest diameter of ring.

On the ventral side multilocular disk pores are numerous, these occurring from last to fifth abdominal segment, also present in sternal region of thorax, lacking on head. Venter with small oral collar tubular ducts of 2 distinct sizes abundant, appearing more numerous along lateral areas of body. Oral rim tubular ducts of the same size as those of dorsum are present in lateral areas of abdominal segments forward to mesothorax, none present in sternal areas of thoracic segments or on head. Ventral setae numerous, generally longer than those of dorsum, particularly so along median area of abdominal segments. Trilocular pores numerous and generally distributed over venter, with a few clear areas showing on thorax and head.

Circulus lacking. Antennae relatively short, 8-segmented, the second, third, and eighth segments longest. Legs comparatively large, hind femora and tibiae with small translucent pores. Claws without denticle or tooth on plantar surface. Mouthparts short and broad.

NOTES. In spite of the presence of auxiliary setae in the penultimate cerarii, and because of the fact that all other morphological characteristics of this mealybug are so typical of Chorizococcus McKenzie, the new species is here assigned to this genus.

This species appears rather closely related to Chorizococcus peregrinus (Green), but differs from it in possessing ventral multilocular disk pores in sternal region of thorax, and in the presence of auxiliary setae in the penultimate cerarii, these structures lacking in peregrinus.

Type material of this species was kindly made available to the author by Dr. Harold Morrison, Coccidologist at Washington, D.C.

\section{Chorizococcus peregrinus (Green)}

Due to marked changes in the taxonomic status of the so-called Trionymus lounsburyi (Brain) mealybug, the following information is here presented.

Synonymy. Pseudococcus (Trionymus) peregrinus Green; Pseudococcus lounsburyi Brain, misidentification; Trionymus lounsburyi (Brain), misidentification.

Common name. Lily-bulb mealybug.

NOTES. The author is greatly indebted to Dr. Harold Morrison for presenting information which has led to what is here believed to be the correct identity of this mealybug in California. Needless to say, the synonymy of the species has been considerably confused up to the present time.

Green (1925) adequately described and illustrated peregrinus. He recorded the external features of the adult female as dull slate gray, and the eggs as pale pink or violaceous. According to his notes, the mealybug is concealed among the roots at some distance below the soil surface. Green further remarked that in its structural characters it is most nearly allied to Trionymus lounsburyi (Brain). Brain (1912), however, described lounsburyi 


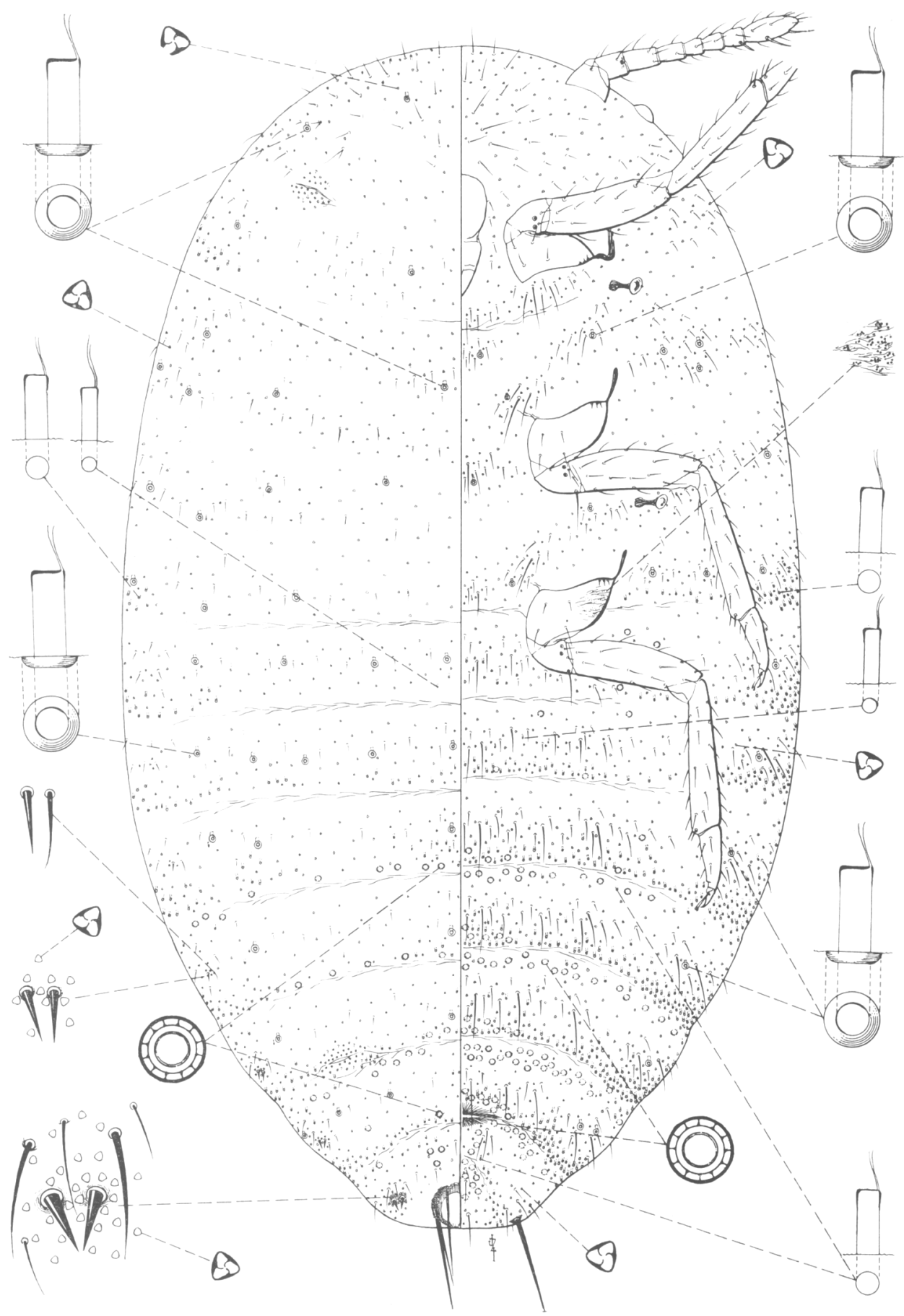

Fig. 5. Chorizococcus psoraleae McKenzie, new species, collected on California tea, Psoralea physodes (Leguminosae), Stanford University, San Francisquito Creek, Santa Clara County, California. 
as gregarious and occupying a position between the leaf bases. He also gave the color of the adult female as "purplish," and of the eggs as "orange yellow."

Zimmerman (1948) includes Trionymus lounsburyi (Brain) in his Insects of Hawaii, Homoptera, Volume 5, and states that the body contents of the adult female of this species when mashed are purplish brown, and that the eggs are more or less brownish orange or reddish. Zimmerman states that the mealybugs were found near the base of an Amaryllis leaf, and were attended by Pheidole ants.

Unfortunately, Trionymus lounsburyi is not recognizable from Brain's description. However, with the evidence presented above, it is the author's opinion that the species present in California on Haworthia is Green's species.

\section{Chorizococcus psoraleae McKenzie, new species}

(Figure 5)

Suggested common name. California tea mealybug.

Hosts and distribution. Type and paratypes from Psoralea physodes (Leguminosae), Stanford University, San Francisquito Creek, Santa Clara County, collected October 27, 1918, by G. F. Ferris, this representing the only known collection of the mealybug.

Type material. Holotype adult female ( 1 specimen mounted on 1 slide), and a single paratype example have been deposited in the University of California, Department of Entomology and Parasitology Museum collection at Davis. Two additional paratypes have been included in the Stanford University Natural History Museum collection, Stanford University.

Habit. Presumably occurring exposed on the foliage of the host. No other information is available.

Recognition characters. Length of largest available specimen is approximately $3.00 \mathrm{~mm}$. On the dorsum the number of cerarii are reduced, there being normally only 3 or 4 pairs that are recognizable counting forward from the anal lobes. Anal lobe cerarius with 2 rather small, slender, conical cerarian spines, 3 or 4 slender auxiliary setae, and a few scattered trilocular pores; remaining cerarii along abdominal margin with but 2 conical spines or setae, these progressively smaller, more slender, and usually more widely separated than anal lobe pair, no auxiliary setae, and with scarcely any concentration of trilocular pores. Dorsal body setae all small and slender. Dorsum with a few oral rim tubular ducts, these arranged in a single row of from 3 or 4 to 7 or 8 across each abdominal segment, with the exception of the last, and scattered over the thoracic segments and head. Oral collar tubular ducts quite numerous along margin of abdomen, fewer across abdominal segments, sparse along margin of thorax and head. Trilocular pores distributed over entire dorsum. Multilocular disk pores present on fifth to ninth abdominal segments, these arranged in rows extending across the segments to lateral margins. Anal ring of normal size for the genus, with its setae about twice as long as the greatest diameter of the ring.

On the ventral side, multilocular disk pores are present on all abdominal segments, more numerous from apical to sixth segments, especially in midregion of the abdomen. Oral collar tubular ducts of two distinct sizes present 


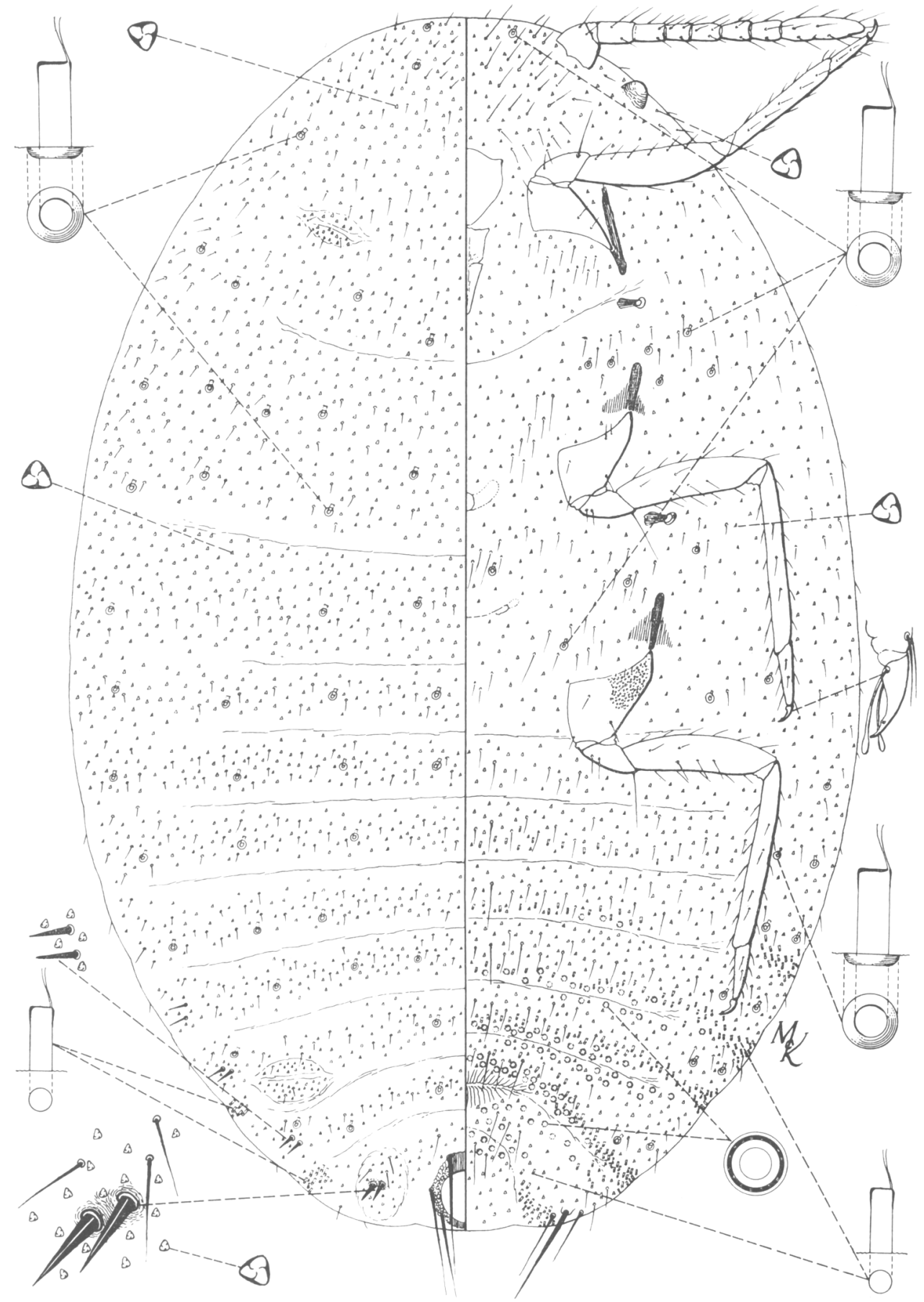

Fig. 6. Chorizococcus wilkeyi McKenzie, new species, collected on Agoseris grandiflora (Compositae), 8 miles west of Placerville, El Dorado County, California. 
on abdomen, the larger ones predominant, numerous along lateral areas of the body. Oral rim tubular ducts of the same size as those of dorsum occur in small numbers along the margin of the abdomen, and a few are to be found in the sternal areas of meso- and metathorax, lacking on prothorax and head. Ventral body setae are slender and generally longer than those on dorsum. Trilocular pores are rather numerous and generally distributed over venter.

Circulus lacking. Antennae relatively short, 8-segmented. Legs proportionately large; hind coxae with cluster of translucent pores at base; claw without denticle or tooth on plantar surface. Mouthparts short and broad.

NOTES. In the character of dorsal multilocular disk pores on abdomen, this species appears related to Chorizococcus abroniae and $C$. brevicruris, both herein described as new, but differs from them mainly in having more abdominal cerarii.

\section{Chorizococcus wilkeyi McKenzie, new species}

(Figure 6)

Suggested common name. Wilkey mealybug.

Hosts and distribution. Type and paratypes from Agoseris grandiflora (Compositae), 8 miles west of Placerville, El Dorado County, California, June 13, 1958, collected by R. F. Wilkey and H. L. McKenzie, this representing the only known collection of the mealybug.

Type material. Holotype female ( 1 specimen mounted on 1 slide) and paratypes have been deposited in the University of California, Department of Entomology and Parasitology Museum collection at Davis; paratypes have been placed in the California State Department of Agriculture, Bureau of Entomology collection at Sacramento; a paratype has been included in the Stanford University Natural History Museum collection, Stanford University; and paratypes have been sent to the United States National Collection of Coccoidea at Washington, D.C.

Habit. Occurring at the base of plant within the leaf sheaths. At full maturity the adult female is thickly covered with a fine, short, delicate, white secretion. A definite ovisac was not observed. When living specimens of this mealybug are put into 70 per cent alcohol for preservation, they immediately turn light pale green.

Recognition characters. Length of largest available specimen is about 3.25 $\mathrm{mm}$. On the dorsum the number of cerarii are reduced, there being normally only 3 or 4 pairs that are recognizable counting forward from the anal lobes. Anal lobe cerarius with 2 rather small and slender conical setae, and usually 3 slender auxiliary setae and a few scattered trilocular pores. Remaining cerarii along abdominal margin with but 2 conical setae, these progressively smaller, more slender, and usually more widely separated than anal lobe pair, no auxiliary setae, and with scarcely any concentration of trilocular pores. Dorsal body setae all small and slender. Dorsum with a few oral rim ducts, these arranged in a single row of from 3 or 4 to 7 or 8 across each abdominal segment, with the exception of the last, and scattered over the thoracic segments and head. A few tubular ducts of the oral collar type occur dorsally along margin of posterior abdominal segments. Trilocular pores distributed 
over entire dorsum. Anal ring of normal size for the genus, with its setae about twice as long as the greatest diameter of the ring.

On the ventral side, multilocular disk pores are present in considerable numbers, predominantly in the mid-region of the abdomen, from the apical to the fifth abdominal segments. Small tubular ducts of the oral collar type occur in this same region and in considerable numbers in the lateral areas of the eighth to fourth abdominal segments. Oral rim tubulars of the same size as those on dorsum occur in small numbers along the margin of the abdomen, and a few are to be found in the sternal areas and about the spiracles of the thorax, 1 or 2 near the antennae. Ventral setae are slender and generally longer than those on dorsum. Trilocular pores are rather numerous and generally distributed over venter.

Circulus lacking. Antennae slender, normally 8-segmented, the eighth segment at times showing a suggestion of being divided. Legs very slender in relation to their length, hind coxae with cluster of pores at base, and claws with a very small, at times almost indistinguishable, denticle or tooth.

NOTES. This species differs strikingly from all other Chorizococcus available for examination in the slenderness of the legs and antennae in relation to their length. This character was not used in the key, but it certainly stands out when a direct comparison is made with the other species.

I take great pleasure in dedicating this species to Mr. R. F. Wilkey of the California State Department of Agriculture, who was the first to discover the mealybug on a collecting trip we took together.

\section{Genus Cryptoripersia Cockerell}

During the preparation of the revised key to North American genera of Pseudococcidae, it was noted that Trionymus hypolithus Shotwell, had closer affinities with Cryptoripersia than Trionymus. Apparently the species was assigned to Trionymus primarily because of the elongate body form. It is believed, however, that there is not enough accumulated evidence to advance shape of body alone to the position of a primary generic characteristic. Trionymus hypolithus is, therefore, transferred to Cryptoripersia.

\section{Genus Dysmicoccus Ferris}

Ferris (1950-53) in Volumes V and VI of his Atlas points out that the distinction between Dysmicoccus and Trionymus is extremely obscure as far as certain species are concerned. In fact, he remarks, it seems probable that the greater the number of species discovered the greater the difficulties are likely to become!

The author has become very much aware of this situation, and in order that an arbitrary division might be made between these 2 genera, it has been necessary to transfer 2 species of Trionymus, namely, junceus (McConnell) and merrilli Ferris, into Dysmicoccus. The main key separation of Dysmicoccus from Trionymus appears to lie in the number of dorsal cerarii, there being 6 or more pairs present, including the frontal ones, in the former genus, as compared to 5 or fewer pairs, including the frontal ones, in the latter genus. Almost certainly species will turn up eventually that will tend to 
cut across such an arbitrary separation basis, but it should work considerably better for the species now known than using the body shape separation basis.

\section{Genus Heliococcus Sulc}

One new California species of Heliococcus is described in this publication. A modification of Ferris' 1953 key to North American Heliococcus, to include the new species, is here presented.

\section{Key to Heliococcus Species of North America}

1. Dorsum with but a very small number of quite inconspicuous, enlarged ducts, these

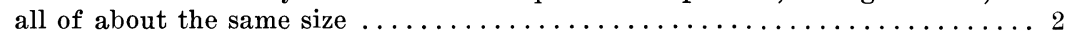

Dorsum with numerous enlarged ducts of various sizes.............

2 (1). Ventral multilocular disk pores present................ insignis (Lobdell)

Ventral multilocular disk pores lacking.............. adenostomae MeKenzie

3 (1). Dorsal enlarged ducts predominantly of the smaller size, with the larger ducts few osborni (Sanders)

Dorsal enlarged ducts predominantly of the larger size, the smaller ducts few stachyos (Ehrhorn)

\section{Heliococcus adenostomae McKenzie, new species}

(Figure 7)

Suggested common name. Adenostoma heliococcus mealybug.

Hosts and distribution. Holotype female and single paratype of the same sex from Adenostoma fasciculatum (Rosaceae), 11 miles east of Calpella, Mendocino County, California, collected May 28, 1959, by T. R. Haig (Calif. State Dept. Agr. \#59E29-59). Two specimens of what is here believed to represent this species are at hand from the same host, collected at Coulterville, Mariposa County, California, June 1, 1954, by R. P. Allen (Calif. State Dept. Agr. \#54F133). These specimens were originally mounted in a temporary mounting medium. Later they were soaked off, boiled in lacto-phenol, restained, and mounted singly on microscope slides. Apparently, the subsequent treatment they received was too severe since the morphological characters were much obliterated.

Type material. Holotype female, mounted on 1 slide, has been deposited in the University of California, Department of Entomology and Parasitology Museum collection at Davis, and a paratype female has been included in the California State Department of Agriculture, Bureau of Entomology collection at Sacramento.

Habit. No available information.

Recognition characters. Length of available mounted specimens is approximately $2.20 \mathrm{~mm}$. Body shape broadly oval. Dorsum with cerarii represented in 18 pairs, anal lobe cerarii with 2 rather small, conical, slightly lanceolate spines, accompanied by 3 or 4 auxiliary setae, and a few associated trilocular pores; all other cerarii with 2 slender, paired spines or setae, except those of the head region with 2 to 3 , very small and obscure setae and accompanied by a small group of trilocular pores; some of the cerarii, particularly anal lobe and penultimate pairs, appear to be borne upon membranous elevations. Characteristic enlarged dorsal tubular ducts few in type specimen, all of the same size, confined mainly to abdomen, there being 1 or 2 just 


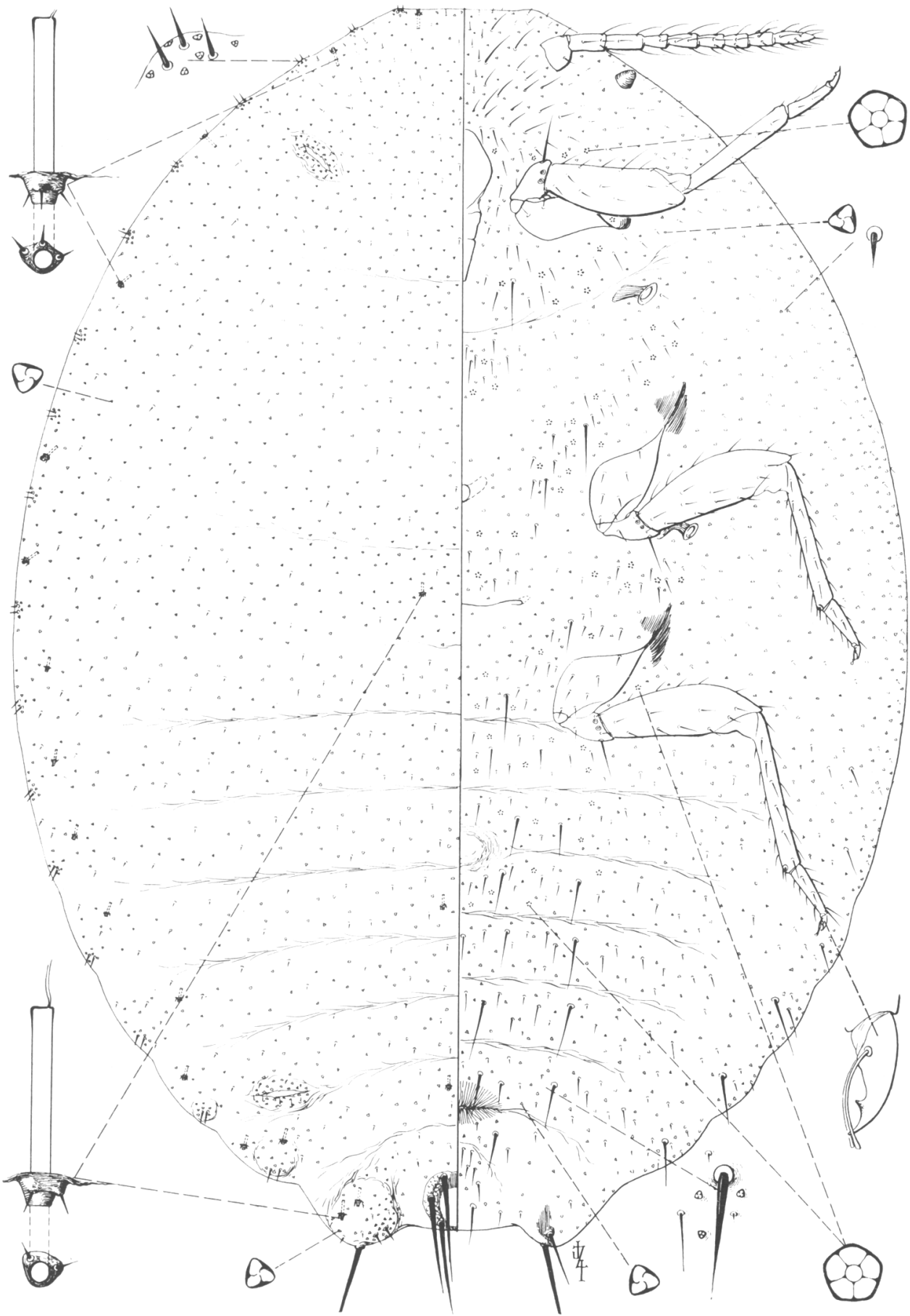

Fig. 7. Heliococcus adenostomae MeKenzie, new species, collected on Adenostoma fasciculatum (Rosaceae), 11 miles east of Calpella, Mendocino County, California. 
in from the cerarius on most of the abdominal segments and occasionally 1 or 2 near the median line on 2 or 3 of the segments, a few marginal ones on thorax and head. Dorsal body setae small and sparse. Trilocular pores relatively sparse and generally scattered over dorsum. Anal ring distinctive for the genus, bearing 6 setae which are longer than diameter of ring.

On the ventral side, multilocular disk pores lacking. Quinquelocular pores appear on fifth and preceding abdominal segments, as well as in cephalic region, and on head. Tubular ducts lacking. Ventral setae slender and generally much longer than those on dorsum. Trilocular pores relatively sparse although generally distributed over venter, a few "clear areas" appearing in sternal areas.

Circulus apparently present, although very poorly and indistinctly developed. Anal lobes with a ventral small, irregular, sclerotized area. Antennae 9-segmented. Legs well developed, and with noticeably produced denticle or tooth on claw.

NOTES. This species appears to be closely allied to Heliococcus insignis (Lobdell), but differs from it principally in lacking ventral multilocular disk pores on abdomen.

\section{Genus Humococcus Ferris}

Two new California species of Humococcus Ferris are described in this paper. Both species seem quite closely related to Humococcus atriplicis Ferris. Ferris' (1953) key to North American species of this genus has been modified to accommodate the new species.

\section{Key to Humococcus Species of North America}

1. Anal ring closely surrounded by numerous setae.......... porterae (Cockerell)

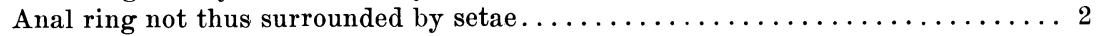

2 (1). Tubular ducts of the oral $\operatorname{rim}$ type present on dorsum $\ldots \ldots \ldots \ldots \ldots \ldots \ldots$

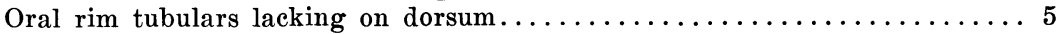

3 (2). Dorsal multilocular disk pores present on abdomen $\ldots \ldots \ldots \ldots \ldots \ldots \ldots \ldots \ldots$

Dorsal multilocular disk pores lacking on abdomen............ caritus MeKenzie

4 (3). At least a few oral rim and oral collar ducts present ventrally on head and thorax; anal ring removed by three or four times its own diameter from apex of abdomen atriplicis Ferris

Oral rim and oral collar ducts lacking ventrally on head and thorax; anal ring removed only by slightly more than twice its own diameter from apex of abdomen inornatus McKenzie

5 (2). Cerarii of the anal lobes represented by pairs of small, quite stout setae muhlenbergiae Ferris

Cerarii of the anal lobes represented by slender setae.........hilariae (Ferris)

\section{Humococcus caritus McKenzie, new species}

(Figure 8)

Suggested common name. Saltgrass mealybug.

Hosts and distribution. Type and paratypes from Distichlis spicata (Gramineae), Lancaster, Los Angeles County, California, collected July 28, 1957, by K. Stephens (Calif. State Dept. Agr. \#57H1-22), this representing the only known collection of the mealybug.

Type material. Holotype female, mounted on 1 slide, has been deposited 


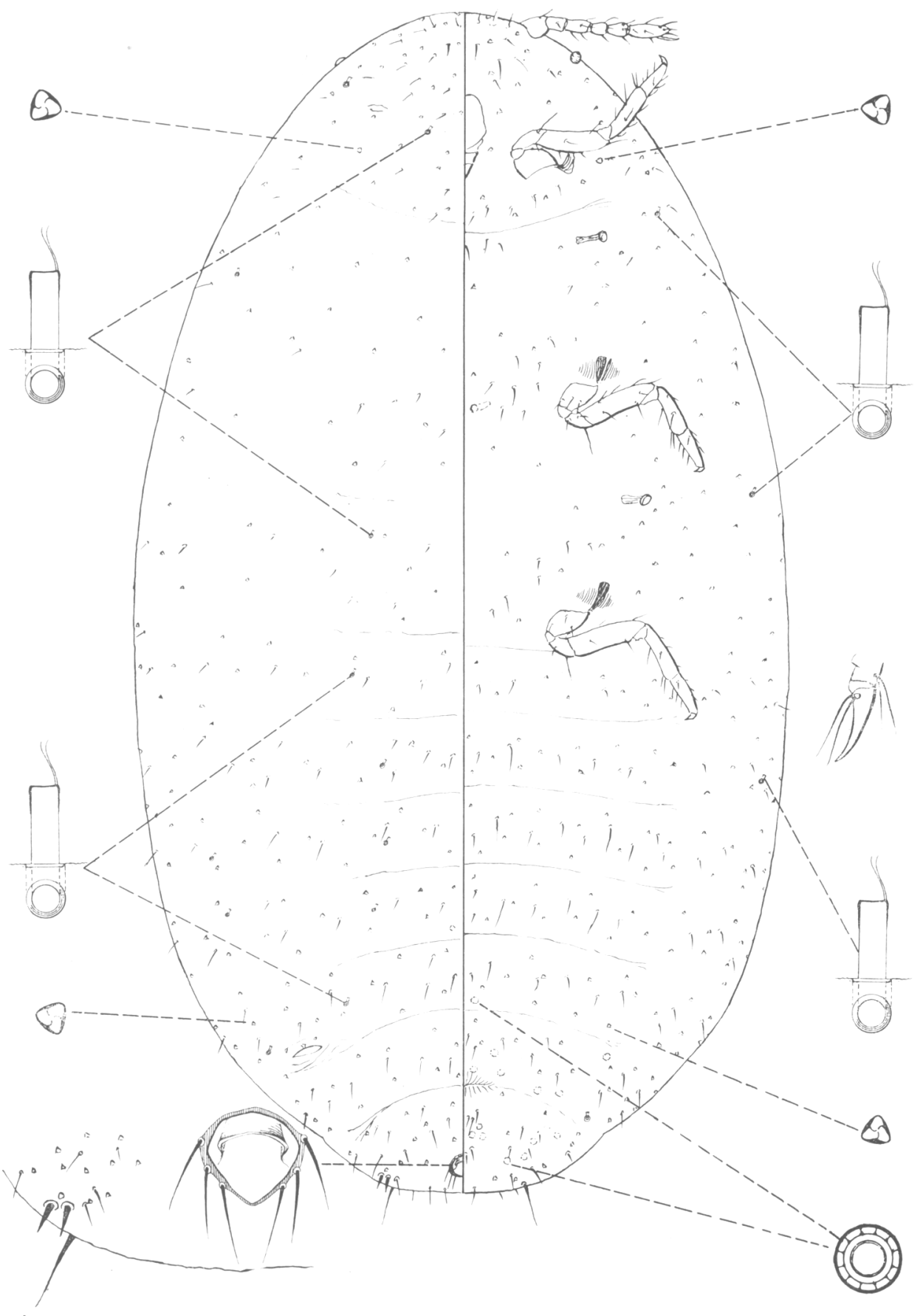

Fig. 8. Humococcus caritus McKenzie, new species, collected on saltgrass, Distichlis spicata (Gramineae), at Lancaster, Los Angeles County, California. 
in the University of California, Department of Entomology and Parasitology Museum collection at Davis; a paratype has been placed in the California State Department of Agriculture collection at Sacramento; and a paratype has been sent to the United States National Collection of Coccoidea at Washington, D.C.

Habit. No available information.

Recognition characters. Length of largest available specimen is about $2.00 \mathrm{~mm}$. Dorsum with but one pair of cerarii on anal lobes, these represented only by a pair of conical, rather slender, setae, accompanied by 2 or 3 slender auxiliary setae, and with scarcely any concentration of trilocular pores. Dorsal multilocular disk pores lacking. Dorsal body setae sparse, all small and slender. Trilocular pores very sparse and generally scattered over abdomen, fewer on head and thorax. Small ducts of the oral rim type occur sparingly over dorsum. Anal ring distinctive for the genus, set at about its own diameter from apex of body, consisting merely of a narrow, sclerotized anterior band which is interrupted along posterior border of the opening, and which bears 6 small setae which are about as long as the diameter of ring.

On the venter, multilocular disk pores very few, confined to the posterior portion of body, present on last two or three abdominal segments. A very few, only 3 or 4 , oral rim tubulars situated along body margin. Ventral setae short and slender, sparse, fewer on thoracic segments than rest of body.

Circulus lacking. Antennae short, 6-segmented. Legs comparatively short, with tiny denticle or tooth on claw. Mouthparts short and broad.

NOTES. This species appears to be most closely related to Humococcus atriplicis Ferris, but differs from it principally in lacking dorsal multilocular disk pores, and having fewer of these structures ventrally on abdomen.

The illustration of this species was prepared by Professor Ferris.

\section{Humococcus inornatus McKenzie, new species}

(Figure 9)

Suggested common name. Inornate mealybug.

Hosts and distribution. Type and paratypes from undetermined host collected at Garlic Springs, near Barstow, San Bernardino County, California, April 8, 1935, by J. D. Maple. This represents the only known collection of this mealybug.

Type material. Holotype female, mounted on 1 slide, and paratypes have been deposited in the University of California, Department of Entomology and Parasitology Museum collection at Davis; and a paratype has been sent to the United States National Collection of Coccoidea at Washington, D.C.

Habit. No available information.

Recognition characters. Length of largest available specimen is approximately $1.85 \mathrm{~mm}$. Form as mounted elongate oval to slightly pyriform. Dorsum with cerarii entirely lacking. Dorsal multilocular disk pores present in considerable numbers from last to fifth segments, these for the most part extending across segment to lateral margin. Dorsal surface with but very few setae, these all small and slender. Trilocular pores rather evenly distributed, with a few, small, dorsal tubular ducts of the oral rim type situ- 


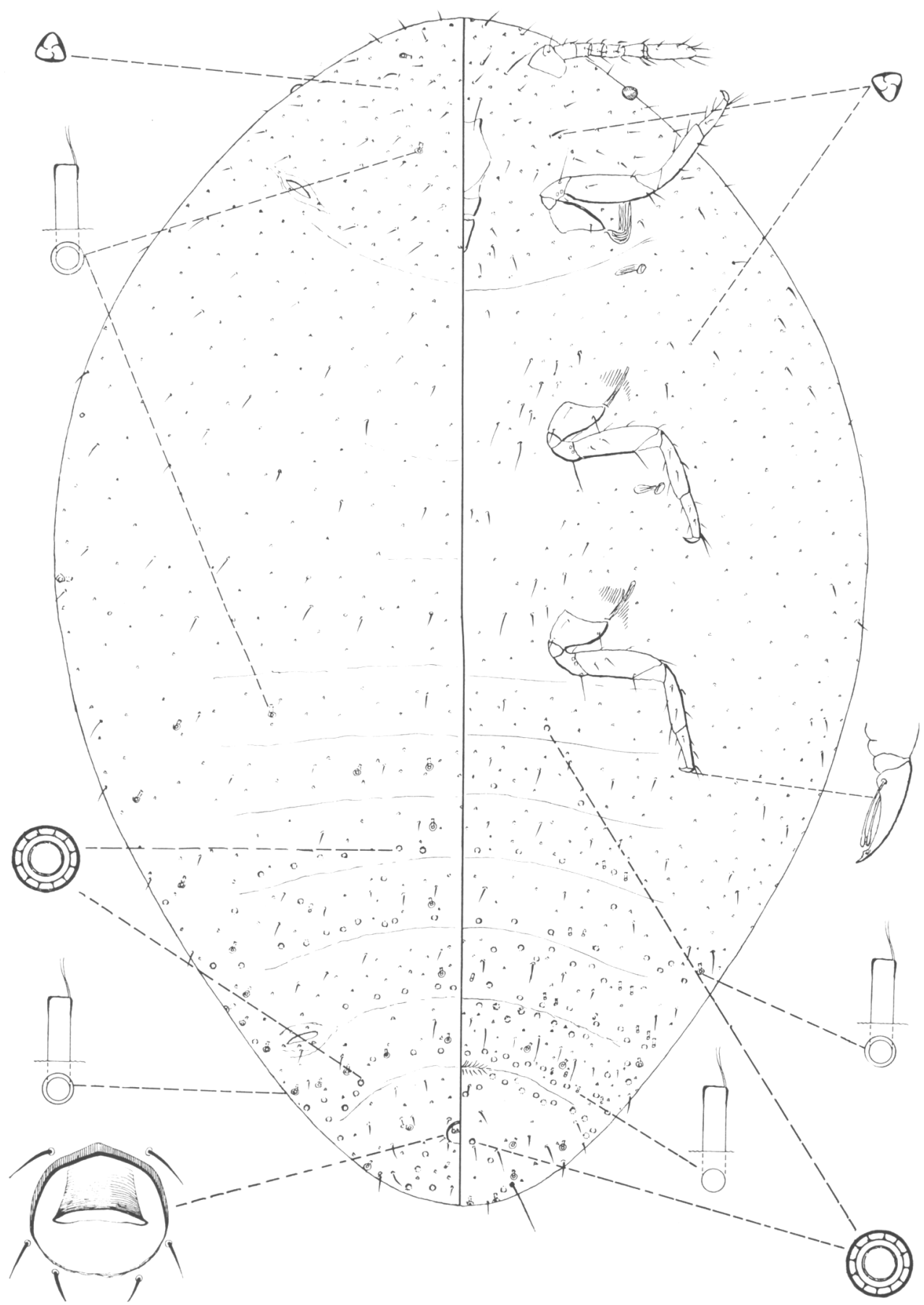

Fig. 9. Humococcus inornatus McKenzie, new species, collected near Barstow, at Garlic Springs, San Bernardino County, California, on an undetermined host. 
ated mostly on abdomen, a few located on head and along thoracic margin. Tubular ducts of the oral collar type sparsely located on last abdominal segment. Anal ring quite small, removed by about $2 \frac{1}{2}$ times its own diameter from apex of abdomen, consisting of a simple, sclerotized ring, interrupted posteriorly, slightly expanded in its lateral areas, and surrounded by 6 small setae.

On the venter, multilocular disk pores present in considerable numbers from apical to the third abdominal segment, these mostly in rows extending across the segment to lateral margin, fewer on segments 3 and 4 . Ventral oral rim ducts are situated especially on terminal abdominal segments, none present on head or sternal areas. A few, small, simple, tubular ducts of the oral collar type sparsely situated ventrally on fifth to eighth abdominal segments. Ventral setae short and slender, sparse, fewer on thoracic segments than rest of body.

Circulus lacking. Antennae short, 7-segmented. Legs comparatively short, with a small denticle or tooth on claw. Mouthparts short and relatively broad.

NOTES. This species seems quite closely related to Humococcus atriplicis Ferris, but differs from it in lacking oral rim and oral collar ducts ventrally on head and thorax; anal ring removed by slightly more than twice its own diameter from apex of abdomen, and surrounded by, but not bearing, 6 small setae. The construction of the anal ring does not seem to match any other species previously included in this group.

The illustration for this species was prepared by Professor Ferris.

\section{Genus Phenacoccus Cockerell}

Four new California species of Phenacoccus are described in this study, and are here added to those included in Ferris' (1953) Atlas, Volume VI. The addition of these new species has necessitated a modification of Ferris' key to Phenacoccus to absorb them. The revised key is here presented.

\section{Key to Phenacoccus Species of North America}

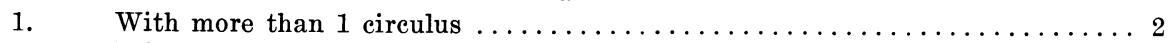

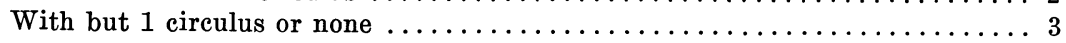

2 (1). Abdominal cerarii consisting of clusters of numerous conical setae

Abdominal cerarii for the most part with but 2 dearnessi King

3 (1). Multilocular disk pores entirely lacking

Multilocular disk pores present at least on the venter in the region of the vulva. 5

4 (3). Anal lobe cerarii with 6 to 10 enlarged setae or spines, these all about the same size and borne in a sclerotized area; quinquelocular pores lacking ventrally

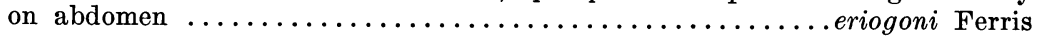

Anal lobe cerarii with but 2 enlarged setae or spines; quinquelocular pores present ventrally on abdomen ............................lycii Ferris

5 (3). Multilocular disk pores present on both dorsum and venter, at least on the

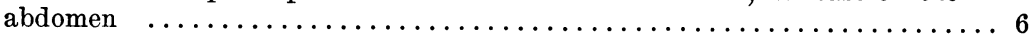

Multilocular disk pores confined to the venter..................... 13

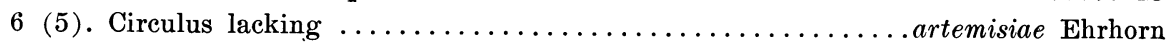

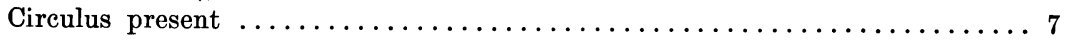

7 (6). Enlarged setae of the anal lobe cerarii 6 to 10, these all of essentially the same size and borne in a more or less sclerotized area........helianthi (Cockerell) 
Enlarged setae of the anal lobe cerarii normally 2 and of essentially the same size, with 1 or more additional setae of various sizes at times present, these not borne in a sclerotized area $\ldots \ldots \ldots \ldots \ldots \ldots \ldots \ldots \ldots \ldots \ldots$

8 (7). At least 1 abdominal segment with a dorsal, median cerarius consisting of 2 to 3

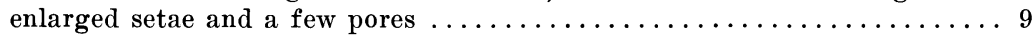

Abdominal segments all without such a dorsal cerarius . . . . . . . . . . . 11

9 (8). Dorsum and the lateral margins of the body with numerous multilocular disk pores as far forward as the head; dorsum with very numerous small tubular ducts

acericola King

Dorsum and the lateral areas of the body with multilocular disk pores only as far forward, at the most, as the mesothorax; tubular ducts very few and scat-

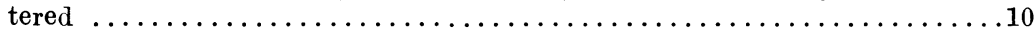

10 (9). Dorsal body setae throughout of the same shape and of approximately the same size as those of the cerarii; dorsal median cerarii present on all the abdominal segments except the ninth ................faveolus (Cockerell)

Dorsal body setae for the most part distinctly smaller and more slender than those of the cerarii ; dorsal median cerarii present only on abdominal segments 7 and $8 \ldots \ldots \ldots \ldots \ldots \ldots \ldots \ldots \ldots \ldots \ldots \ldots \ldots \ldots \ldots \ldots \ldots \ldots \ldots \ldots \ldots \ldots$ franseriae Ferris

11 (8). Circulus very narrowly and very strongly produced laterally, resembling the socalled "ox yoke" of early pioneer days........gossypii Townsend and Cockerell

Circulus round or oval and but very slightly or not at all produced laterally ...12

12 (11). With numerous dorsal multilocular disk pores present on all abdominal segments, except the last, a few situated on thorax and head; circulus quite small, transversely oval, occurring on fourth abdominal segment, not divided by segmental line; as far as known occurring only on Gramineae.....graminosus MeKenzie

Dorsal multilocular disk pores occurring for the most part along posterior border of abdominal segments 6 and 7 , completely lacking on thorax and head; circulus noticeably large, usually slightly oval, occurring on segmental line between fourth and fifth abdominal segments ..............eremicus Ferris

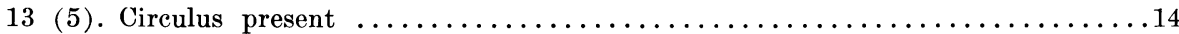

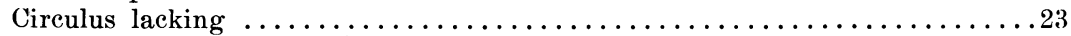

14 (13). Dorsum entirely without tubular ducts scattered over surface (ignore strictly

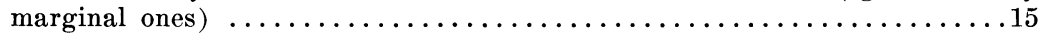

Dorsum with a considerable number of tubular ducts scattered over surface. .19

15 (14). With 17 or 18 recognizable pairs of cerarii present $\ldots \ldots \ldots \ldots \ldots \ldots \ldots \ldots$

With 15 or less recognizable pairs of cerarii present ......echeveriae McKenzie

16 (15). Multilocular disk pores extremely few, there being less than 20 and these confined to the posterior margin of the eighth abdominal segment immediately anterior to the vulva and the area posterior to the vulva...........defectus Ferris

Multilocular disk pores present in considerable numbers about the vulva and forward at least to the seventh segment $\ldots \ldots \ldots \ldots \ldots \ldots \ldots \ldots \ldots$

17 (16). With a small but distinct sclerotized area surrounding the base of each cerarius rubivorous Cockerell

Without a small sclerotized area surrounding the base of each cerarius.....18

18 (17). Antennae normally 8-segmented; circulus normally very small and oval; multilocular disk pores extending forward to the segment posterior to the circulus

solani Ferris

Antennae normally 9-segmented; circulus normally larger, rather lax and subject to distortion, sometimes slightly produced laterally; multilocular disk pores usually confined to the area immediately about the vulva and to segment 7

solenopsis Tinsley

19 (14). Abdominal segments 7 to 8 each with a median, dorsal cerarius, the setae of which are nearly as large as those of the lateral cerarii; dorsal tubular ducts especially abundant in the lateral areas of abdominal segments 6 to 9

capensis Ferris

Abdominal segments without such dorsal median cerarii; dorsal tubular ducts not thus concentrated along the margins of the abdominal segments ......20 
20 (19). Many of the dorsal body setae as large and as long as, or longer than, those of

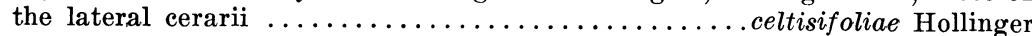

Dorsal body setae noticeably smaller than those of lateral cerarii .......21

$21(20)$. With 17 or 18 recognizable pairs of cerarii present . . . . . . . . . . . 22

With 15 or less recognizable pairs of cerarii present ........minimus Tinsley

$22(21)$. Hind tibiae straight-sided, relatively slender and without or with very few translucent dots or pores; ventral quinquelocular pores present in considerable numbers from sixth abdominal segment anterior to and including sternal areas; circulus relatively large and $\operatorname{lax} \ldots \ldots \ldots \ldots$ tibiaegracilis McKenzie

Hind tibiae definitely swollen and with fairly numerous but not densely clustered translucent dots or pores; quinquelocular pores few and inconspicuous, occurring principally in head region; circulus quite small and oval

colemani Ehrhorn

$23(13)$. With 18 pairs of recognizable cerarii on dorsum; venter with scarcely more than 10 multilocular disk pores, these lying immediately anterior to the vulva

pauperatus Ferris

Cerarian pairs reduced, there being normally only 4 or 5 that are recognizable counting forward from anal lobes; ventral multilocular disk pores present on ninth to usually fifth abdominal segments; as far as known occurring only

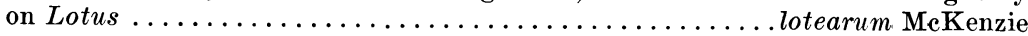

\section{Phenacoccus echeveriae McKenzie, new species}

(Figure 10)

Suggested common name. Echeveria mealybug.

Hosts and distribution. Type and paratypes from Echeveria sp. (Crassulaceae), near Hemet, San Jacinto River, Riverside County, California, collected February 22, 1936, by F. R. Platt, this representing the only known collection of this mealybug.

Type material. Type and paratypes of this mealybug have been deposited in the University of California, Department of Entomology and Parasitology Museum collection at Davis; and a paratype has been sent to the United States National Collection of Coccoidea at Washington, D.C.

Habit. No information.

Recognition characters. Length of largest available specimen about 1.75 $\mathrm{mm}$. Pseudococcidae with variable number of cerarii on the dorsum, in type species with at least 15 discernible pairs, or associations of "spines" with triloculars on each side that can be regarded as more or less developed cerarii, anal lobe pair being "complete" cerarii, that is, each is made up of 2 conical spines, a cluster of trilocular pores around these spines, and in or at the edge of this cluster 1 or more slender setae obviously associated with the cerarius. Penultimate cerarii without accessory setae, progressively smaller and more slender. Anterior cerarii with the spines so slender and widely separated as to leave some question as to their validity. Dorsal ostioles well developed. Dorsal body setae all small and slender. A few tubular ducts of the oral collar type occur dorsally along the margin of the posterior abdominal segments. Trilocular pores rather evenly distributed over entire dorsum. Anal ring with 6 setae, these longer than the greatest diameter of ring.

On the ventral side, multilocular disk pores are present in considerable numbers, predominantly in the mid-region of the abdomen, from apical to fourth abdominaI segments. Small tubular ducts of the oral collar type occur 


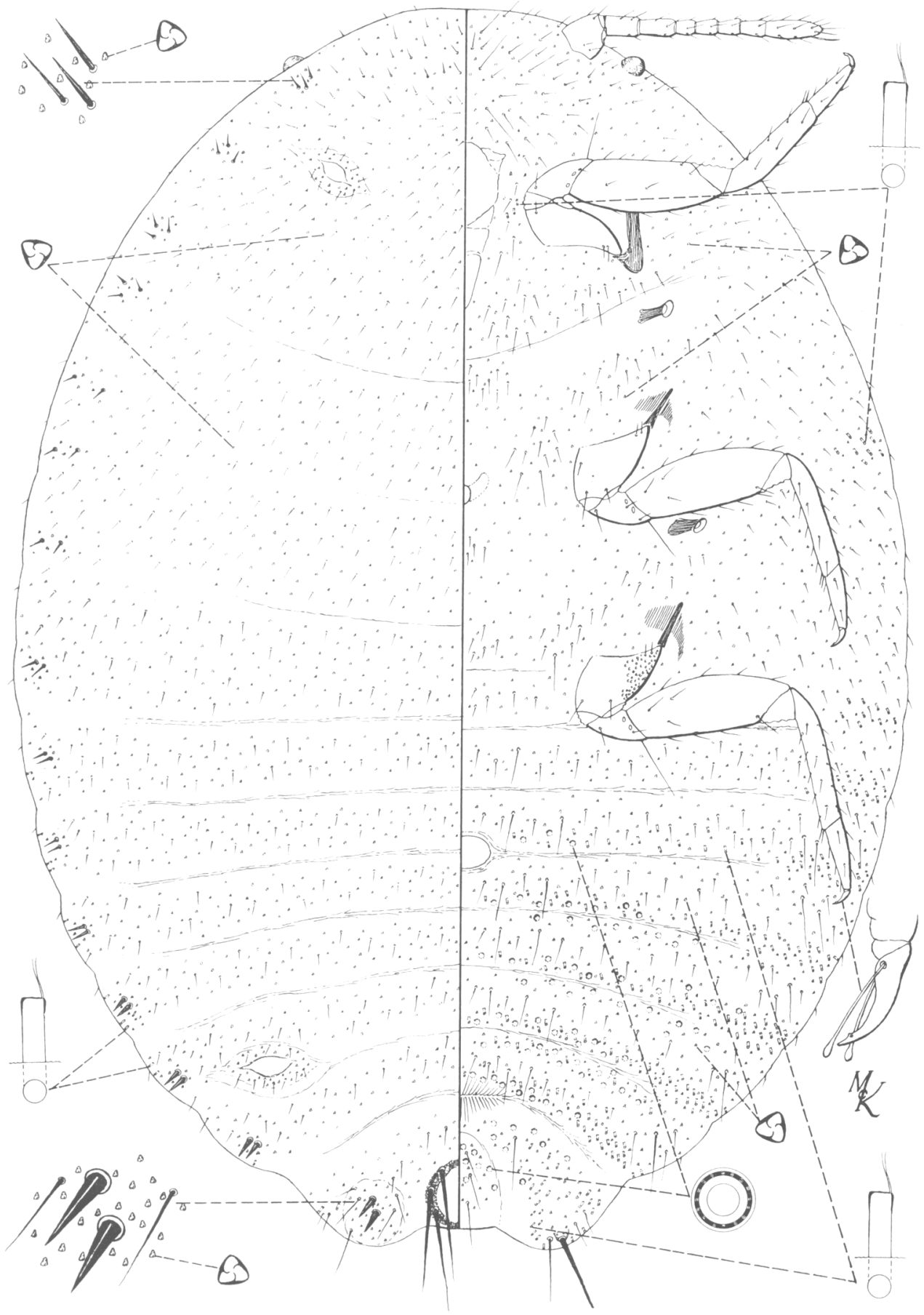

Fig. 10. Phenacoccus echeveriae McKenzie, new species, collected near Hemet, San Jacinto River, Riverside County, California, on Echeveria sp. (Crassulaceae). 
in this same region and in considerable numbers in the lateral areas of the ninth to second abdominal segments, and one group present along margin of thorax. Ventral setae are slender and generally longer than those on dorsum. Trilocular pores are generally distributed over entire venter.

Circulus present, transversely oval, extending across the fold between the fourth and fifth abdominal segments. Antennae normally 8-segmented although at times 7 -segmented. Eyes present. Legs relatively stout, hind coxae with a cluster of translucent dots or pores at base, and with a very small, at times indistinguishable, denticle or tooth on the claw. Body form at maturity rotund.

NOTES. Phenacoccus echeveriae McKenzie appears to resemble, at least to some degree, Phenacoccus minimus Tinsley, but differs from it in dorsal tubular ducts with a diameter less than that of the outer circle of the multilocular disk pores, whereas in minimus the diameter of these ducts is as great as that of the outer circle of the multilocular disk pores. In addition, minimus possesses ventral quinquelocular pores on thorax and head, these structures apparently lacking in echeveriae.

\section{Phenacoccus graminosus McKenzie, new species}

(Plate 1, middle row, left ; figure 11)

Suggested common name. Ryegrass mealybug.

Hosts and distribution. Type and paratypes from Lolium sp. (Gramineae), Berkeley, Alameda County, California, collected September 24, 1953, by R. P. Allen and R. T. Straw (Calif. State Dept. Agr. \#53I301). Additional paratypes are available from the following hosts and localities in Alameda County: on ryegrass, Berkeley, July 22, 1953, W. A. Kroger, collector (Calif. State Dept. Agr. \#53G350); on ryegrass, Alameda, August 20, 1953, W. A. Kroger, collector (Calif. State Dept. Agr. \#53H243) ; on ryegrass, Oakland, September 11, 1953, J. V. Lonergon, collector (Calif. State Dept. Agr. \#53I87) ; on bromegrass, San Leandro, September 23, 1953, S. W. Sibray, collector (Calif. State Dept. Agr. \#53I253); on Hordeum sp. Oakland, September 23, 1953, R. P. Allen and J. V. Lonergon, collectors (Calif. State Dept. Agr. \#53I297 and \#53I303) ; on Lolium sp., Oakland, September 22, 1953, R. P. Allen and R. T. Straw, collectors (Calif. State Dept. Agr. \#53I319). Other paratypes from California are on hand as follows: on ryegrass, San Pablo, Contra Costa County, October 10, 1953, D. J. Bingham, collector (Calif. State Dept. Agr. \#53J165) ; on ryegrass, San Rafael, Marin County, October 10, 1953, D. J. Bingham, collector (Calif. State Dept. Agr. \#53I166) ; on Hordeum sp., North Salinas, Monterey County, March 21, 1955, R. P. Allen and R. V. Emparan, collectors (Calif. State Dept. Agr. \#55C796 ) ; on grass, presumably, under walnut tree, Vallejo, Solano County, December 10, 1956, D. R. Haug, collector (Calif. State Dept. Agr. \#65L198); and on lawngrass and grass, Sunnyvale, Santa Clara County, April 7, 1959, T. R. Haig and E. Winkler, collectors (Calif. State Dept. Agr. \#59D15-37).

Specimens of what appear to be this species were rather recently (December 22, 1958) sent to the author for identification by Miss Helen M. Brookes of the University of Adelaide, Waite Agricultural Research Institute, South Australia. The mealybugs were collected principally on members of the 


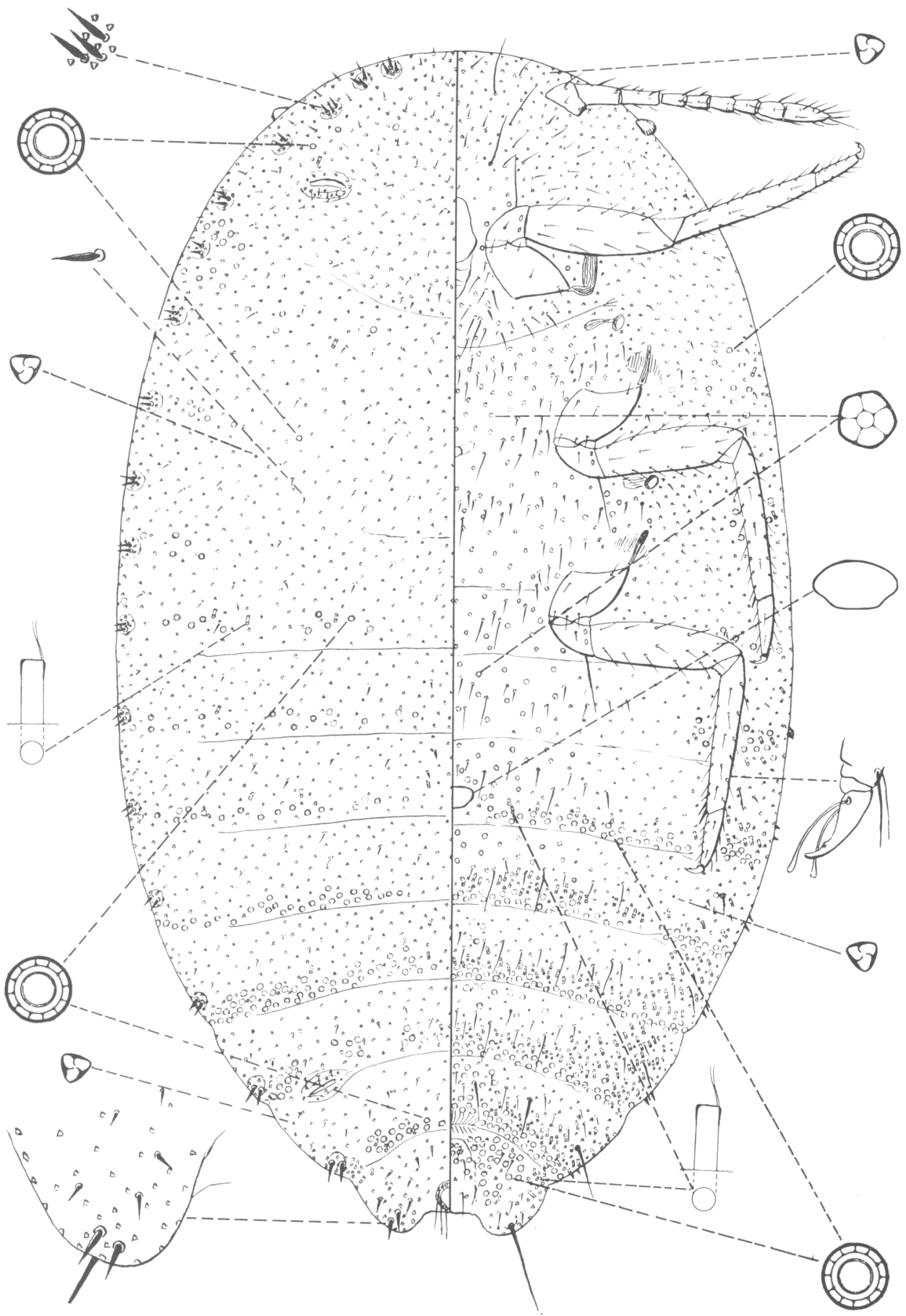

Fig. 11. Phenacoccus graminosus McKenzie, new species, a grass-infesting mealybug which, apparently, occurs commonly in Alameda County, California. The species may prove to be an introduced one. 
Gramineae in that region. The species was also taken on Trifolium repens (white clover) and Medicago sativa (alfalfa) grown in pot-culture experiments in glasshouses, and on Trifolium fragiferum (strawberry clover), growing in small demonstration plots of various pasture plants, including plots of grasses, at the Waite Institute. According to Miss Brookes, and if I interpret her correspondence correctly, the occurrence of this mealybug on members of Leguminosae is a rather restricted one, being confined to plants grown in glasshouses or in small demonstration plots of mixed pasture plants, including many types of grasses. As far as can be determined the species has not been collected on legumes growing in commercial plantings, or under strictly field conditions.

Collections of this species at hand from South Australia, and here designated as metatypes, are recorded as follows: on Trifolium repens (white clover), Adelaide, Waite Institute (in glasshouse), April 28, 1954, C. Kleinig, collector; on Hordeum (barley), Adelaide, Waite Institute (in glasshouse), November 12 and 14, 1957, L. Paleg, collector; on Triticum (wheat), Redbanks, July 31, 1958, H. M. Brookes, collector; on Phalaris tuberosa (bulb canarygrass), Auburn, December 17, 1958, K. M. Doull, collector; and on Trifolium fragiferum (strawberry clover), Adelaide, Waite Institute (demonstration plot of various pasture plants including many grasses), January 16, 1959, H. M. Brookes, collector.

Additional records of graminosus in South Australia are reported in correspondence to the author from Miss Brookes as follows: on Medicago sativa (alfalfa), Adelaide, Waite Institute (in glasshouse), February 17, 1956, collector not indicated; on Hordeum (barley), Brinkworth, November 13, 1957, collector not indicated ; and on Lolium (ryegrass), Tintinara, September 16,1958 , collector not indicated.

Type material. Holotype female mounted on 1 slide, and paratypes have been deposited in the University of California, Department of Entomology and Parasitology Museum collection at Davis; paratypes have been placed in the California State Department of Agriculture, Bureau of Entomology collection at Sacramento; in the California Academy of Sciences, Golden Gate Park, San Francisco, California; in the Stanford University Natural History Museum collection, Stanford University; in the University of Adelaide, Waite Agricultural Research Institute collection, Adelaide, South Australia; and paratypes have been sent to the United States National Collection of Coccoidea, Washington, D.C.

Habit. Adult females covered with a fine powdery waxy secretion. Eggs are laid in a loose, amorphous ovisac. Usually found clustered along the sheathing leaf-base, and at ground level, in crown of host. Miss Brookes reports their living in large colonies among the spikelets of Phalaris tuberosa, feeding on the peduncle rather than on the ovaries.

Recognition characters. Length of largest available specimen is approximately $3.25 \mathrm{~mm}$. Usually, 18 pairs of cerarii are present, there being a pair between the frontal and ocular pairs, those on prothorax and head, for the most part, represented by 3 small, conical setae and a limited number of scattered trilocular pores ; remaining cerarii with but 2 conical setae, except anal lobe pair which, in addition to the 2 larger conical setae, exhibit 3 or 4 


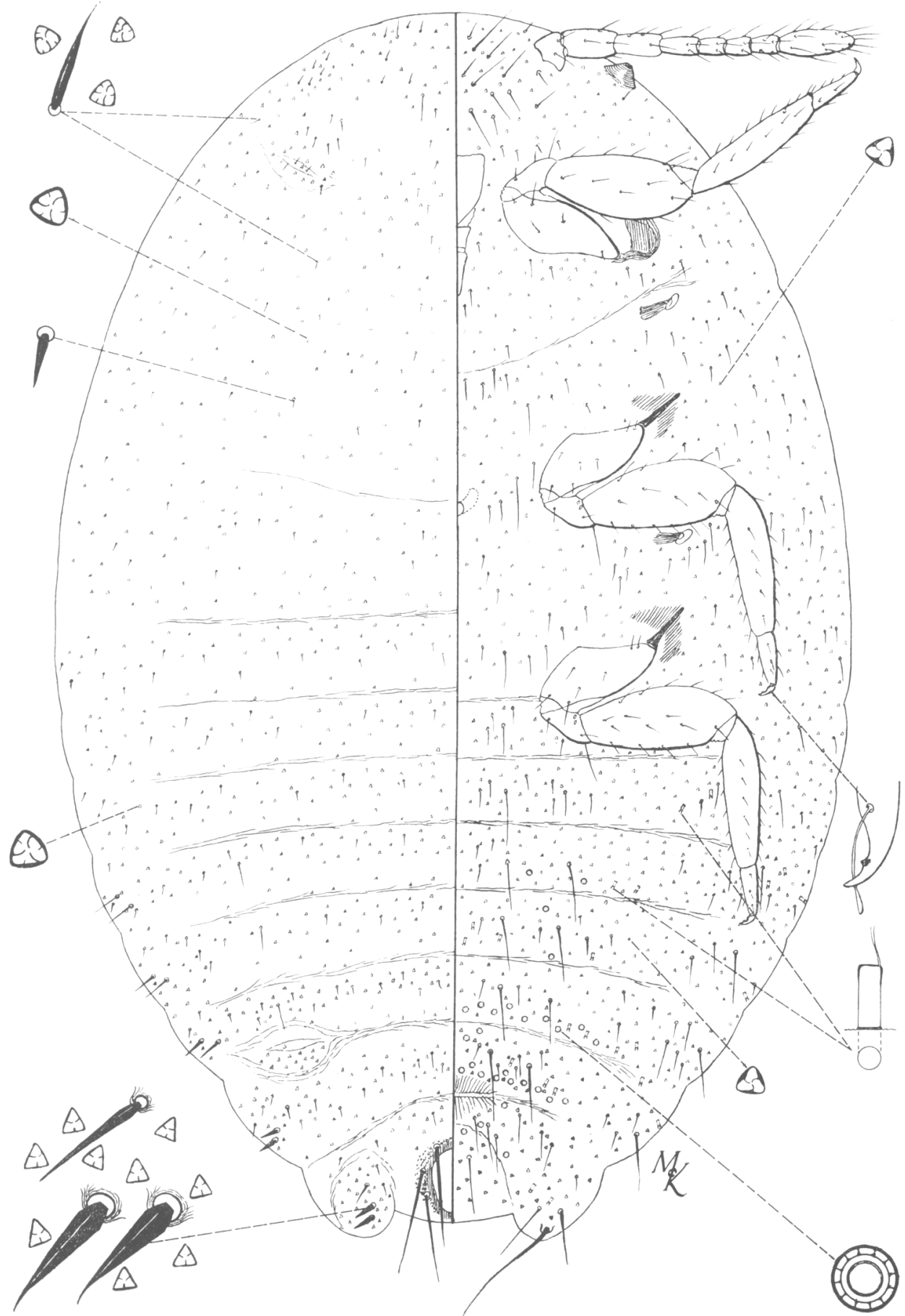

Fig. 12. Phenacoccus lotearum McKenzie, new species, collected on Lotus sp. (Leguminosae), Summit, Santa Susana Pass, Ventura County, California. 
smaller setae; all cerarii with scarcely any concentration of trilocular pores, and never with accompanying slender, auxiliary setae. Dorsal multilocular disk pores are present in considerable numbers on all abdominal segments, except the last, and a few are distributed, mostly in groups, submarginally on thorax and head. Dorsal body setae sparse, all small and slender. Trilocular pores are rather abundant and evenly beset over entire dorsum. Tubular ducts with a slight oral collar are sparsely distributed over dorsum. Anal ring of normal form and size for genus, with 6 setae, these about twice as long as greatest diameter of ring.

On the venter, multilocular disk pores are present in considerable numbers on all abdominal segments, these extending across segment to lateral margins, except on segments 2 and 3 where they occur as a submarginal group; a few submarginal groups also occur on thorax. Quinquelocular pores, which are considerably smaller than the multilocular pores, are rather abundantly distributed in the median region of the anterior abdominal segments, the thorax, and a few on the head. Small, rather elongate tubular ducts with a slight oral rim are situated abundantly on last 5 or 6 abdominal segments, more sparsely so anterior to these. Ventral setae are slender and generally longer than those of dorsum. Trilocular pores rather evenly distributed on venter except in sternal regions.

Circulus present, slightly laterally oval, and not divided by a segmental line, occurring on segment 4 of abdomen. Antennae moderately long, 9segmented. Legs large and comparatively long. Claws with a prominent denticle or tooth. Mouthparts broad.

NOTES. This species keys to Phenacoccus eremicus Ferris in Ferris' (1953), Atlas, Volume VI, page 395. It differs markedly from eremicus in possessing far more numerous dorsal multilocular disk pores on abdomen and thorax; fewer dorsal oral collar ducts; ventral circulus differently shaped and not situated on segmental line; and more numerous ventral quinquelocular pores, these situated in a different manner.

Dr. Harold Morrison has kindly examined the illustration of graminosus and has made the following remarks about it in correspondence to the author dated August 12, 1958, "This seems as you indicate to be clearly separated from anything else thus far reported from the United States. There are several Phenacoccus species described from other parts of the world that have dorsal multiloculars, and some of these have been reported from grass, but so far as can be told from the descriptions none of these has a ventral circulus. Your report of collection on several hosts in the Bay Area would tend to make one suspicious of possible introduction."

The illustration for this species was prepared by Professor Ferris from specimens collected at two different localities in Alameda County. The drawing has been modified somewhat by the author to meet certain necessary changes resulting from an examination of a long series of mounted examples.

\section{Phenacoccus lotearum McKenzie, new species}

(Figure 12)

Suggested common name. Lotus mealybug.

Hosts and distribution. Type and paratypes from Lotus sp. (Legumi- 


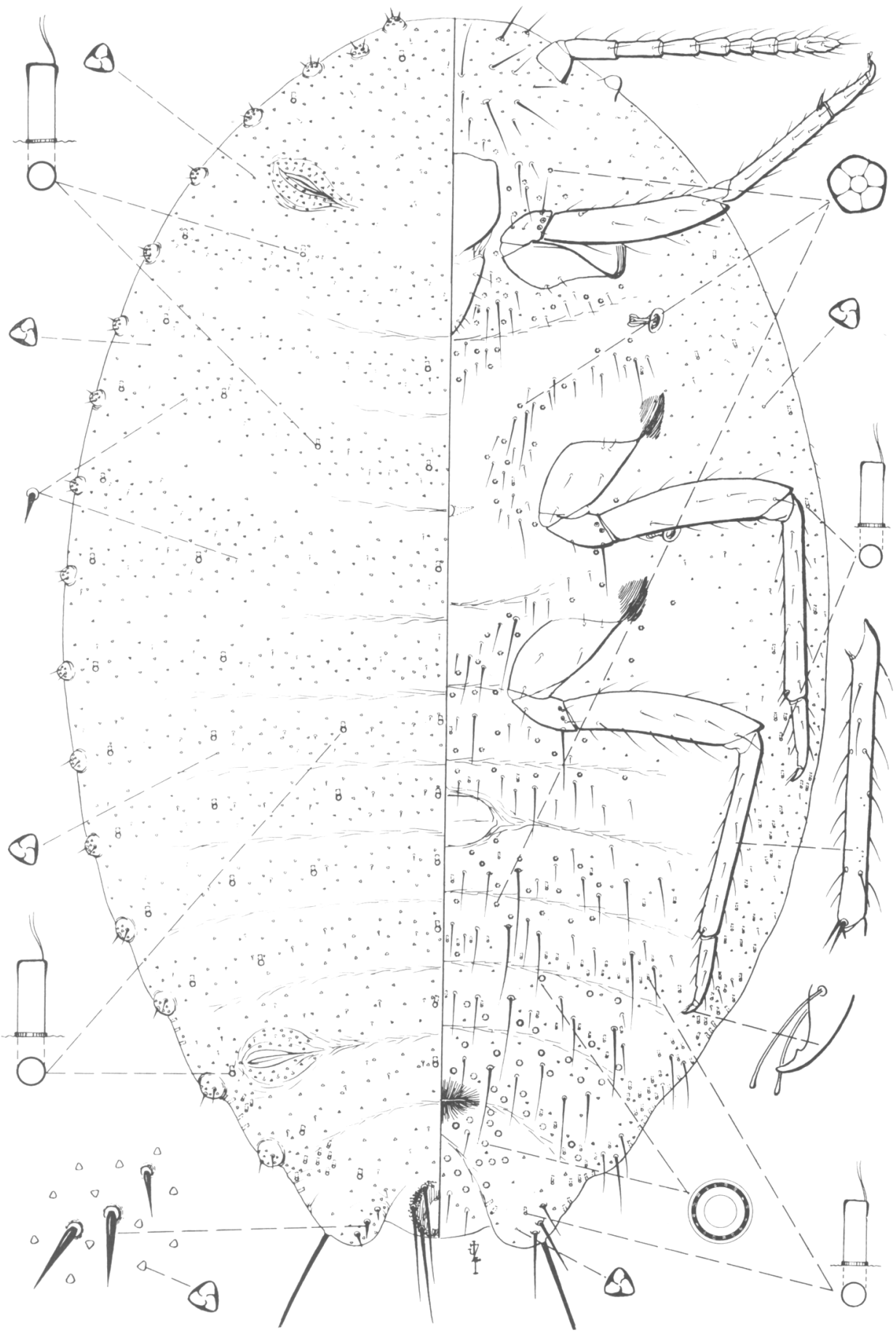

Fig. 13. Phenacoccus tibiaegracilis McKenzie, new species, collected on Garrya sp. (Garryaceae), Cuyama, Ventura County, California. 
nosae), Summit, Santa Susana Pass, Ventura County, California, collected February 27, 1936, by J. D. Maple. Additional paratypes are at hand from Lotus sp., Fillmore, Ventura County, collected February 8, 1936, by J. D. Maple, and from Lotus sp., Whittier, Los Angeles County, collected March 10, 1935, by J. D. Maple.

Type material. Holotype and 1 paratype female, mounted together on 1 slide, and paratypes have been deposited in the University of California, Department of Entomology and Parasitology Museum collection at Davis; 1 paratype has been placed in the Stanford University Natural History Museum collection, Stanford University; and paratypes have been sent to the United States National Collection of Coccoidea at Washington, D.C.

Habit. No information available.

Recognition characters. Length of largest available specimen is about $4.75 \mathrm{~mm}$. On the dorsum the number of cerarian pairs reduced, normally only 4 or 5 that are recognizable counting forward from anal lobes. Anal lobe cerarius represented by 2 rather small, slender, conical setae, a few, usually 3, slender auxiliary setae and a limited number of scattered trilocular pores. Remaining cerarii along abdominal margin with but 2 conical setae, these, from anal lobes forward, progressively smaller, more slender, and usually more widely separated than anal lobe pair, no auxiliary setae, and with scarcely any concentration of trilocular pores. Dorsal body setae sparse, all small and slender. Trilocular pores seem to be somewhat larger than is usual, these sparsely beset over entire dorsum. Anal ring of normal form and size for the genus, with 6 setae, these about twice as long as the greatest diameter of the ring.

On the ventral side, multilocular disk pores are present in variable limited numbers on last abdominal segment to fifth. Small tubular ducts of the oral collar type occur in this same area. Ventral setae are slender and much longer than those on dorsum. Trilocular pores seem somewhat smaller than those of dorsum, evenly distributed throughout entire venter.

Circulus lacking. Antennae moderately long, either 7- or 8-segmented. Legs large, femora robust, claws with a prominent denticle or tooth on plantar surface.

NOTES. This species keys to Phenacoccus pauperatus Ferris in Ferris' 1953, Atlas, Volume VI, pages 395-396. It differs from pauperatus, however, in possessing far more numerous ventral multilocular disk pores on abdomen; only 4 or 5 , usually 4 , discernible dorsal abdominal pairs of cerarii ; antennae 7- or 8-segmented, and legs more robust.

\section{Phenacoccus tibiaegracilis McKenzie, new species}

(Figure 13)

\section{Suggested common name. Garrya mealybug.}

Hosts and distribution. Holotype adult female collected on Garrya sp. (Garryaceae), Cuyama, Ventura County, California, June 11, 1959, by J. Schall (Calif. State Dept. Agr. \#59J6-3). In answer to a request for more material, 2 additional paratype females were taken from the same locality and host by M. Cravens and J. Schall on September 3, 1959 (Calif. State 
Dept. Agr. \#59I18-4). These collections represent the only known material of this mealybug.

Type material. Holotype adult female and single paratype of the same sex have been deposited in the University of California, Department of Entomology and Parasitology Museum collection at Davis. A single paratype female has also been deposited in the California State Department of Agriculture, Bureau of Entomology collection at Sacramento.

Habit. No information.

Recognition characters. Length of largest available mounted specimen is approximately $2.50 \mathrm{~mm}$. Cerarii present in 18 pairs, there being a pair between the frontal and ocular pairs, those on head, for the most part, represented by 3 small, conical setae and a limited number of scattered trilocular pores ; remaining cerarii with but 2 conical setae, except anal lobe pair which, in addition to the 2 larger conical spines, exhibit 1 or 2 smaller setae; all cerarii with scarcely any concentration of trilocular pores, without accompanying slender, auxiliary setae, and borne on slightly raised processes. Body setae sparse, all small and slender. Trilocular pores rather abundant and evenly beset over entire dorsum. Oral collar ducts quite numerous, larger than those of venter, arranged segmentally on abdomen, scattered on thorax and head. Anal ring of normal form and size for genus, with 6 setae, these about twice as long as greatest diameter of ring.

On the venter, multilocular disk pores are present in considerable numbers, predominantly in the mid-region of the abdomen, from apical to seventh segments. Quinquelocular pores, which are considerably smaller than the multilocular disk pores, are rather abundantly distributed in the median region of the anterior abdominal segments and sternal areas of thorax, lacking on head. Oral collar ducts of perhaps two different sizes occur sparsely on abdominal segments, more abundant in lateral areas of apical to third segments, a few on thorax, presumably lacking on head. Ventral body setae are slender and considerably longer than those on dorsum. Trilocular pores rather sparsely distributed on venter except in mid-region of abdominal segments and around quinquelocular pores in sternal region.

Circulus comparatively large and lax, basically transversely oval, apparently divided by segmental line, occurring between fourth and fifth segments. Antennae moderately long, 9-segmented. Legs proportionately long and slender, hind tibiae narrow, straight-sided (from whence the specific name was derived), without or with a very few translucent pores or dots. Claws with a prominent denticle or tooth. Mouthparts relatively broad.

NOTES. This species appears rather closely related to Phenacoccus colemani Ehrhorn, but differs from it principally in having hind tibiae straightsided, relatively slender and without or with very few translucent pores or dots, $^{6}$ as compared to definitely swollen and with fairly numerous, but not densely clustered, pores or dots in colemani. Other differences include a much larger, lax-type circulus, and more numerous ventral quinquelocular

${ }^{6}$ Dr. Harold Morrison has pointed out that Borkhsenius (1949) has used Paroudablis Cockerell as a generic name for the group of Phenacoccus species having tibial characteristics of these two species. Unfortunately, the author feels unqualified to give a critical opinion on the use of Paroudablis, and, therefore, only a mention of it is made at this time. 
pores in tibiaegracilis, as against a much smaller circulus, and very few ventral quinquelocular pores in colemani.

A comparison of the new species with type colemani was made by Dr. Harold Morrison. His comments regarding the species, together with those of the author, have been included in the remarks presented above.

\section{Genus Pseudococcus Westwood}

Two California species of Pseudococcus are described as new in this publication. A modification of Ferris' 1953 key to the North American Pseudococcus to include these new species is here presented.

\section{Key to Pseudococcus Species of North America}

1. Circulus small, transversely oval, normally located on fourth abdominal segment, or if situated between fold of fourth and fifth abdominal segments, not divided by segmental line .......................microcirculus McKenzie

Cireulus normally quite large, and even if small, always extending between fold of fourth and fifth abdominal segments, and divided by segmental line....... 2

2 (1). With not more than 1 dorsal oral rim tubular duct near each of most of the

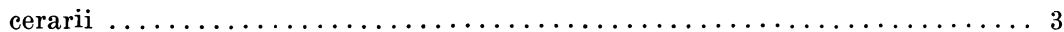

With 2 to 3 , usually 3, dorsal oral rim tubular ducts near each of most of the

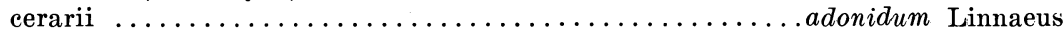

3 (2). With an oral rim tubular duct dorsally just posterior to each frontal cerarius... 4

Never with an oral rim tubular duct in this position........... gahani Green

4 (3). With never more than 2 or 3 dorsal oral rim tubular ducts present on abdomen and associated with cerarii ; circulus small, compressed, transversely oval

importatus McKenzie

With 6 or more dorsal oral rim tubular ducts present on abdomen and associated with cerarii; circulus large and lax ...................... 5

5 (4). Anal lobe cerarius surrounded by a definite and quite large area of sclerotization . 6

Anal lobe cerarius never with more than a faint shadowing of surrounding scleroti-

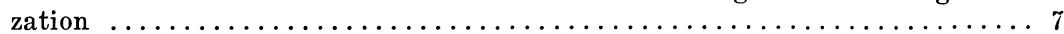

6 (5). Anal lobe cerarii with their conical setae surrounded by a crowded mass of trilocular pores, mesal edge of this mass of pores being close to the mesal margin of the

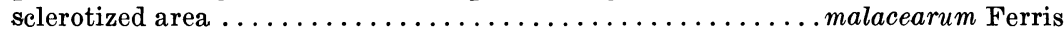

Anal lobe cerarii with their conical setae surrounded by a dispersed group of pores, this group lying in the center of the surrounding sclerotized area

comstocki (Kuwana)

7 (5). Anal lobe cerarii surrounded by a compact, circular group of closely crowded

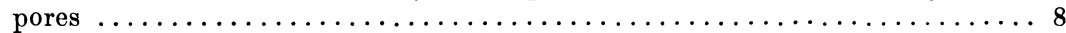

Anal lobe cerarii surrounded by a dispersed group of pores.......... 9

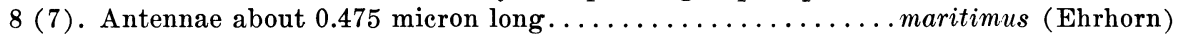

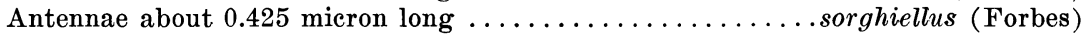

9 (7). Dorsal body setae strikingly long, some of them being as long as or longer than the length of the segment from which they arise...........longisetosus Ferris

Dorsal body setae all small and short, none reaching a length of as much as half the length of the segment to which they belong ...........kingii (Cockerell)

\section{Pseudococcus importatus McKenzie, new species}

(Figure 14)

Suggested common name. Imported mealybug.

Hosts and distribution. Type mealybug specimens from orchid, Vanda sp. (Orchidaceae), taken in quarantine at Honolulu, Hawaii, from California, November 5, 1949, W. K. Wong, collector (U.S.D.A. \#50-1726 ; Honolulu \#36,851). This represents the only known collection of the mealybug. 


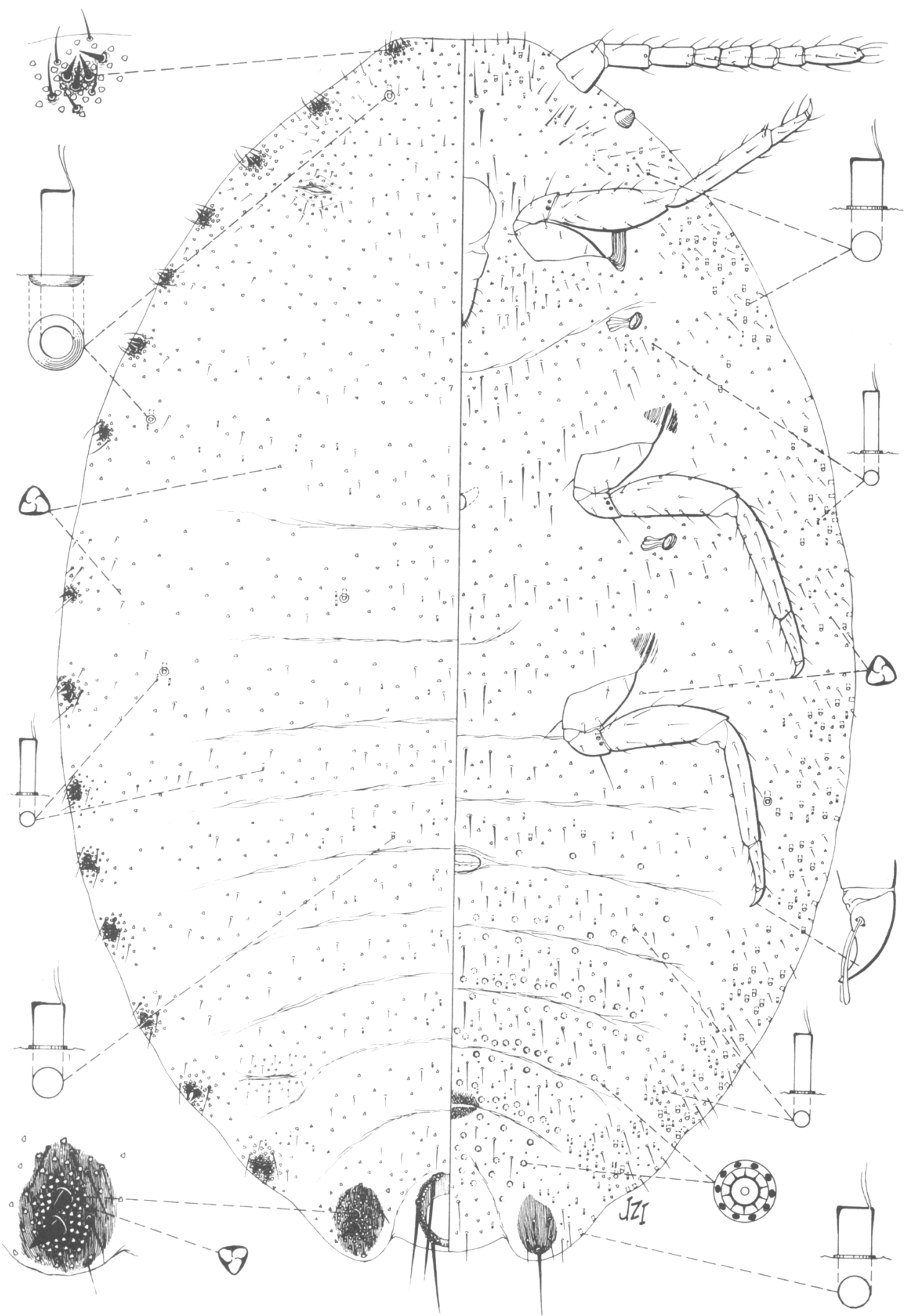

Fig. 14. Pscudococcus importatus McKenzie, new species, collected on Vanda sp. (orchid), taken in quarantine at Honolulu, Hawaii, from California. 
Type material. Holotype female (1 specimen mounted on 1 slide), has been sent to the United States National Collection of Coccoidea, Washington, D.C., and a single paratype female has been deposited in the University of California, Department of Entomology and Parasitology Museum collection at Davis.

Habit. Presumably occurring exposed upon the foliage of the host. No other information is available.

Recognition characters. Length of largest available specimen measures approximately $3.50 \mathrm{~mm}$. On the dorsum, normally with 16 pairs of cerarii, anal lobe cerarius with 2 large, conical setae, these surrounded by numerous, crowded, trilocular pores and 5 or 6 slender auxiliary setae, the whole enclosed within a well-defined, somewhat ovoid, sclerotized area; the remaining cerarii with 2 conical and somewhat smaller setae, except for some of those in the cephalic region and head which may have 3 or 4 , and each with a cluster of trilocular pores and slender auxiliary setae. Dorsal body setae all small and slender. Dorsal oral rim ducts present in very limited numbers, only 7 or 8 observed, the majority occurring submarginally on thorax and head, only 1 or 2 situated near cerarii on second or third abdominal segments. Trilocular pores evenly distributed over entire dorsum. A few oral collar ducts of two distinct sizes present on abdomen and thorax, lacking on head. Anal ring of normal form and size for the genus, with its 6 setae about twice as long as the greatest diameter of the ring.

On the ventral side, multilocular disk pores numerous, predominantly in mid-region of abdomen, from apical to fourth segment, none present on thorax and head. Oral collar ducts of two distinct sizes are present in considerable numbers from the apical abdominal segment to head, appearing in clusters particularly along submargins of body. Only 1 or 2 oral rim ducts observed on venter, these apparently located on either third or fourth abdominal segments. Ventral body setae small and slender, usually slightly longer than those on dorsum. Trilocular pores evenly distributed on venter.

Circulus small and transversely oval, situated between fold of fourth and fifth abdominal segments, normally divided by segmental line. Legs well developed. Claws without denticle or tooth on plantar surface.

NOTES. This species seems quite closely related to Pseudococcus comstocki (Kuwana), but differs in lacking ventral multilocular disk pores in sternal area ; a smaller, undivided circulus, and fewer dorsal oral rim ducts. It also appears to have some affinity with Pseudococcus microcirculus McKenzie, herein described as new, and which also attacks orchids, but differs in possessing more numerous ventral multilocular disk pores on abdomen ; a larger circulus situated on segmental fold; and normally only 16 pairs of dorsal cerarii as compared to 17 pairs in microcirculus.

Specimens of this species were kindly made available to the author by Dr. Harold Morrison, Coccidologist at Washington, D.C. 


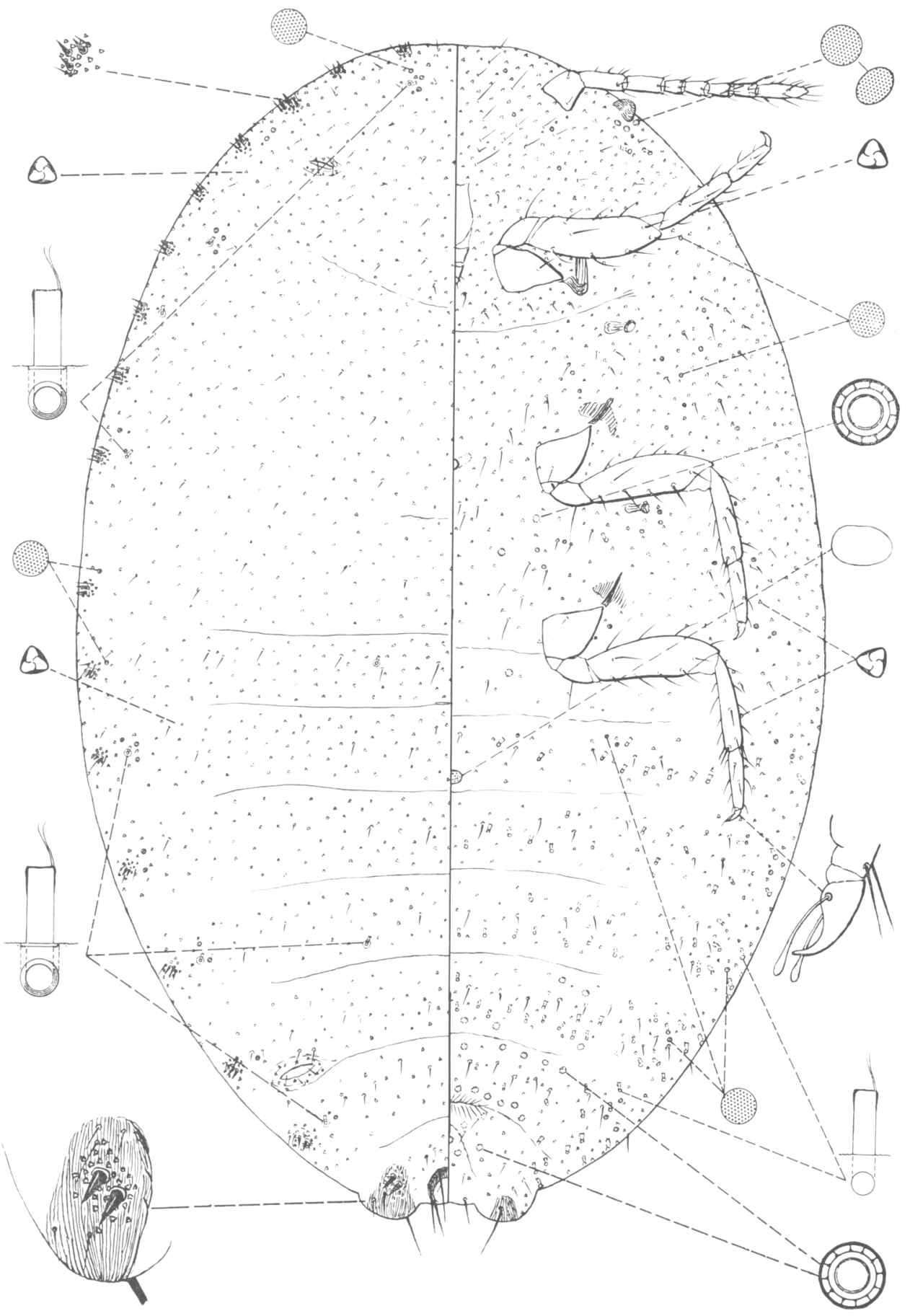

Fig. 15. Pseudococcus microcirculus McKenzie, new species, an orchid-infesting species found in nurseries in the San Francisco Bay area of California. 


\section{Pseudococcus microcirculus McKenzie, new species}

(Figure 15)

\section{Suggested common name. Orchid mealybug.}

Hosts and distribution. Type and paratypes from orchid (Orchidaceae) in nursery at Lafayette, Contra Costa County, California, October 18, 1954, lulu \#36,851). This represents the only known collection of the mealybug.

Type material. Holotype female (1 specimen mounted on 1 slide), has been sent to the United States National Collection of Coccoidea, Washington, D.C., by D. J. Bingham and J. Simmen (Calif. State Dept. Agr. \#54J389). Additional paratypes have been collected on orchids in nurseries from the following localities in Marin County, California: on Cattleya sp., Larkspur, September 1, 1954, by R. E. Garvey (Calif. State Dept. Agr. \#54I24); on Cattleya sp., Mill Valley, July 3, 1955, by R. E. Garvey (Calif. State Dept. Agr. \#55H122); on Cattleya sp., San Anselmo, August 21, 1956, by R. E. Garvey (Calif. State Dept. Agr. \#56H359) ; on Dendrobium sp., Alto, Mill Valley, March 10, 1958, by D. J. Bingham and R. E. Garvey (Calif. State Dept. Agr. \#58C14-1) ; on orchids, Brassavola nodosa and Odontoglossum sp., San Anselmo, September 4, 1958, by D. Smith and R. E. Garvey, and on Cattleya sp., Lochlomond (near San Anselmo), September 16, 1958, R. E. Garvey, collector.

Type material. Holotype female ( 1 specimen mounted on 1 slide), and paratypes, from various localities cited above, have been deposited in the University of California, Department of Entomology and Parasitology Museum collection at Davis ; in the California State Department of Agriculture, Bureau of Entomology collection at Sacramento; in the Stanford University Natural History Museum collection, Stanford University; and have been sent to the United States National Collection of Coccoidea at Washington, D.C.

Habit. The adult female of this species is smoothly dusted with wax and shows no definite bare areas. The insects occur exposed upon the foliage of the host.

Recognition characters. Length of largest available specimen measures approximately $2.75 \mathrm{~mm}$. Body form broadly oval as mounted. Dorsal aspects of the mealybug show the following morphological details: normally with 17 pairs of cerarii, anal lobe cerarius with 2 large, conical setae, these surrounded by numerous but not crowded trilocular pores and 5 or 6 slender auxiliary setae, the whole enclosed within a well-defined, somewhat ovoid, sclerotized area; the remaining cerarii with 2 conical, somewhat smaller setae, except for some of those in the cephalic region which may have 3 to 4 , and each with a cluster of trilocular pores and several slender auxiliary setae. A few dorsal body setae all small and slender. Dorsal oral rim ducts present and proportionately quite small, situated singly near a few of the cerarii from the eighth abdominal segment to prothorax, occasionally one present posterior to the frontal cerarius, and normally much reduced in numbers over the remainder of the dorsum, occurring chiefly as 1 or 2 ducts in a median longitudinal series on abdomen, the pattern rather variable but essentially as shown in the accompanying illustration of the species. A few small, round or oval, submarginal loculi or discoidal pores are present, some 
associated with oral rim ducts, others occurring singly or in groups of 2 or 3 . Trilocular pores evenly distributed over entire dorsum. Anal ring of normal form and size for the genus, with its 6 setae about twice as long as the greatest diameter of the ring.

On the ventral side, multilocular disk pores are present in very few numbers, predominantly in the mid-region of the abdomen, from the apical segment to the seventh segment, often a single pore appearing on the third and sixth segments, and sometimes an occasional pore anterior to this on sternal areas of thorax. Small tubular ducts of the oral collar type are fairly abundant from the apical to fourth abdominal segments, a few observed on thorax and head. Oral rim ducts are lacking on venter. A few of the small, round or oval loculi or discoidal pores, similar to those on dorsum, are present, those associated with the eyes appearing somewhat larger than others distributed on head, sternal areas, and submarginally on abdomen. Ventral body setae small and slender. Trilocular pores on venter evenly distributed.

Circulus very small and transversely oval, normally situated on fourth abdominal segment, sometimes located on segmental line, but not divided by fold between the fourth and fifth segments. Legs well developed, the claws without a denticle or tooth.

NOTES. The most striking morphological feature of this mealybug is, as its name suggests, the small oval circulus situated on the fourth abdominal segment, not divided by the segmental fold between the fourth and fifth segments, and the rather unusual small, round or oval loculi or discoidal pores, situated on both body surfaces. The new species differs from all known North American Pseudococcus forms in the possession of these morphological characteristics.

Of the known species of this group, it appears most closely related to Pseudococcus comstocki (Kuwana), particularly in the structure of the anal lobe and other cerarii, but the small circulus and presence of the oval loculi or discoidal pores both dorsally and ventrally among other things, preclude confusion with this form. It also appears to have some affinity with Pseudococcus importatus McKenzie, herein described as new, and which also attacks orchid, but differs in having fewer ventral multilocular disk pores on abdomen; a smaller circulus situated on fourth segment; and normally with 17 pairs of dorsal cerarii as compared to 16 pairs in importatus.

The illustration for this species was made by Professor Ferris.

\section{Genus Puto Signoret}

Four California species of Puto are described as new in this publication. Ferris' 1953 key to the North American species of Puto has been recast to include the new forms here presented.

\section{Key to Puto Species of North America}

1. Ventral multilocular disk pores present on last 2 abdominal segments....... 2 Ventral multilocular disk pores lacking on last 2 abdominal segments nulliporus MeKenzie

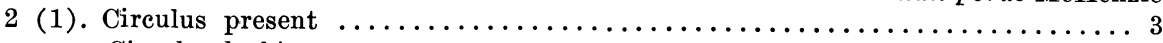
Circulus lacking $\ldots \ldots \ldots \ldots \ldots \ldots \ldots \ldots \ldots \ldots \ldots \ldots \ldots \ldots$ acirculus McKenzie

3 (2). Ventral multilocular disk pores present in thoracic and head regions.......4 
Ventral multilocular disk pores lacking in thoracic and head regions, except 1 or 2 near spiracles .................... profusus McKenzie

4 (3). Circulus partially or even completely divided medially by a constriction; a Central American species at present known from orchids ........... ulter Ferris

Circulus with no trace of such a median constriction $\ldots \ldots \ldots \ldots \ldots \ldots \ldots$

5 (4). Dorsum with tubular ducts in addition to those occurring in or about the cerarian plates; antennae normally 8-segmented, although at times 9-segmented; anal ring frequently with 8 or more setae; occurring as far as known on conifers cupressi (Coleman)

Dorsum entirely without tubular ducts other than those which may occur in the immediate vicinity of the cerarian plates; antennae normally 9-segmented; anal ring normally with 8 setae $\ldots \ldots \ldots \ldots \ldots \ldots \ldots \ldots \ldots \ldots \ldots \ldots \ldots \ldots \ldots$

6 (5). Cerarian plates without tubular ducts, and not accompanied by such ducts, except for occasionally 1 or 2 ducts on the terminal plates $\ldots \ldots \ldots \ldots \ldots \ldots$

Cerarian plates for the most part with tubular ducts..............11

7 (6). Dorsum with great numbers of lanceolate setae, each of which arises from a welldeveloped basal sclerosis, these scleroses at times coalescing to form little, irregular plates; as far as known occurring only on grasses

calcitectus (Cockerell)

Dorsum without enlarged sclerotic setal bases, the setal tubercles for the most

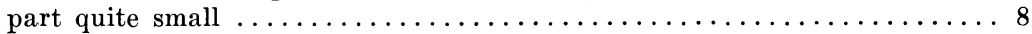

8 (7). Circulus small, broadly oval on its transverse diameter; a species at present known only from high altitudes in California........... bryanthi Ferris

Circulus elongate on its transverse axis $\ldots \ldots \ldots \ldots \ldots \ldots \ldots \ldots \ldots \ldots$

9 (8). With from 13 to 20 enlarged setae or spines on anal lobe cerarius; a species known only from high altitudes in California..........pricei McKenzie

With 28 to 38 , or perhaps even more, enlarged setae or spines on anal lobe

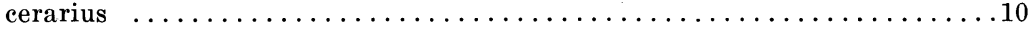

10 (9). Dorsal body setae rather sparse, arranged for the most part in patches or interrupted rows; a species with a wingless male, known at present only from the

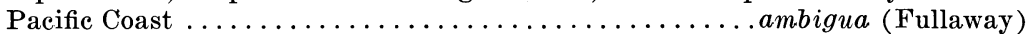

Dorsal body setae very numerous, not thus occurring in separate patches and interrupted rows; a tropical species at present known from the West Indies barberi (Cockerell)

11 (6). Cerarian plates all extremely large, more or less rectangular in form; at present known only from Arctostaphylos in California...........arctostaphyli Ferris

Cerarian plates in large part only moderately large, circular or oval . . . . . . 12

12 (11). Cerarian plates usually including but 2 tubular ducts, occasionally with 3 , rarely

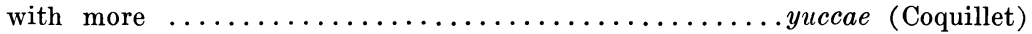

Cerarian plates with for the most part not less than 4 tubular ducts, frequently

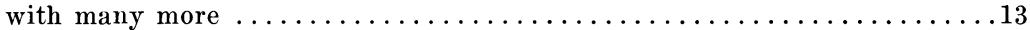

13(12). Dorsal body setae for the most part as large as those of the cerarii, arranged in discrete patches over the body with bare areas among the patches, these patches especially evident along the midline of the abdominal dorsum

lasiorum (Cockerell)

Dorsal body setae for the most part smaller than the cerarian setae, scattered, not thus arranged in discrete patches...........mexicanus (Cockerell)

\section{Puto acirculus McKenzie, new species}

(Figure 16)

Suggested common name. Grass-infesting puto.

Hosts and distribution. Type and paratypes from Elymus sp. (wild rye), (Gramineae), Santa Paula, Ventura County, California, June 10, 1958, collected by L. R. Gillogly and J. L. Weber, this representing the only known collection of the mealybug.

Type material. Holotype female (1 specimen mounted on 1 slide), and paratypes have been deposited in the University of California, Department 


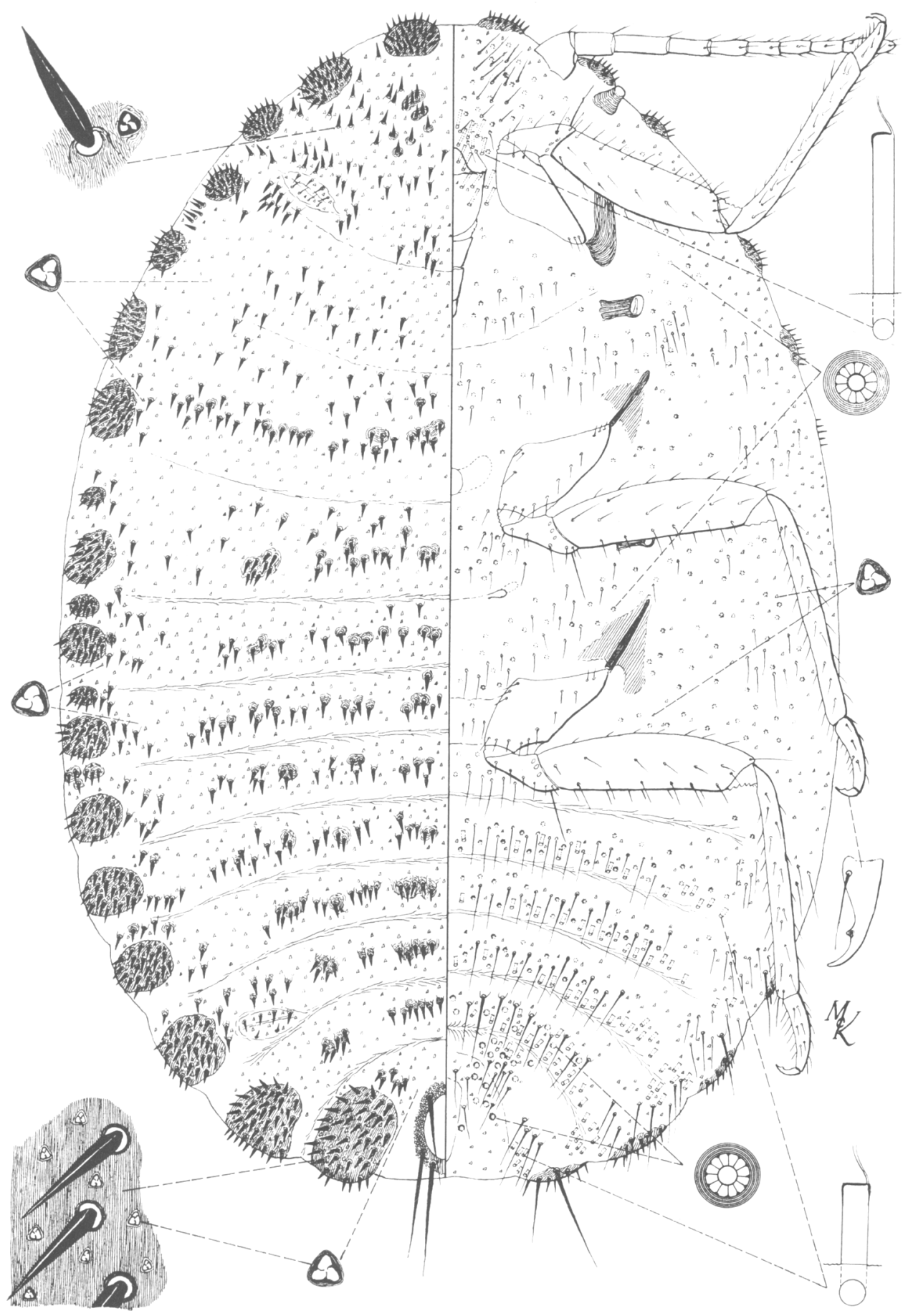

Fig. 16. Puto acirculus McKenzie, new species, collected on wild rye, Elymus sp. (Gramineae), at Santa Paula, Ventura County, California. 
of Entomology and Parasitology Museum collection at Davis; paratypes have been placed in the California State Department of Agriculture, Bureau of Entomology collection at Sacramento ; in the Stanford University Natural History Museum collection, Stanford University; and have been sent to the United States National Collection of Coccoidea at Washington, D.C.

Habit. Presumably concealed beneath the sheathing bases of host leaves. No other information available.

Recognition characters. Adult female reaching a length of approximately $5.25 \mathrm{~mm}$., broadly oval as mounted on microscope slide. On the dorsum the cerarii appear basically in 18 pairs, this arrangement, however, interrupted by the division of individual cerarii or the interpolation of others; each cerarius formed upon a sclerotized plate bearing from 2 or 3 to as many as 40 , or perhaps even more, enlarged setae, these setae apically pointed and slightly lanceolate, trilocular pores borne on cerarian plates in usually somewhat fewer numbers than the setae. Dorsal body setae similar in form to those of cerarii, numerous and arranged in transverse bands on the abdominal segments and covering the thoracic segments and head, most of the setae are situated upon a small, sclerotic plate that forms a slight tubercle; here and there these plates coalesce to form irregular, sclerotized areas. Trilocular pores distributed over entire dorsum. Anal ring with 6 elongate setae.

On the ventral side of the body, multilocular disk pores are present, these quite broad and having a more or less sclerotized outer ring, situated predominantly in the mid-region, from posterior to the vulva as far forward as the head, those anterior to the last 3 abdominal segments being slightly smaller. Tubular ducts of oral collar type are present in rather small numbers on venter of abdominal segments, and a few more slender and elongate ones are situated in the cephalic region just anterior to the mouthparts. Trilocular pores sparingly distributed over venter with the exception of the midthoracic region where they appear to be entirely lacking.

Circulus lacking. Antennae slender, normally 9-segmented. Legs unusually large and slender, with claws exhibiting a distinct and well-developed denticle or tooth.

NOTES. The most distinctive feature of this form, and one that separates it immediately from all known North American species of Puto, is the absence of a circulus. It approaches Puto calcitectus (Cockerell) in possessing dorsal setae which arise from well-developed basal scleroses, these scleroses at times coalescing to form small, irregular plates. Like calcitectus, this species also occurs on a grass.

\section{Puto nulliporus McKenzie, new species}

(Figure 17)

Suggested common name. A composite puto.

Hosts and distribution. Type and paratype from Bebbia juncea var. aspera (Compositae), 9 miles south Palo Verde, Imperial County, California, collected April 8, 1959, by G. Beevor and W. P. Cronk (Calif. State Dept. Agr. \#59D16-15), this representing the only known collection of the mealybug.

Type material. Holotype female (1 specimen mounted on 1 slide), and paratypes have been deposited in the University of California, Department 


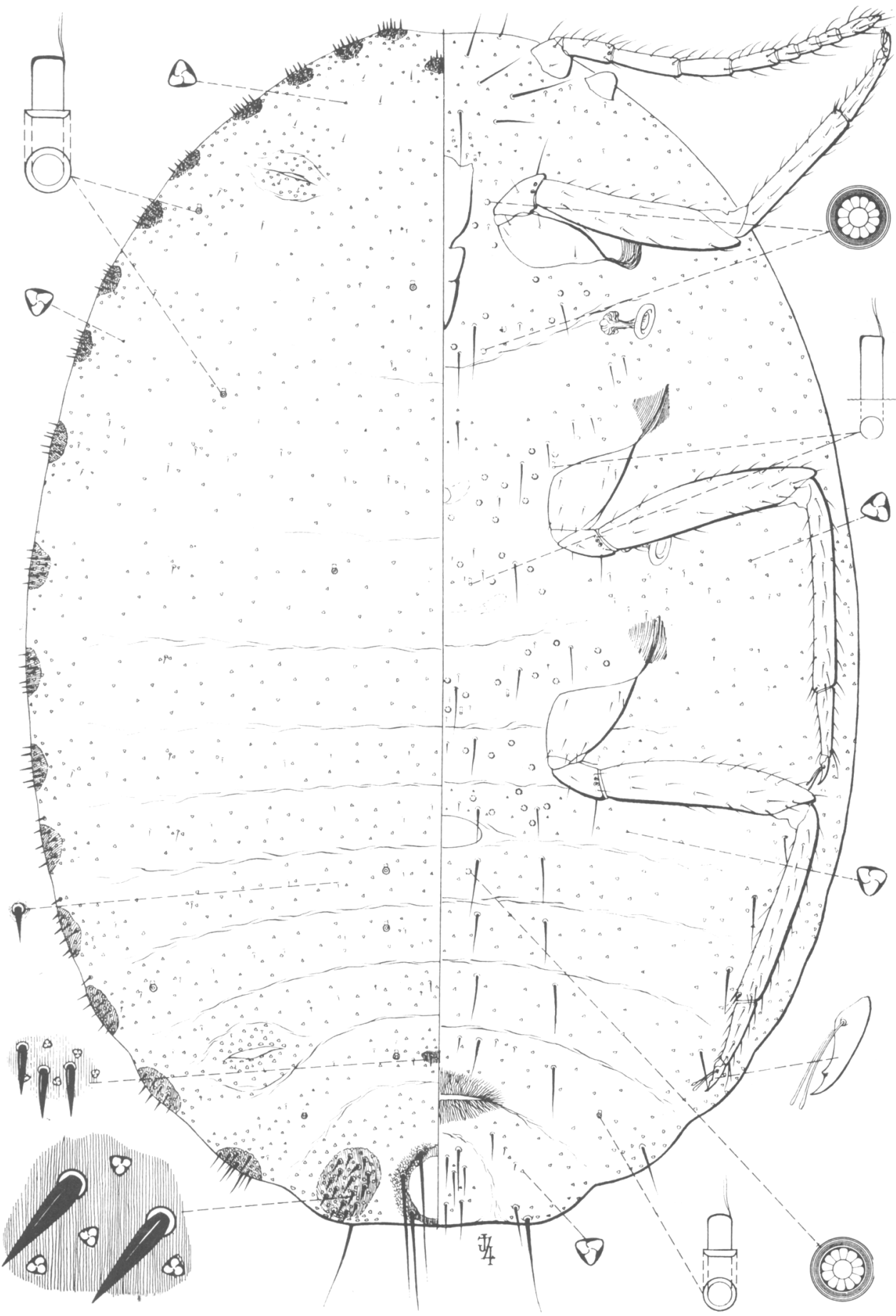

Fig. 17. Puto nulliporus McKenzie, new species, collected on Bebbia juncea var. aspera (Compositae), 9 miles south of Palo Verde, Imperial County, California. 
of Entomology and Parasitology Museum collection at Davis; paratypes have been placed in the California State Department of Agriculture, Bureau of Entomology collection at Sacramento; in the Stanford University Natural History Museum collection, Stanford University; and have been sent to the United States National Collection of Coccoidea at Washington, D.C.

Habit. No available information.

Recognition characters. Length of largest available adult female measures approximately $3.50 \mathrm{~mm}$. On the dorsum the cerarii appear basically in 18 pairs, this arrangement, however, interrupted by the division of individual cerarii or the interpolation of others. Anal lobe cerarii largest; one small dorsal median cerarius normally present on eighth abdominal segment, each cerarius formed upon a sclerotized plate bearing from 2 to 3 in the smaller cerarii, to as many as 18 (in anal lobe cerarii), or perhaps even more, enlarged setae, these setae apically pointed and slightly lanceolate. Trilocular pores borne on cerarian plates usually somewhat more numerous than the setae. Tubular ducts resembling the oral rim type are sparingly distributed over the dorsum. Dorsal body setae for the most part definitely smaller and more slender than those of cerarii, arranged in a broken single row on abdominal segments, scattered over thoracic segments. Trilocular pores distributed over entire dorsum. Anal ring with 6 elongate setae.

On the ventral side of the body, multilocular disk pores are lacking on last 5 abdominal segments (occasionally a single one is found on fifth segment), sparsely distributed from fourth segment anteriorly to sternal region of thorax. One or two tubular ducts resembling the oral rim type, smaller than those on dorsum, may be found on abdomen. A few oral collar ducts are present on thorax, particularly in sternal area, and just anterior to the mouthparts. Trilocular pores sparingly distributed over venter.

Circulus quite small, broad, transversely oval. Antennae long and slender, normally 9-segmented. Legs unusually large and slender, with claws exhibiting a distinct and well-developed denticle or tooth.

NOTES. In the nature of the small, broad transversely oval ventral circulus, this species appears to have affinities with Puto bryanthi Ferris. It differs, however, in lacking ventral multilocular disk pores on last four abdominal segments, these present in bryanthi.

Mounted specimens of this species were kindly made available to the author by R. F. Wilkey of the California State Department of Agriculture, Bureau of Entomology, at Sacramento, California.

\section{Puto pricei McKenzie, new species}

(Figure 18)

Suggested common name. Price mealybug.

Hosts and distribution. Type and paratypes from under rocks and in needle debris around the base beneath Pinus contorta (lodgepole pine), (Pinaceae), Yosemite National Park, Dana Fork of Tuolumne River (10,000 feet elevation), Tuolumne County, collected September 6, 1959, by D. W. Price. Additional paratypes of this species were collected under fallen logs beneath Pinus albicaulis (white bark pine) $1 / 2$ mile south Tioga Pass $(10,000$ feet elevation), Tuolumne County, September 7, 1959, and in the same gen- 


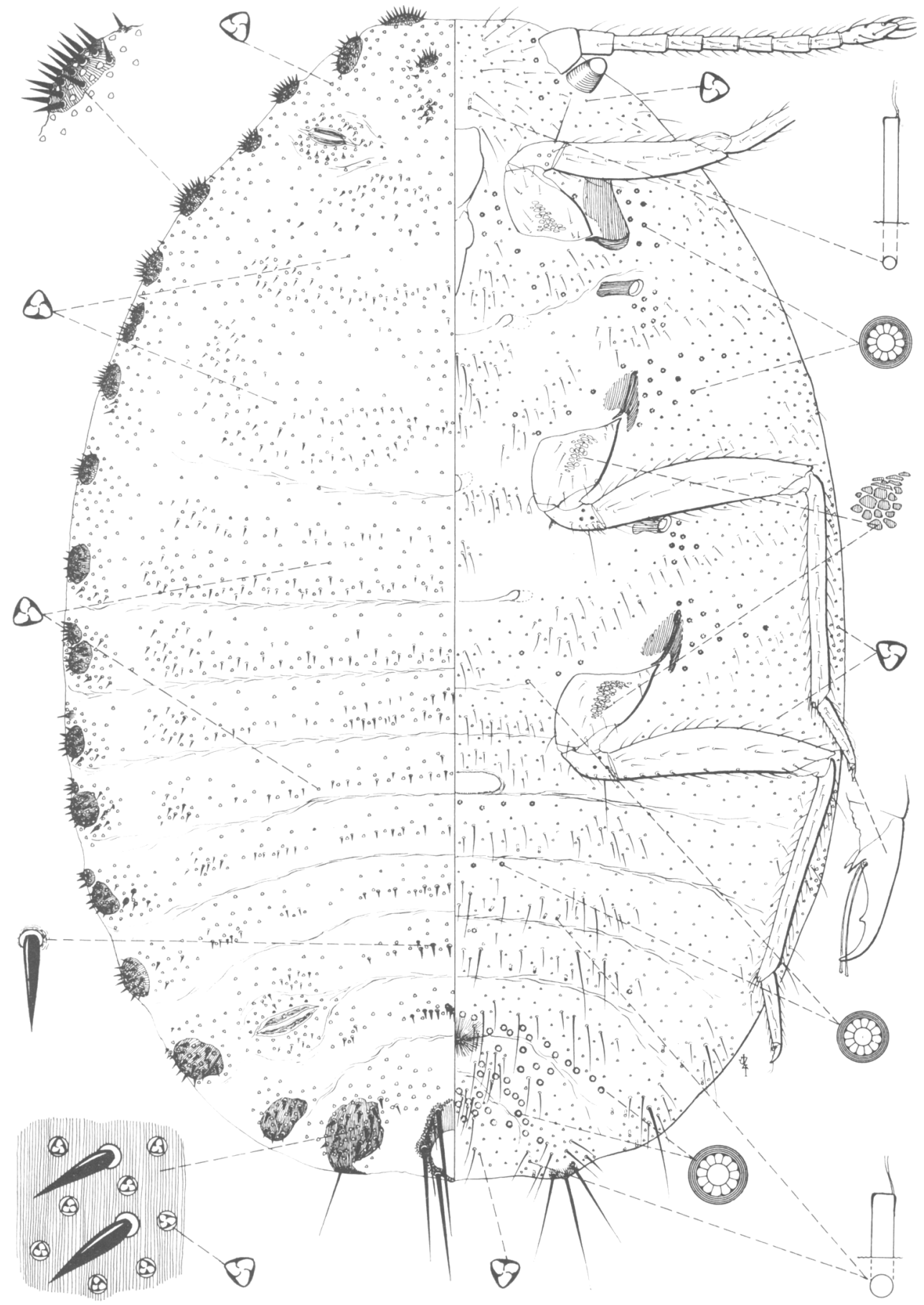

Fig. 18. Puto pricei McKenzie, new species, collected under rocks and in needle debris around the base beneath lodgepole pine, Pinus contorta (Pinaceae), Yosemite National Park, Dana Fork of Tuolumne River (10,000 feet elevation), Tuolumne County, California. 
eral area 1 mile south of Mt. Dana (11,000 feet elevation), September 8, 1959 , by D. W. Price. These three lots represent the only known collections of this mealybug.

Type material. Holotype female (1 specimen mounted on 1 slide), and paratypes of this species have been deposited in the University of California, Department of Entomology and Parasitology Museum collection at Davis; paratypes have also been placed in the California State Department of Agriculture, Bureau of Entomology collection at Sacramento; in the Stanford University Natural History Museum collection, Stanford University; and in the United States National Collection of Coccoidea at Washington, D.C.

Habit. According to D. W. Price who collected the species, this mealybug was found at high altitudes of from 10,000 to 11,000 feet elevation, under and adhering tightly to rocks, and in needle debris around the base of lodgepole pine. He also found the mealybug under fallen logs beneath white bark pine. Partially grown nymphs and fully mature adults were evident at the time these collections were made. No very definite ovisac is formed. The mealybugs apparently were not feeding on plant roots at the time collected.

Recognition characters. Adult female broadly oval, reaching a length of approximately $3.50 \mathrm{~mm}$. On the dorsum the cerarii appear basically in 18 pairs, this arrangement, however, interrupted by the division of individual cerarii or the interpolation of others; each cerarius formed upon a scleratized plate bearing from 3 or 4 to as many as 19 to 20 enlarged spines or setae, these setae apically pointed and slightly lanceolate; trilocular pores borne on cerarian plates usually somewhat more numerous than the conical setae. Dorsal body setae similar in form to those of cerarii, numerous and arranged in transverse bands on the abdominal segments and covering the thoracic segments and head. Trilocular pores distributed over entire dorsum. Anal ring with normally 6 large and 4 smaller elongate setae.

On the ventral side of the body, multilocular disk pores are present on last two abdominal segments, sparsely distributed in mid-region from seventh segment anteriorly to sternal region and head, more numerous in coxal and spiracular areas, those anterior to last two abdominal segments being slightly smaller in diameter. One or 2 oral collar tubular ducts are situated just anterior to the mouthparts. Trilocular pores sparingly distributed over venter with the exception of certain "clear areas" on mid-thoracic region where they appear to be entirely lacking.

Circulus present, broad, transversely oval and with margins appearing somewhat crenulated. Antennae long and slender, normally 9-segmented. Legs unusually large and slender, with basal part of coxae presenting a distinctive, reticulated, pattern; claws exhibiting a well-developed denticle or tooth on plantar surface and a pair of rather unusual, sclerotized, spurs at base.

NOTES. On the basis of high altitude habitat, this Puto would approach bryanthi Ferris, and on the basis of the elongate, transversely oval circulus, it would come close to ambigua (Fullaway). Among other things it differs from bryanthi in the circulus character, and from ambigua in possessing fewer ventral multilocular disk pores on abdominal segments 3 to 7 , and in sternal and head areas. It may be distinguished from both bryanthi and 


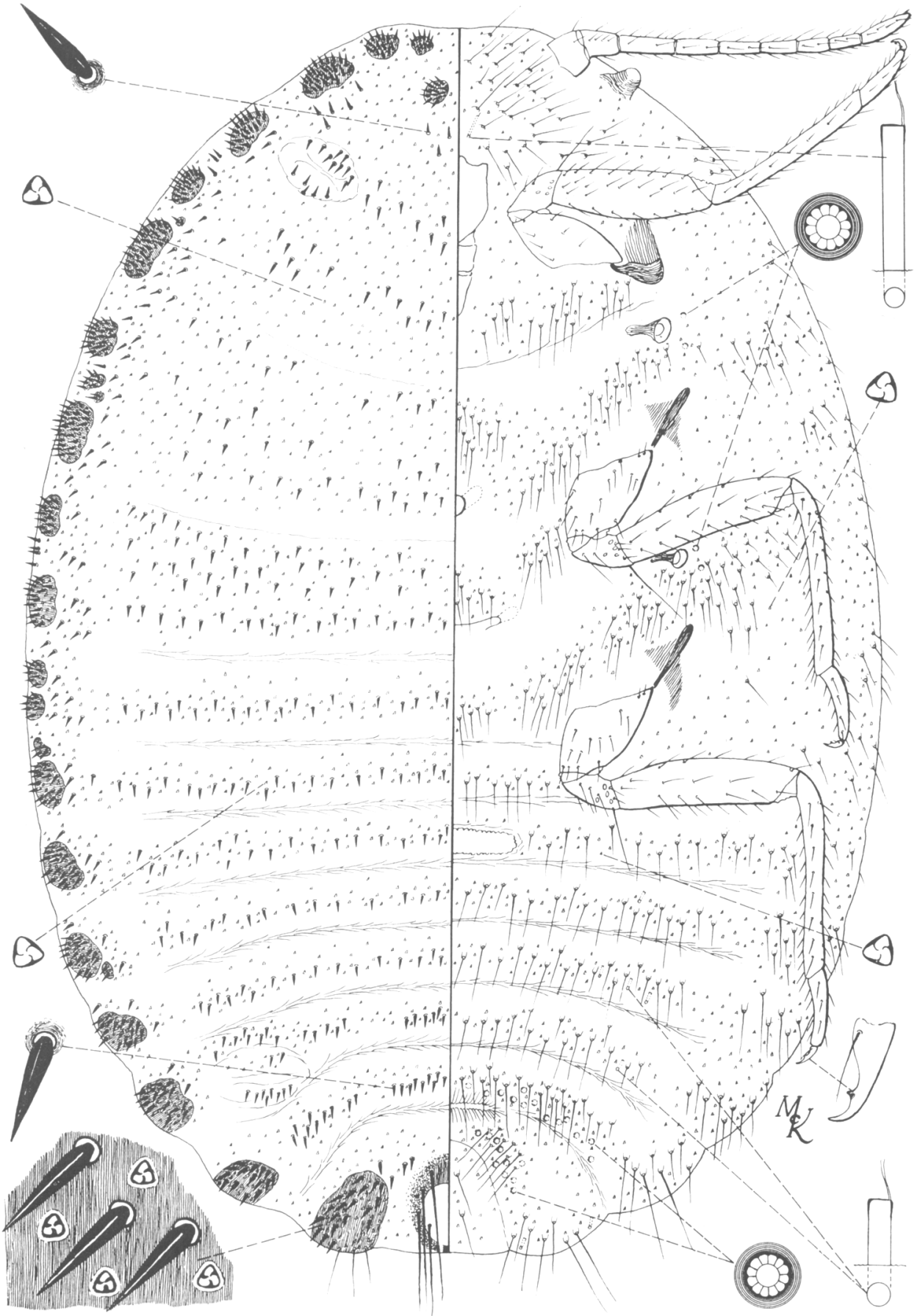

Fig. 19. Puto profusus McKenzie, new species, collected on Douglas Fir, Pseudotsuga taxifolia (Pinaceae), at Carrville, Trinity County, California. 
ambigua in having fewer, 20 or less, enlarged setae or spines on anal lobe cerarius, as compared to 28 or more in the last two species mentioned.

I take pleasure in naming this mealybug after Douglas W. Price, who not only collected the species, but also furnished valuable information about its specific habitat.

\section{Puto profusus McKenzie, new species}

(Figure 19)

Suggested common name. Douglas fir mealybug.

Hosts and distribution. Type and paratype from Pseudotsuga taxifolia (Pinaceae), Carrville, Trinity County, California, June, 1933, collected by E. C. Van Dyke, this representing the only known collection of the mealybug.

Type material. Holotype female and 1 paratype of the same sex, both mounted on 1 microscope slide, have been deposited in the University of California, Department of Entomology and Parasitology Museum collection, at Davis. Unfortunately, this collection represents the only known examples of this species at the present time.

Habit. No information.

Recognition characters. Adult female reaching a length of approximately $6.00 \mathrm{~mm}$, broadly oval as mounted on microscope slide. On the dorsum the cerarii appear basically in 18 pairs, this arrangement, however, interrupted by the division of individual cerarii or the interpolation of others; each cerarius formed upon a sclerotized plate bearing from 2 or 3 to as many as 24 , or perhaps even more, enlarged setae, these setae apically pointed and slightly lanceolate. Trilocular pores borne upon the cerarian plates in numbers about equal to the number of setae. Dorsal body setae as large as or only slightly smaller than the cerarian setae, quite numerous and arranged in transverse bands on the abdominal segments and more irregularly on thoracic segments and head. Trilocular pores distributed over entire dorsum. Anal ring with 8 elongate setae.

On the ventral body surface, a few multilocular disk pores, all of the same size, are present, these quite broad and having a more or less sclerotized outer ring, apparently confined to abdominal segments 8 and 9 only, completely missing on remaining abdominal segments and on thoracic segments and head, except for 1 or 2 near spiracles. A very few tubular ducts of oral collar type are present on venter of abdominal segments, and 1 or 2 more slender and elongate ones are situated in the cephalic region just anterior to the mouthparts. Trilocular pores are distributed, mostly in bands, on thoracic and abdominal segments.

Circulus transversely elongate-oval, its margin appearing crenulate. Antennae slender, normally 9-segmented. Legs unusually large and slender, with claws exhibiting a distinct and well-developed denticle or tooth.

NOTES. One of the outstanding morphological differences of this mealybug, compared to other North American species of this group, is the absence of ventral multilocular disk pores in the thoracic and head regions, except for 1 or 2 near spiracles, the remainder apparently confined to abdominal segments 8 and 9 . It shares with Puto cupressi (Coleman) a transversely 


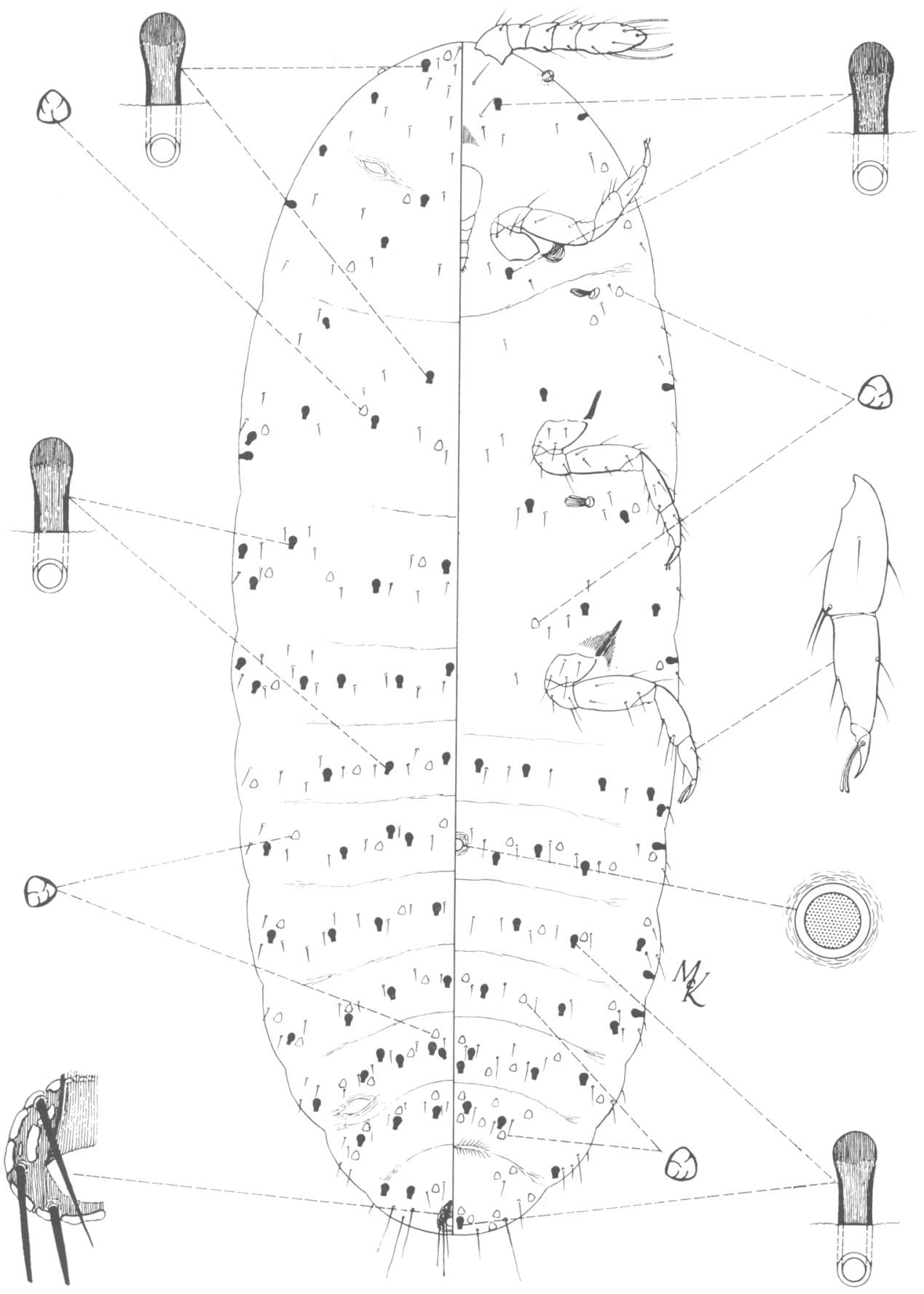

Fig. 20. Pygmaeococcus morrisoni McKenzie, new species, a tiny mealybug collected in juniper leaf mold at Coalinga, Fresno County, California. 
elongate-oval circulus, with crenulated margin, 8 long setae on anal ring, and a similar host preference, but differs principally in lacking tubular ducts associated with the cerarian plates, and, as previously mentioned, the absence of ventral multilocular disk pores on head and thorax, except 1 or 2 near spiracles, the remainder confined to the eighth and ninth abdominal segments.

\section{Genus Pygmaeococcus McKenzie, new genus}

Genotype. This genus is here established for the reception of a single species, Pygmaeococcus morrisoni McKenzie, described as new in this publication.

Recognition characters. An extremely small pseudococcid, adult female at maturity measuring not more than $0.75 \mathrm{~mm}$ in length. Dorsum with cerarii entirely lacking, the anal lobes commonly with several slender setae. Dorsal ostioles well developed although not sclerotized. Dorsal body setae small and slender. Dorsum and venter with an unusual type of invaginated duct, and with what appears to be a septum across the inner end. Trilocular pores present on both surfaces, these comparatively large. Bi- or tritubular pores, and multilocular disk pores lacking. Small, short, slender spines are sparsely situated on dorsum and venter. Anal ring relatively small, but well developed and complete, its pores large, oval or irregularly shaped, and with 6 elongate setae.

One small circulus present ventrally, this morphologically on the fourth abdominal segment. Antennae 5-segmented, set close together at apex of head, their bases ordinarily being separated by less than the width of a basal segment, the sensory setae of terminal segment strongly developed and unusually long and large. Legs stout, usually rather conspicuously spinose because of the development of enlarged setae on inner margin of tibia and tarsus. Claws without denticle, the digitules equaling or slightly exceeding the claw in length, apically swollen. Eyes present, well developed.

NOTES. This is a most unusual mealybug, distinguishable from other known pseudococcids by its extremely small size, measuring not more than $0.75 \mathrm{~mm}$ in length at maturity, and in the possession of rather remarkable invaginated ducts situated on both surfaces of the body.

It is perhaps most closely related to Rhizoecus Künckel d'Herculais, differing principally in the characters just mentioned.

\section{Pygmaeococcus morrisoni McKenzie, new species}

(Figure 20)

Suggested common name. Morrison pygmy mealybug.

Hosts and distribution. Type and paratypes collected in juniper leaf mold, Coalinga, Fresno County, California, 5 miles west in Warthon Canyon, June 25, 1958, by H. L. Wilson (Calif. State Dept. Agr. \#58G10-32). Excellent mounted examples of this new mealybug were made available to the author mainly through the efforts of R. F. Wilkey of the California State Department of Agriculture, Bureau of Entomology.

Habit. No information available.

Type material. Holotype female (1 specimen mounted on 1 slide, and paratypes have been deposited in the University of California, Department of 
Entomology and Parasitology Museum collection at Davis ; other paratypes have been placed in the California State Department of Agriculture, Bureau of Entomology collection at Sacramento ; in the Stanford University Natural History Museum collection, Stanford University; and have been sent to the United States National Collection of Coccoidea at Washington, D.C.

Recognition characters. The description of the genus will apply as the description of this species.

NOTES. As previously mentioned, there are no known species of Pseudococcidae which approach this new form in minuteness of size (mature adult female measuring not more than $0.75 \mathrm{~mm}$ in length), and which possess remarkable and most unusual type of invaginated ducts distributed on both dorsal and ventral surfaces.

The author takes great pleasure in naming this unusual mealybug after Dr. Harold Morrison, who not only pointed out the apparent need for a new genus to accommodate this species but also has given much assistance in completing the publication.

\section{Genus Rbizoecus Künckel d'Herculais}

The author has accepted Ferris' (1953) interpretation of Rhizoecus, as recorded in his Atlas, Volume VI. Apparently, the absence of eyes, number of antennal segments, presence or absence of circuli, presence or absence of bi- or tritubular pores, and length of claw digitules, do not in themselves have much significance as generic characters. It is suspected, however, that with the discovery and description of more of these obscure, soil-inhabiting species-and when they are better known-more generic segregates will have to be considered.

Ferris' (1953) key to North American species of Rhizoecus is recast and modified to absorb five new California species herein described. The revised key is here presented.

\section{Key to Rhizoecus Species of North America}

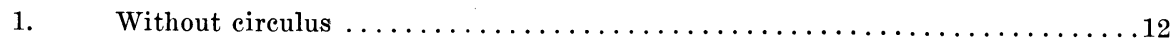

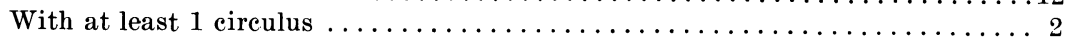

2 (1). Tritubular pores definitely present, although at times quite small and incon-

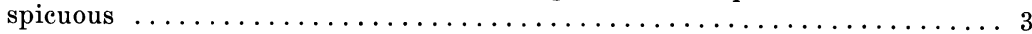

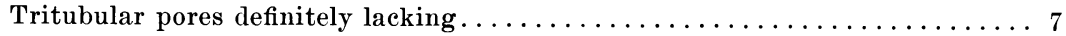

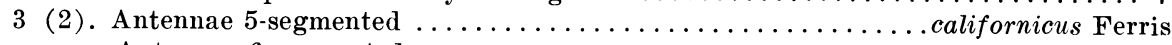

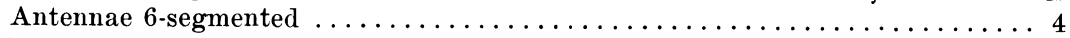

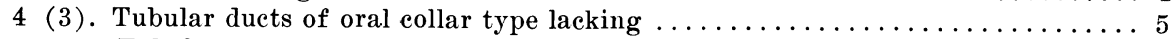

Tubular ducts of oral collar type present, both dorsally and ventrally, very small,

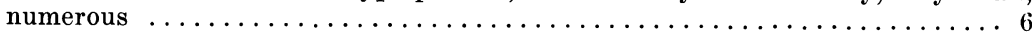

5 (4). Multilocular disk pores lacking ventrally on abdomen....leucosomus (Cockerell) Multilocular disk pores present ventrally on abdomen ........ sonomae McKenzie

6 (4). Digitules long and slender, setose, extending practically to tip of claw

Digitules short, setose, not extending beyond middle of claw cacticans (Hambleton)

maritimus (Cockerell)

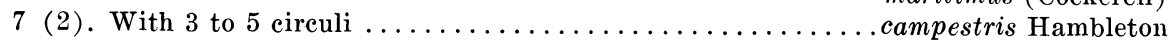

With not more than 2 circuli $\ldots \ldots \ldots \ldots \ldots \ldots \ldots \ldots \ldots \ldots \ldots \ldots \ldots$

8 (7). Multilocular disk pores present ventrally on thorax..... bituberculatus McKenzie Multilocular disk pores lacking on thorax venter..............9 


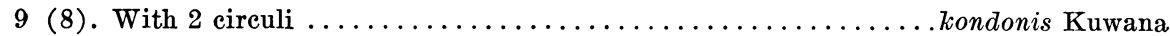

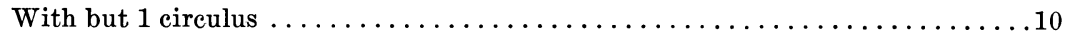

10 (9). Eighth abdominal segment with from 35 to 50 multilocular disk pores on venter spinosus McKenzie

Eighth abdominal segment with normally less than 20 multilocular disk pores on

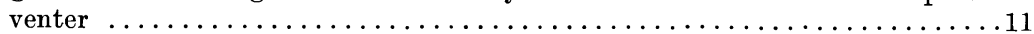

11(10). Multilocular disk pores present on dorsum of eighth abdominal segment; with tubular ducts, joined as pairs, extending internally on body.. solani Hambleton

Multilocular disk pores lacking on dorsum of eighth abdominal segment; with very small bitubular-type pores, divaricating, and projecting externally

totonicopanus Hambleton

12 (1). Dorsum of most abdominal segments with a transverse row of tritubular pores, these rows having from 10 to 16 pores; antennae 5-segmented

falcifer Künckel d'Herculais

Dorsum of abdominal segments with tritubular pores not thus arranged, or if rows can be detected they include not more than 6 to 7 pores........13

13(12). Anal lobes terminating in a small but distinct area of sclerotization. . . . . . 14

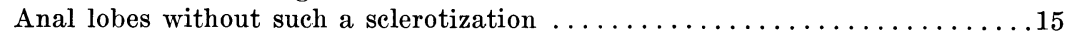

14(13). Inner row of pores of the anal ring clouded....................

Inner row of pores of the anal ring not clouded........distinctus (Hambleton)

15(13). Multilocular disk pores present only on venter of the abdomen.........16

Multilocular disk pores-even if very few-present dorsally and ventrally ...20

16(15). Abdominal segments 6 to 7 ventrally each with a transverse row of small tritubular pores extending across the median region.........mayanus (Hambleton)

No abdominal segment with transverse row of tritubular pores in the median

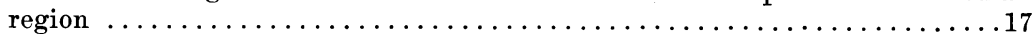

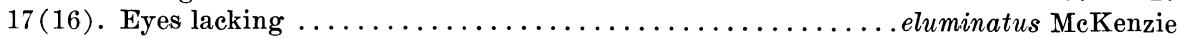

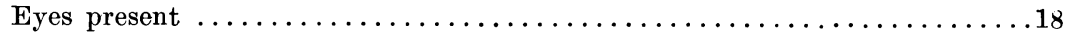

18(17). A very few small ventral tubular ducts present posterior to vulva.........19

Small ventral tubular ducts lacking anywhere on body.....pritchardi MeKenzie

19(18). Anal lobe area each with 2 elongate setae and 2 or 3 smaller auxiliary setae; 1 to 4 body setae associated with each tritubular pore....cyperalis (Hambleton)

Anal lobe area each with 3 elongate setae and 5 to 8 smaller auxiliary setae; body setae not associated with tribular pores ........nemoralis (Hambleton)

$20(15)$. Dorsal multilocular disk pores forming distinct rows on all segments from mesothorax to abdominal segment $8 \ldots \ldots \ldots \ldots \ldots$ graminis (Hambleton)

Dorsal multilocular disk pores very few and scattered, not forming rows americanus (Hambleton)

\section{Rhizoecus bituberculatus McKenzie, new species}

(Figure 21)

Suggested common name. Bituberculate mealybug.

Hosts and distribution. Type and paratypes in soil under Quercus wislizenii (Fagaceae), 4 miles west of Newcastle, Placer County, California, collected March 21, 1958, by W. H. Lange, L. M. Smith, and R. O. Schuster. Additional paratype specimens were found in the same area and habit as above, collected April 15, 1958, and March 10, 1959, by L. M. Smith and R. O. Schuster. Soil from the collections was subjected to Berlese funnel trap treatment, and a total of 17 mealybug examples were subsequently recovered. These lots represent the only known collections of this mealybug.

Type material. Holotype female mounted on 1 slide, and paratypes of this species have been deposited in the University of California, Department of Entomology and Parasitology Museum collection at Davis ; and paratypes have been sent to the United States National Collection of Coccoidea at Washington, D.C. 


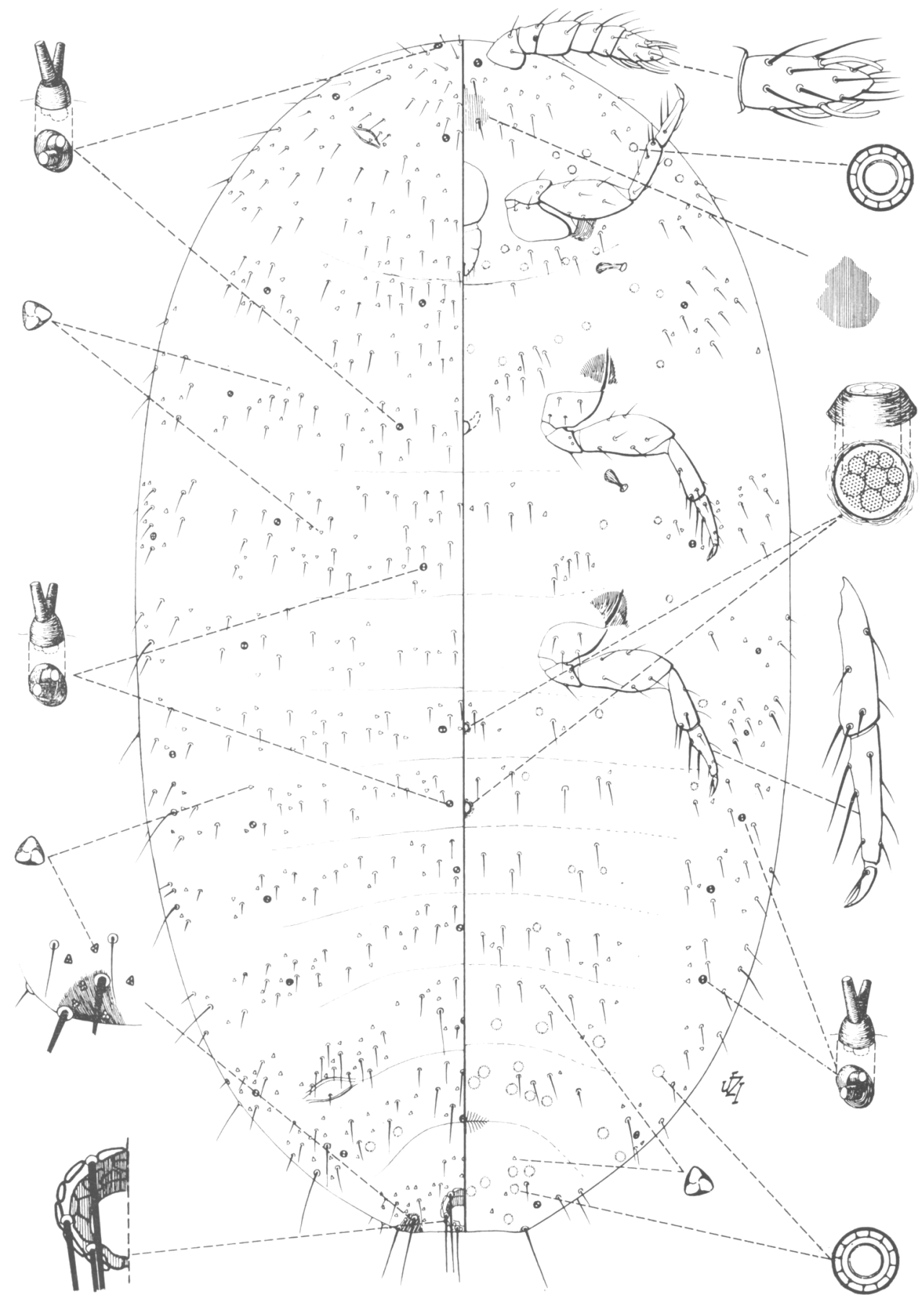

Fig. 21. Rhizoecus bituberculatus MeKenzie, new species, collected in soil under Quercus wislizenii (Fagaceae), 4 miles west of Neweastle, Placer County, California. 
Habit. Only information is that the mealybug occurs on the roots.

Recognition characters. Length of largest available mounted specimen is approximately $1.20 \mathrm{~mm}$. On the dorsum, cerarii entirely lacking, the anal lobes with several slender setae of various lengths, these set in a quite distinct, but small area of sclerotization. Tubular pores of the bitubular type scattered over dorsum, rather numerous, as many as 44 observed. Dorsum beset with relatively small numbers of trilocular pores and small setae, these arranged in rather widely separated areas particularly in the thoracic region and on abdomen between segments and in lateral patches. Tubular ducts of the oral collar type lacking. Multilocular disk pores lacking on dorsum except for a few along posterior border of eighth abdominal segment. Anal ring borne at apex of abdomen, its setae but little longer than its greatest diameter, its pores large, oval and irregularly shaped, some appearing clear and open, others with varying amounts of pigmentation. Dorsal ostioles well-developed, their rims sclerotized.

Ventrally, multilocular disk pores of two slightly different sizes, the larger ones present on apical to along border of seventh segment, the smaller ones present on segments 6 to 3 , and scattered in patches on head and thorax. Bitubular pores few, apparently confined to a series along body margin, these as large as those of dorsum. Trilocular pores on abdomen and thorax confined to isolated patches of pores and setae, showing as rather marked "clear areas." Tubular ducts of oral collar type lacking. Ventral setae sparse, short and slender.

Apparently, with only 1 conical circulus present, this on the morphologically fourth abdominal segment, although in one of the five specimens of the type series, 2 conical circuli are evident on third and fourth segments, the one on fourth segment largest. Eyes lacking. Antennae 6-segmented, quite short and stout, apical segment bearing 3 sensory setae, interantennal space equal to slightly more than width of basal segment. Legs relatively short, stout, tibia and tarsi armed with stout spines, claws with long, setose digitules extending approximately to tip.

NOTES. The new species, Rhizoecus bituberculatus McKenzie, does not seem to fit satisfactorily into Ferris' key to North American species of Rhizoecus, but perhaps nearest to solani. It differs from solani in possessing a different type of bitubular pore, and 2 different sizes of ventral multilocular disk pores. It is perhaps most closely related to Rhizoecus spinosus McKenzie, herein described as new, but differs mainly in the possession of ventral multilocular disk pores on thorax.

Dr. Harold Morrison has kindly examined this species and has made important comments regarding its relationship to other Rhizoecus species. He concurs with the author that the species is new, and his ideas have been incorporated into the morphological notes just presented.

\section{Rbizoecus cacticans (Hambleton)}

Synonymy. Ripersiella cacticans Hambleton; Rhizoecus epiphylli Ferris.

NOTES. During the course of this investigation the two type specimens of Rhizoecus epiphylli Ferris, were examined. This species was described by Ferris (1953), in his Atlas, Volume VI, The Pseudococeidae, Part II, page 


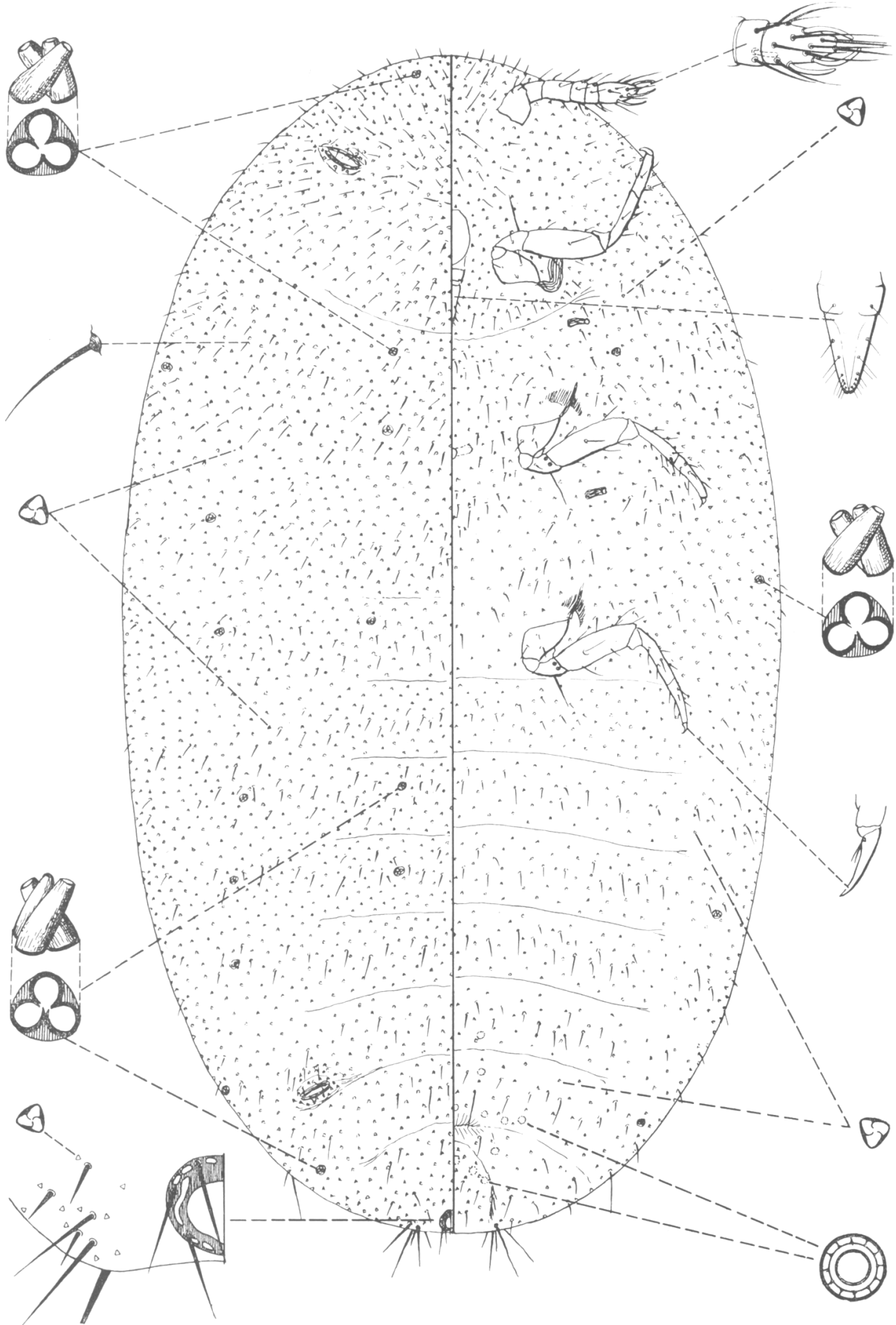

Fig. 22. Rhizoecus eluminatus McKenzie, new species, collected on Gloxinia sp. (Gesneriaceae), at Bayside, Humboldt County, California. 
442, figure 171. It is suspected that Professor Ferris may have mislabeled the drawing, and that it may refer to another species. The type specimens of epiphylli definitely possess tritubular pores, a few exceedingly small, strongly sclerotized, tubular ducts, as well as lack ventral multilocular disk pores, characteristics all typical of cacticans. Rhizoecus epiphylli Ferris is, therefore, placed as a synonym of Rhizoecus cacticans (Hambleton).

\section{Rhizoecus eluminatus McKenzie, new species}

(Figure 22)

Suggested common name. Blind mealybug.

Hosts and distribution. Type and paratypes from Gloxinia sp. (Gesneriaceae), Bayside, Humboldt County, California, collected September 24, 1954, by W. D. Thomas (Calif. State Dept. Agr. \#54I391), and from Achillea ageratifolia (Compositae), Berkeley, University of California greenhouse, Alameda County, California, collected during May, 1959, by A. E. Pritchard, these representing the only known collections of the mealybug.

Type material. Holotype female, mounted on 1 slide, and paratypes have been deposited in the University of California, Department of Entomology and Parasitology Museum collection at Davis; and 1 paratype has been forwarded to the United States National Collection of Coccoidea at Washington, D.C.

Habit. No further information.

Recognition characters. Length of largest available mounted specimen is approximately $1.80 \mathrm{~mm}$. On the dorsum, cerarii entirely lacking, the anal lobes with 4 or 5 slender setae of various lengths, but no sclerotization. Tritubular pores scattered over dorsum, rather few, the total number scarcely exceeding 28. Trilocular pores rather numerous, evenly distributed over dorsum. Dorsal body setae small and slender. Tubular ducts and multilocular disk pores lacking. Anal ring borne close at apex of abdomen, coarsely cellular, its setae but little longer than its greatest diameter. Dorsal ostioles well developed, their rims sclerotized.

Ventrally, multilocular disk pores present in the area of the vulva and along posterior border of seventh segment, observed range from 13 to 17, average 14. Tritubular pores very few, apparently confined to a series along body margins, these as large as those of dorsum. Trilocular pores possibly less numerous than on dorsum, evenly distributed. Tubular ducts lacking. Ventral setae short and slender.

Circulus lacking. Eyes absent. Antennae 6-segmented, quite stout, with their bases rather widely spaced for this group, being separated by more than twice the width of a basal segment. Legs relatively short, claws with very short, apically acute, digitules.

NOTES. This species is most closely related to Rhizoecus pritchardi McKenzie, herein described as new, but differs from it principally in the complete absence of eyes. Dr. Harold Morrison has kindly compared the two species under one ocular, and has made the following remarks about them in a letter to the author dated August 8, 1958: "The most conspicuous point of difference is that the eyes in pritchardi (Colma) may readily be seen, 


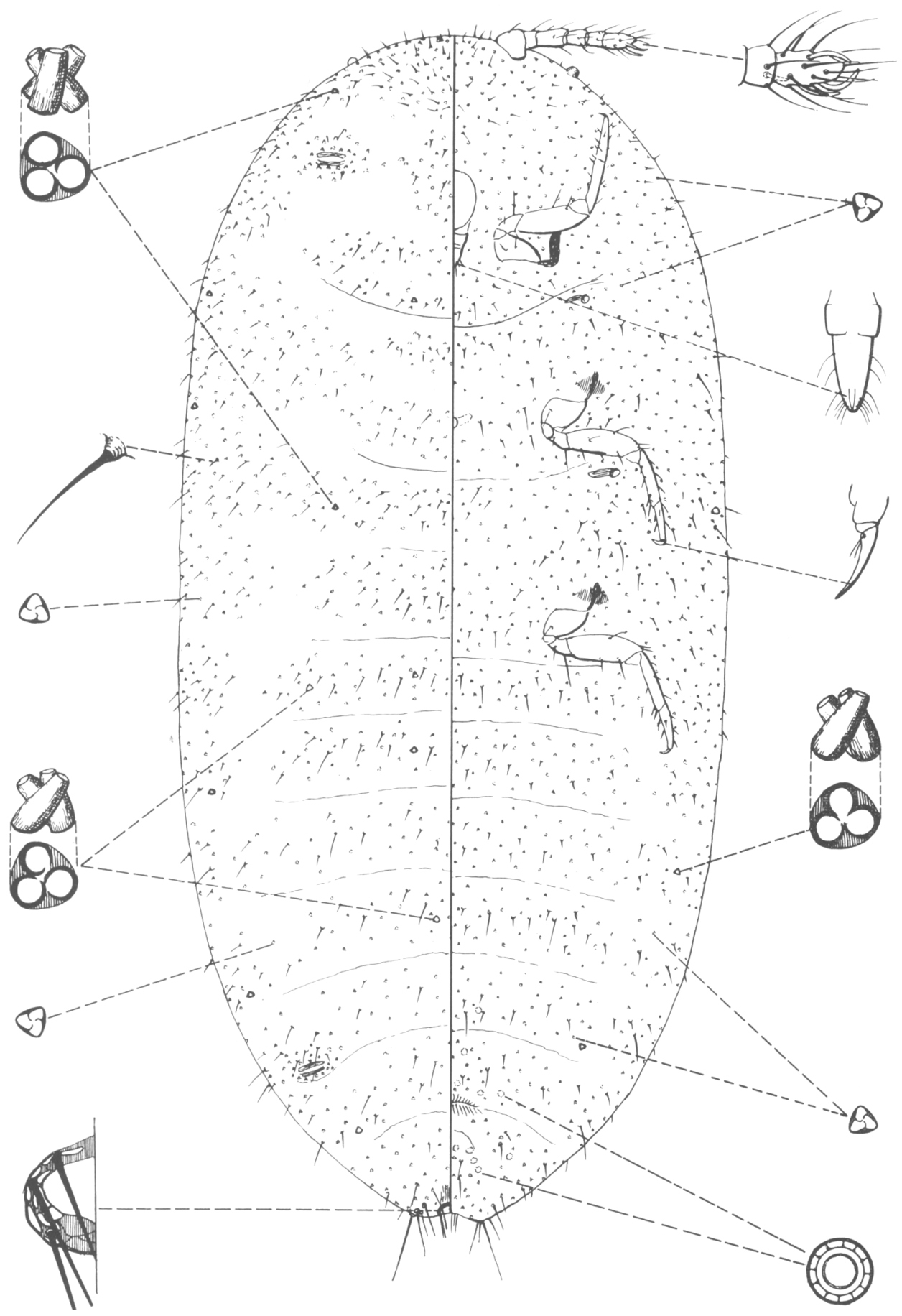

Fig. 23. Rhizoecus pritchardi MeKenzie, new species, originally described from maidenhair fern roots, Adiantum sp. (Polypodiceae), collected at Colma, San Mateo County, California. 
while I have not been able to see these organs in eluminatus (Bayside) specimens. Beyond this, when specimens from these two collections are placed side by side under one ocular the antennae of pritchardi are deflnitely more slender than those of eluminatus, the beak is just a little shorter in the first, with its tip definitely rounded, in contrast to the very slightly longer beak with bluntly angulate tip of the second. The legs seem pretty much alike, except the femora are recognizably not quite so stout in the first, the anal lobes and the anal ring setae appear practically identical, the number of multiloculars in the ventral abdominal region seem to be about the same; the distribution pattern of the tritubular ducts seems much the same, but with enough variability to create uncertainty as to the true average pattern. Unless you can resolve the problem of presence or absence of eyes satisfactorily, it seems to me that you might have to consider these as two distinct things."

Rhizoecus eluminatus is also related to Rhizoecus cyperalis (Hambleton), and $R$. nemoralis (Hambleton), but may be readily differentiated from them by the total absence of eyes; more numerous ventral multilocular disk pores; and lack of very small tubular ducts posterior to vulva. The femora of cyperalis are also definitely stouter.

The illustration for this species was prepared by Professor Ferris. The enlarged drawings of tritubular ducts have been modified by the author as a result of an examination of an extended series of specimens.

\section{Rbizoecus kondonis Kuwana}

(Plate I, bottom row, left)

NOTES. As has been already pointed out in the introductory paragraph entitled "Economic Importance," this species, $R$. kondonis, appears to be one of the more widespread and economically important forms of subterranean mealybugs in California. Plate I, bottom row, right, shows damage caused to alfalfa by this mealybug.

Additional California records for the species include: Concord, Costra Costa County, January 24, 1955, on strawberry (roots), D. J. Bingham, collector. Davis, Yolo County, November 12, 1958, in soil under leaf mold, L. M. Smith collector.

\section{Rhizoecus pritchardi McKenzie, new species}

(Plate I, middle row, right ; figure 23)

Suggested common name. Pritchard mealybug.

Hosts and distribution. Type and paratypes from Adiantum sp. (Polypodiceae), Colma, San Mateo County, California, collected January 17, 1957, by E. L. Labadie and D. J. Bingham (Calif. State Dept. Agr. \#57A287). Additional paratypes are available from the following hosts and localities: on Saintpaulia sp. (Gesneriaceae), Escondido, San Diego County, California, collected February 21, 1956, by A. A. Church (Calif. State Dept. Agr. \#56B139); on Adiantum sp., San Bruno, San Mateo County, California, collected April 29, 1958, by A. E. Pritchard; on Achillea ageratifolia (Compositae), Arctostaphylos sp. (Ericaceae), and Geum borisi (Rosaceae), 
Oakland, Alameda County, California (in Montclair Nursery), collected during 1957 by A. E. Pritchard; on Chrysanthemum sp. (Compositae), San Francisco, San Francisco County, California, collected February 18, 1959, by A. M. Crull; on Polygala capitata (Polygalaceae), Berkeley, University of California greenhouse, Alameda County, California, collected during May, 1959, by A. E. Pritchard; and on Saintpaulia sp. (Gesneriaceae), Santa Barbara, Santa Barbara County, California (in E. Allen Nursery), collected February 18, 1960, by M. Suskin (Calif. State Dept. Agr. 60C1-1.

Type material. Holotype female, mounted on 1 slide, and paratypes of this species have been deposited in the University of California, Department of Entomology and Parasitology Museum collection at Davis; and paratypes have been placed in the following collections: California State Department of Agriculture, Bureau of Entomology collection at Sacramento ; California Academy of Sciences, Golden Gate Park, San Francisco; Stanford University Natural History Museum collection, Stanford University ; and in the United States National Collection of Coccoidea at Washington, D.C.

Habit. Occurring in the soil on and about the roots of the host, secreting a small amount of wax which, when the insects are numerous, gives the soil a somewhat whitish, powdery appearance.

Recognition characters. Length of largest available mounted specimen is approximately $1.85 \mathrm{~mm}$. On the dorsum, cerarii entirely lacking. Anal lobes with 4 or 5 slender setae of various lengths, but without sclerotization. Tritubular pores scattered over dorsum, rather few, the total number scarcely exceeding 22. Trilocular pores fairly abundant, certain specimens showing these rather unevenly distributed, exhibiting "clear areas," particularly on the thorax and anterior abdomen. Dorsal body setae small and slender. Tubular ducts of oral collar type, and multilocular disk pores lacking. Anal ring borne at apex of abdomen, its setae but little longer than its greatest diameter. Dorsal ostioles well-developed, their rims sclerotized.

Ventrally, multilocular disk pores present in the area of the vulva and along posterior border of seventh segment, observed range from 11 to 19 , average 13.9. Tritubular pores very few, apparently confined to a series along body margins, these as large as those of dorsum. Trilocular pores fairly numerous and evenly distributed. Tubular ducts lacking. Ventral setae short and slender.

Circulus lacking. Eyes present. Antennae 6-segmented, quite short and stout, with their bases rather widely spaced for this group, being separated by more than twice the width of a basal segment. Legs relatively short. Claws with short, apically acute, digitules.

NOTES. This species is related to Rhizoecus eluminatus McKenzie, but may be differentiated from it mainly in the possession of eyes. According to Dr. Harold Morrison, who kindly compared the two species under one ocular, the antennae of pritchardi are definitely more slender than those of eluminatus; the beak is shorter in the first, with tip rounded, in contrast to the very slightly longer beak with bluntly angulate tip of the second. species; and the femora is not quite so stout in the first species as compared. to the second. 
Rhizoecus pritchardi McKenzie is also related to Rhizoecus cyperalis (Hambleton), and $R$. nemoralis (Hambleton), but differs from them in two characters: more numerous ventral multilocular disk pores, and lack of small ducts posterior to vulva.

The illustration for this species was prepared by Professor Ferris. The enlarged drawings of trilocular ducts have been modified by the author as a result of an examination of an extended series of specimens.

\section{Rhizoecus sonomae McKenzie, new species}

(Figure 24)

Suggested common name. Sonoma rhizoecus mealybug.

Hosts and distribution. Holotype adult female collected in leaf mold, 2 miles west of Petrified Forest, Sonoma County, California, February 23, 1959, by W. R. Bauer and J. S. Buckett. A single paratype adult female is also at hand taken from the type locality collected on October 25, 1959, by J. S. Buckett. Unfortunately, these two lots represent the only known collections of this mealybug.

Type material. Holotype female of this species has been deposited in the University of California, Department of Entomology and Parasitology Museum collection at Davis, and a single paratype specimen has been included in the California State Department of Agriculture, Bureau of Entomology collection at Sacramento.

Habit. No information other than that the mealybug occurs in the ground where it presumably feeds on the roots of plants.

Recognition characters. Length of mounted adult female is approximately $1.00 \mathrm{~mm}$. On the dorsum the cerarii are entirely lacking. Anal lobes with several slender setae of various lengths, but without sclerotization. Tritubular pores scattered over dorsum, rather numerous, there being as many as 36 observed. Dorsum moderately beset with trilocular pores and small body setae. Oral collar ducts lacking. Multilocular disk pores present in few numbers along posterior border of eighth abdominal segment. Anal ring borne at apex of abdomen, its 6 setae at least twice as long as greatest diameter of ring; its pores large, oval and irregularly shaped, some appearing clear and open, others with possibly varying amounts of pigmentation. Dorsal ostioles well developed.

Ventrally, multilocular disk pores present in some numbers in the region of the vulva and in a transverse row along the posterior border of segment 7, 1 or 2 pores in same position on segment 6 , and from 7 to 12 such pores present, on each side, in prothoracic and mesothoracic areas. Tritubular pores few, apparently confined to a series along body margin, extending from posterior abdomen to head region, these pores as large as those of dorsum. Trilocular pores distributed very much as on the dorsum except on thorax where they are confined to isolated patches, along with setae, showing as rather marked "clear areas." Oral collar ducts lacking. Ventral body setae relatively sparse, short, and slender.

On the ventral side a single, small, round circulus is present, this on the morphologically fourth abdominal segment. Eyes apparently present on two specimens before me. Antennae 6-segmented, quite short and stout, apical 


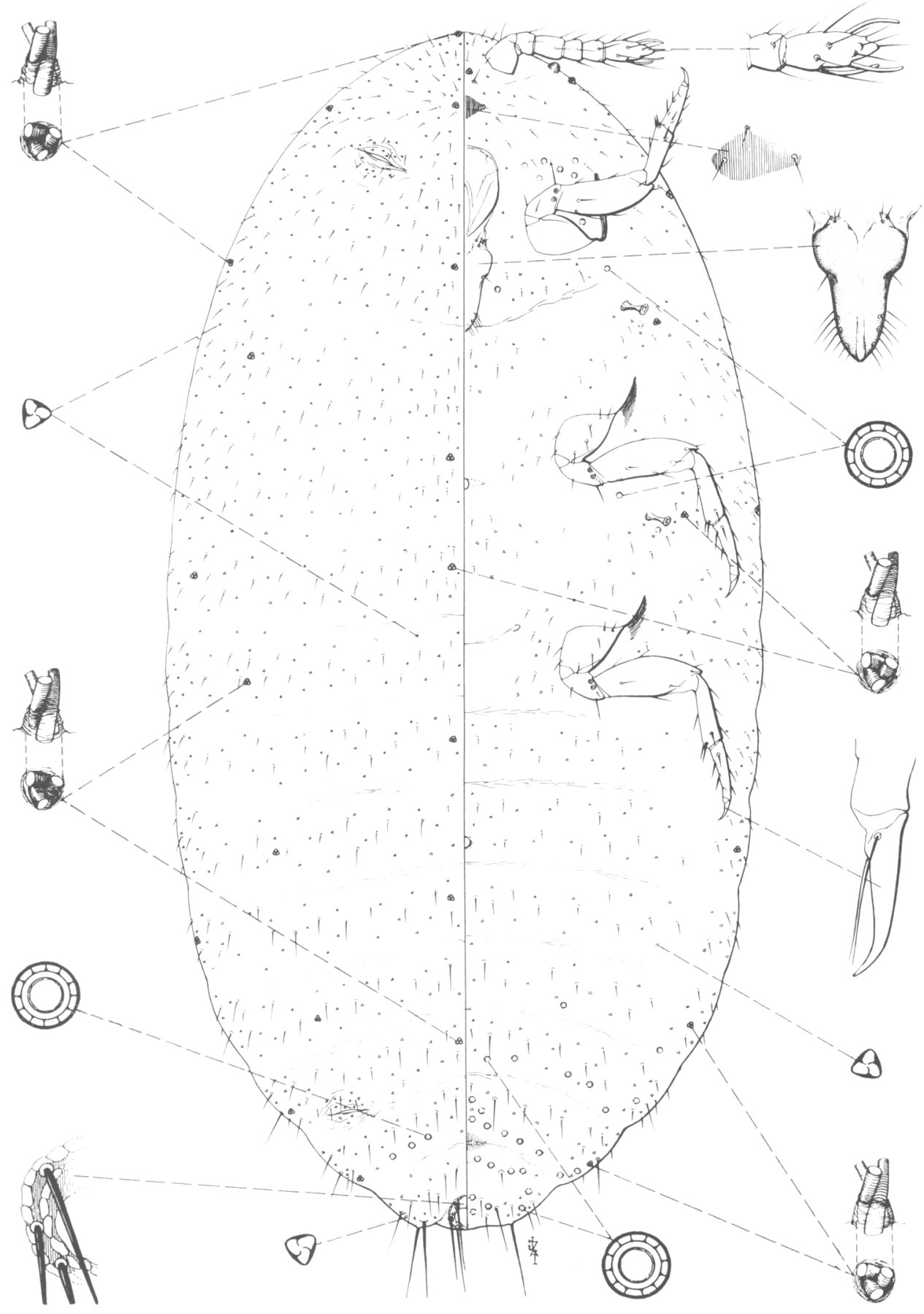

Fig. 24. Rhizoecus sonomae McKenzie, new species, collected in leaf mold, 2 miles west of Petrified Forest, Sonoma County, California. 
segment bearing 3 sensory setae; interantennal space equal to approximate width of basal segment. Legs relatively short, stout; tibia and tarsi armed with stout spines; claw with long, setose digitules extending approximately to claw tip; without denticle or tooth. Beak broad at base, almost parallelsided, tapering toward a blunt tip. Sclerotized patch present anterior to mouthparts.

NOTES. This new species, Rhizoecus sonomae, keys to Rhizoecus leucosomus (Cockerell) using Ferris' (1953) key to North American species of Rhizoecus, but differs from it mainly in the possession of both dorsal and ventral multilocular disk pores on abdomen, these lacking in leucosomus.

The holotype example of this species was made available through the courtesy of R. F. Wilkey of the California State Department of Agriculture, Bureau of Entomology, Sacramento. Mr. Wilkey not only pepared an excellent slide mount of the mealybug, but also made a special effort to get the specimen into the hands of the author.

\section{Rhizoecus spinosus McKenzie, new species}

(Figure 25)

Suggested common name. Spinose mealybug.

Hosts and distribution. Type and paratype collected at Hopland, Mendocino County, California, August 30, 1957; host not indicated but presumably in soil, by T. Eriksen (Calif. State Dept. Agr. \#57H29-16), this lot representing the only known collection of the mealybug.

Type material. Holotype female mounted on 1 slide, and a single paratype of this species will be deposited in the University of California, Department of Entomology and Parasitology Museum collection at Davis.

Habit. No information but presumably collected in the soil.

Recognition characters. Length of largest available mounted specimen is approximately $2.00 \mathrm{~mm}$. On the dorsum, cerarii entirely lacking. The anal lobes with several slender setae of various lengths, these set in a quite distinct, but small, area of sclerotization. Tubular pores of the bitubular type present, normally not more than 5 or 6 on each abdominal segment, except the last, a total of approximately 30 observed. Dorsum beset with numerous body setae, those occurring along margin and median areas quite long, presenting a rather setose appearance which has prompted the specific name. Trilocular pores rather numerous, in lateral view appearing as two different types, one with raised central cone, the other as jagged protruding points, these and the setae arranged in rather widely separated areas particularly in the thoracic region and on abdomen between segments and in lateral patches. Tubular ducts of oral collar type lacking. Multilocular disk pores lacking on dorsum except for 3 or 4 near posterior border of eighth abdominal segment. Anal ring borne at apex of abdomen, its setae but little longer than its greatest diameter, its pores quite small, oval and irregularly shaped, some appearing clear and open, others with varying amounts of pigmentation, inner area without pores, clear. Dorsal ostioles well-developed, their rims sclerotized.

Ventrally, multilocular disk pores present in considerable numbers on last 3 abdominal segments. Bitubular pores apparently confined to abdomen, 


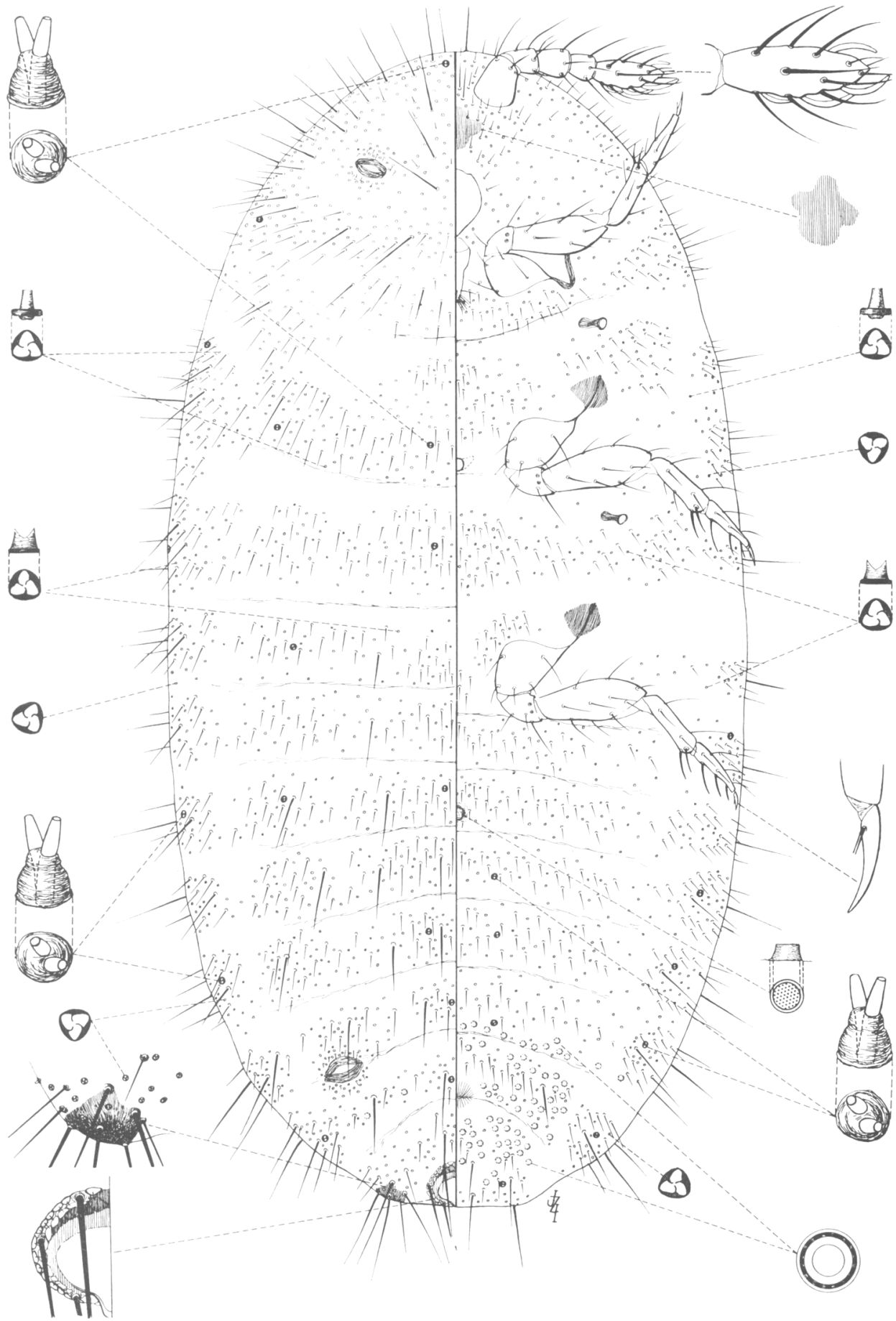

Fig. 25. Rhizoecus spinosus McKenzie, new species, collected on roots of an undetermined host at Hopland, Mendocino County, California. 
these occurring on median area and along body margin. Trilocular pores of the two types previously discussed present on abdomen and thorax, on thorax confined to isolated patches of pores and setae, showing as rather marked "clear areas." Tubular ducts of the oral collar type lacking. Ventral setae short and slender.

Circulus small, round, conical, present on fourth abdominal segment. Eyes lacking. Antennae 5-segmented, quite short and stout, apical segment bearing 4 sensory setae, interantennal space equal to slightly less than width of basal segment. Legs stout. Tibiae and tarsi armed with stout spines. Claws with very short, setose digitules extending to less than half the length of claw.

NOTES. Using Ferris' (1953) key to North American species of Rhizoecus, this species comes perhaps nearest to the Rhizoecus solani Hambleton and $R$. totonicopanus Hambleton couplet than elsewhere. However, it is quite different from the last two mentioned species in possessing a different type of bitubular pore, more numerous ventral multilocular disk pores, and the total absence of tubular ducts of the oral collar type. It is probably most closely related to Rhizoecus bituberculatus McKenzie, herein described as new, but differs mainly in possessing ventral multilocular disk pores on thorax.

\section{Genus Spilococcus Ferris}

Three new California species of Spilococcus are described in this publication. Four species previously placed by Ferris (1950-53) in Spilococcus, have been referred to Chorizococcus McKenzie (see reasons for this transfer on pages 692 and 693). These species are Spilococcus aphyllonis (Cockerell), $S$. irishii (Cockerell), S. neomexicanus (Tinsley), and S. reducta Ferris. The addition of new California species of Spilococcus, and transfer of others to Chorizoccus, have made necessary a modification of Ferris' key to North American species of this group. The revised key is here presented.

\section{Key to Spilococcus Species of North America}

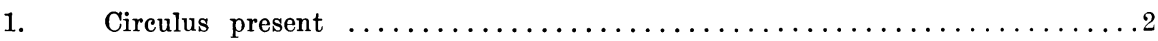

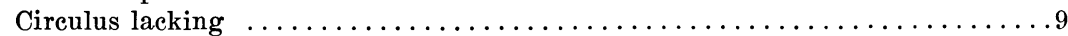

2 (1). Dorsum with oral rim ducts present in numbers, at least over the abdomen and at

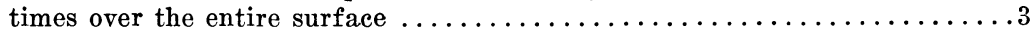

Dorsum with no oral rim ducts or with these confined to a single submarginal

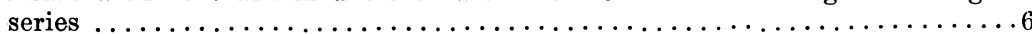

3 (2). With a complete series of 16 to 17 pairs of dorsal cerarii ...............

Dorsal cerarii present in a series of not more than 12 to 15 recognizable pairs. . 5

4 (3). Frontal cerarius definitely developed, with 2 to 3 conical setae set close together larreae Ferris

Frontal cerarii indefinite, represented by a scattered group of 3 or more widely separated conical setae ................steeli (Cockerell and Townsend)

5 (3). Circulus large, normally appearing broadly oval, divided by segmental line between which it lies; small denticle or tooth present on plantar surface of claw cactearum McKenzie

Circulus small, transversely oval, situated on fourth abdominal segment, not divided by segmental line; denticle or tooth lacking on plantar surface of claw parvicirculus MeKenzie

6 (2). Dorsal oral rim ducts entirely lacking $\ldots \ldots \ldots \ldots \ldots \ldots \ldots \ldots \ldots \ldots \ldots \ldots$ Dorsal oral rim ducts present in a submarginal series, at least on the abdomen. 8 


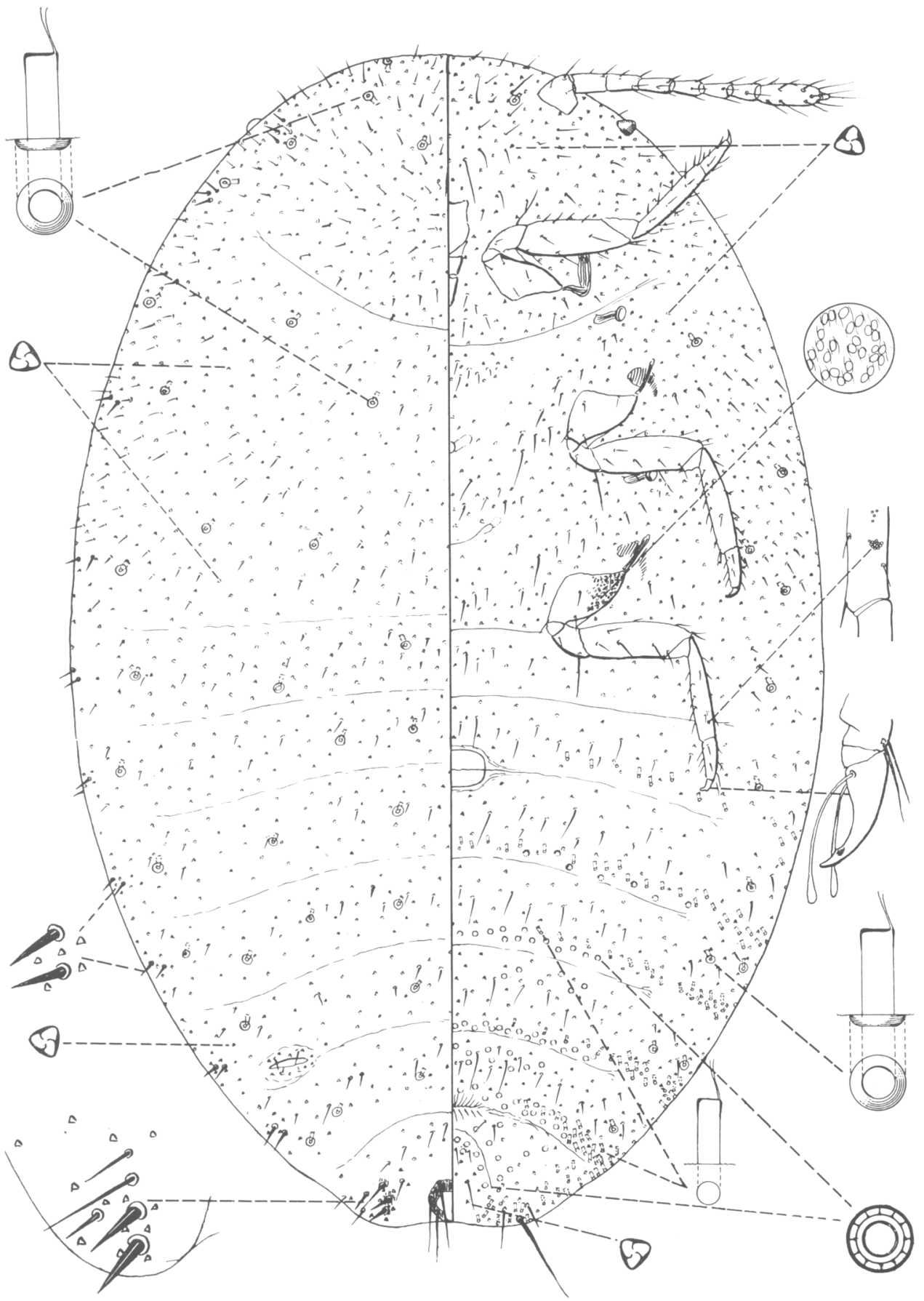

Fig. 26. Spilococcus cactearum McKenzie, new species, a cactus-infesting mealybug quite common in California. 
7 (6). Lateral areas of the body, ventrally, from the eighth abdominal segment to the mesothorax, with clusters of small tubular ducts of oral collar type; occurring as far as known only on Fouquieria in southwestern United States

townsendi (Cockerell)

Lateral areas of the body, ventrally, at the most with merely a few scattered, tubular ducts of oral collar type, occurring as far as known only on juniper juniperi (Ehrhorn)

8 (6). With about 15 pairs of definite cerarii; normally occurring on Cupressaceae and

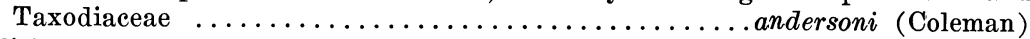

With scarcely more than 6 definite cerarii, these confined to the abdominal segments; occurring normally on Prosopis ...........prosopidis (Cockerell)

9 (1). Lateral areas of the body, ventrally, with clusters of multilocular disk pores sequoiae (Coleman)

Lateral areas of the body, ventrally, without clusters of multilocular disk

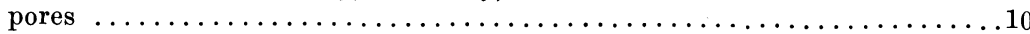

10 (9). Dorsum without oral rim ducts, except for an occasional duct in the head region implicatus Ferris

Dorsum with numerous oral rim ducts $\ldots \ldots \ldots \ldots \ldots \ldots \ldots \ldots \ldots \ldots \ldots \ldots$

11(10). Oral rim ducts of the thoracic and head areas distinctly larger than those of

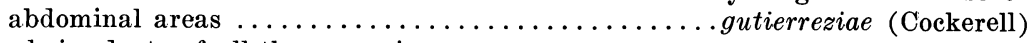

Oral rim ducts of all the same size $\ldots \ldots \ldots \ldots \ldots \ldots \ldots \ldots \ldots \ldots \ldots \ldots \ldots$

12 (11). With at least 15 pairs of recognizable dorsal cerarii present atriplicis (Cockerell)

With 13 or less pairs of dorsal cerarii present .................13

13(12). Oral rim ducts present on ventral side of the head and in the sternal regions

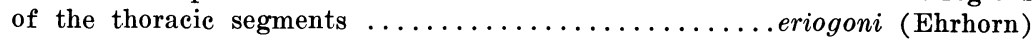

Oral rim ducts lacking in these areas $\ldots \ldots \ldots \ldots \ldots \ldots \ldots \ldots \ldots \ldots \ldots$

14(13). Multilocular disk pores on venter very numerous, there being as many as 50 to 70 on some of the abdominal segments ................

Multilocular disk pores on venter very few, there being scarcely more than 30 on any one abdominal segment .................. pressus Ferris

\section{Spilococcus cactearum McKenzie, new species}

(Plate I, top row, left and right; figure 26)

Suggested common name. Cactus mealybug.

Hosts and distribution. Type and paratypes from Homalocephala texensis (Cactaceae), Berkeley, University of California Botanical Gardens, Alameda County, California, October 4, 1948, R. E. Beer, collector. Additional paratypes are available from the following hosts (Cactaceae) and localities in California: on cactus, Los Angeles, Los Angeles County, June 26, 1941, H. A. Robinson, collector; on cactus, Glendale, Los Angeles County, July 20, 1942, L. E. Myers, collector; on cactus, Pasadena, Los Angeles County, August 14, 1941, V. E. Daniels, collector; on cactus, La Cañada, Los Angeles County, March 7, 1957, Hodge, collector; on cactus, Los Angeles, Los Angeles County, April 9, 1945, R. H. Smith, collector; on Homalocephala texensis, Berkeley, University of California Botanical Gardens, Alameda County, October 11, 1948, R. E. Beer, collector ; on Mammillaria macdougalii, Berkeley, Alameda County, January 24, 1949, W. S. Sibray, collector (Calif. State Dept. Agr. \#49A219); on Myrtillocactus geometrizans, Richmond, Contra Costa County, October 23, 1941, M. R. Bell, collector; on Myrtillocactus sp., in Hayward, Alameda County, on January 31, 1949, W. S. Sibray, collector (Calif. State Dept. Agr. \#49B46); on Echinopsus sp., Hayward, Alameda County, January 28, 1949, W. S. Sibray, collector (Calif. State Dept. Agr. \#49B62); on Mammillaria sp., Petaluma, Sonoma County, De- 
cember 4, 1941, M. R. Bell, collector, (Calif. State Dept. Agr. \#41L62); on Mammillaria sp., San Francisco, San Francisco County, February 3, 1949, A. L. Seeley and S. M. Mather, collectors (Calif. State Dept. Agr. \#49B78) ; on cactus, Paramount, Los Angeles County, November 13, 1950, French, collector; on cactus, Berkeley, University of California Botanical Gardens, Alameda County, March 25, 1958, W. S. Sibray, collector (Calif. State Dept. Agr. \#58C31-38); on Hamatocactus setispinus and Wilcoxia sp., Berkeley, University of California Botanical Gardens, Alameda County, November 4, 1958, A. E. Pritchard and H. L. McKenzie, collectors ; and on Echinomastus johnsonii, Berkeley, University of California Botanical Gardens, Alameda County, January 20, 1959, H. L. McKenzie, collector.

Specimens of this species are also at hand intercepted in quarantine on cactus at El Cajon, San Diego County, California, from Albuquerque, New Mexico, May 26, 1958, G. L. Hill, collector.

Type material. Holotype female ( 1 specimen mounted on 1 slide), and paratypes of this species have been deposited in the University of California, Department of Entomology and Parasitology Museum collection, Davis; paratypes have been placed in the California State Department of Agriculture, Bureau of Entomology collection at Sacramento; paratypes have been deposited in the Stanford University Natural History Museum collection, Stanford University ; and paratypes have been sent to the United States National Collection of Coccoidea, Washington, D.C.

Habit. Occurring exposed on the green, fleshy vegetation and spines of cactus. At full maturity the female is covered with a short, even, light-gray secretion. A definite ovisac is produced by this mealybug at maturity. When specimens are boiled in lacto-phenol or potassium hydroxide during the mounting procedure, they turn dark and much of the body contents form into large blue-black, round globules which are usually quite difficult to remove without damage to the integument.

Recognition characters. Length of largest available specimen is approximately $3.25 \mathrm{~mm}$. Body form broadly oval when mounted. On the dorsum the cerarii appear to be rather poorly developed, there being normally 7 pairs on the abdomen, and from 2 to 7 pairs on thorax and head, these difficult to discern because cerarian spines or setae are usually much more slender and are generally situated farther apart, the total recognizable cerarii, for certain specimens, running as high as possibly 14 or 15 pairs. Anal lobe cerarius with 2 rather small and slender conical setae, usually 3 or 4 slender auxiliary setae and a very few scattered trilocular pores; remaining cerarii along abdominal margin with but 2 setae, these normally more slender and, at times, more widely separated than anal pair, no auxiliary except possibly in a few of those situated on head and thorax, and with scarcely any concentration of trilocular pores. Dorsal body setae all small and slender. Dorsum with a few oral rim ducts, these arranged in a single row of from 6 to 8 across each abdominal segment, except the last, and with only a few scattered ones on thoracic segments and head. Trilocular pores evenly distributed over entire dorsum. Anal ring of normal form and size for the genus, its 6 setae about twice as long as the greatest diameter of the ring. 
On the ventral side, multilocular disk pores are present in considerable numbers, predominantly in the mid-region of abdomen, from apical to fourth segment. Small tubular ducts of the oral collar type occur in this same region and in considerable numbers in lateral areas of the eighth to fourth abdominal segments. Oral rim ducts of the same size as those on dorsum occur in small numbers submarginally on abdomen, thorax and head. Ventral body setae are slender and generally longer than those on dorsum. Trilocular pores generally distributed over venter.

Circulus quite large at times, but very faintly defined in fully developed adults, normally appearing broadly oval, capable of folding along intersegmental line of the segments between which it lies. Antennae slender, normally 8-segmented, the eighth segment usually slightly constricted near tip to form a small projection. Legs relatively small. Hind coxae with a cluster of pores at base, apical half of hind tibiae with small irregular clusters of clear dots or pores, and plantar surface of claws with a very small denticle or tooth.

NOTES. The identity of this mealybug has been of some concern for several years. In 1948 the author sent specimens to Dr. Harold Morrison at Washington, D.C., for identification. At that time it was indicated the species had not been placed as a described species.

In 1844, Bouché described a Coccus mammillaria on Mammillaria and cactus from France and Central America. It was suspected that this species might prove to represent our California cactus-infesting form. Through the kindness of Dr. A. Balachowsky, Director of the Pasteur Institute, Paris, France, mounted specimens of what had been identified as this species were forwarded to the author for study. Subsequently, these examples, together with slide preparations of the cactus-infesting form from various California localities, were sent to Dr. Morrison for examination. The following remarks have been excerpted from his correspondence to the author dated August 26, 1958: "I have previously indicated that the Balachowsky concept of mamillariae derives from an identification I made for him years ago, and that it was based on comparison of his specimens with preparations from the Cockerell collection that were so identified. Green 1930:9, possibly made the same assignment although he reports only the 3 apical pairs of cerarii. At any rate, Lindinger 1934:162, pretty well upset the idea that this dark form with rim-tubulars could be Bouché's mamillariae, although he failed to assign the Bouché name to any modern species concept. Bouché's description of the adult female contains very little usable information beyond the report of a dirty yellow body color and absence of secretionary appendages ; the color indicated hardly seems applicable to this form of yours. It seems probable that the form which you have called cactecrum is not mamillariae of Bouché, in spite of various identifications as this through the years and that it needs a new name."

This species will not key beyond couplet 3 (2) in Ferris' (1953) Atlas, Volume VI, page 463. It resembles to some degree both Spilococcus larreae Ferris and S. steeli (Cockerell and Townsend), but differs in having fewer dorsal oral rim ducts, from 6 to 8 across each abdominal segment (except the ninth), as compared to from 26 to 60 or more such ducts in the other 


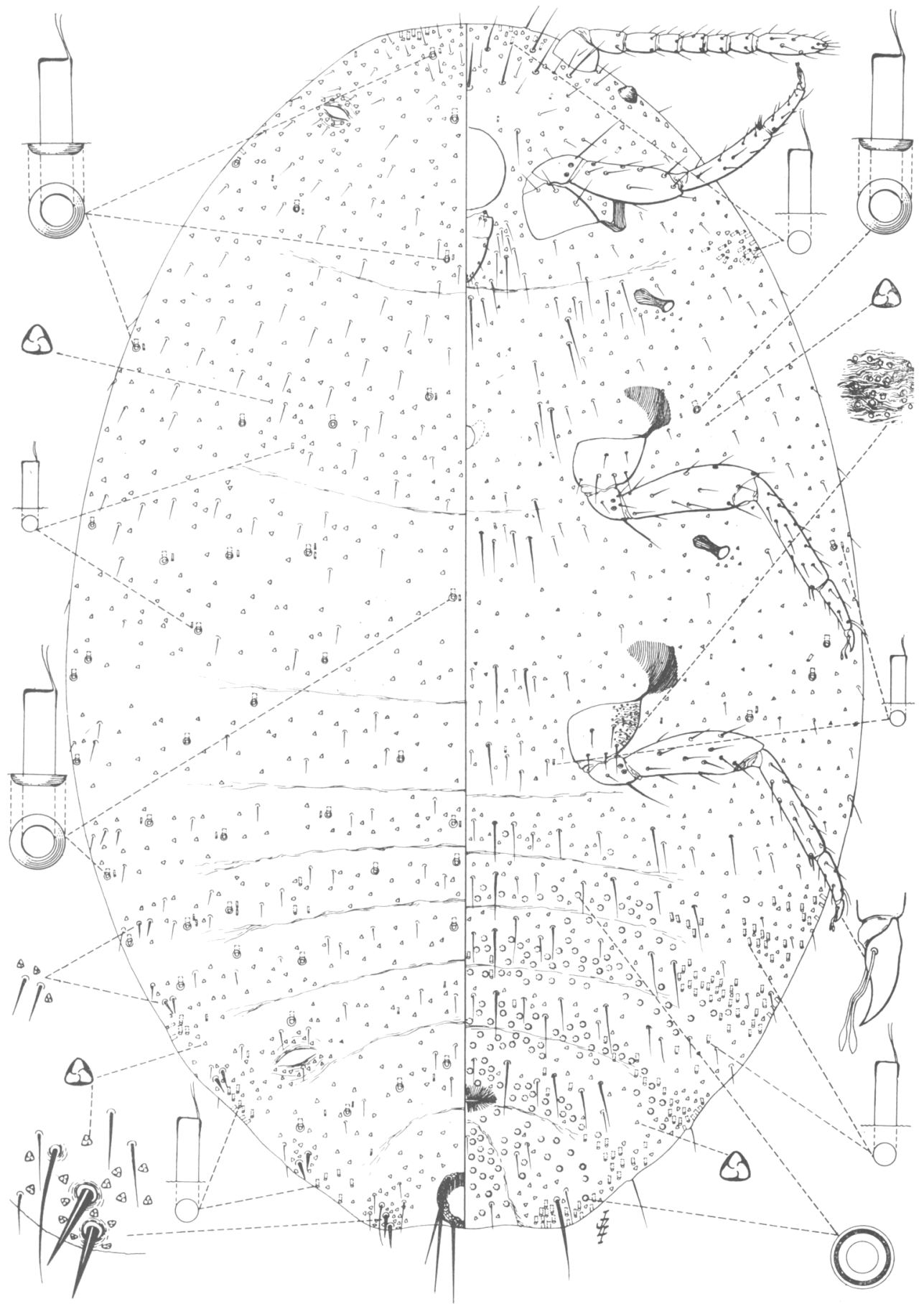

Fig. 27. Spilococcus keiferi McKenzie, new species, collected on Artemisia vulgaris var. heterophylla (Compositae), in South Sacramento, Sacramento County, California. 
two species. Spilococcus cactearum is apparently restricted to members of the Cactaceae, whereas both $S$. larreae and steeli have been recorded only from Larrea divaricata (Zygophyllaceae).

The illustration for this species was made by Professor Ferris from specimens collected on cactus at Hayward and Berkeley. The drawing has been slightly modified by the author to meet certain necessary corrections resulting from an examination of a long series of mounted examples.

\section{Spilococcus eriogoni (Ehrhorn)}

Ferris (1953) in his Atlas, Volume VI, synonymized Spilococcus eriogoni (Ehrhorn) with Spilococcus atriplicis (Cockerell). On the basis of an examination of a considerable amount of material from various hosts and localities in California, believed to represent this form, it is the author's opinion that the two species are definitely distinct. This statement is based on the fact that eriogoni normally has a reduced number of cerarii, there being only 7 to 8 pairs counting forward from the anal lobes, and at times a recognizable ocular or frontal pair present, whereas in atriplicis there are at least 15 recognizable pairs of cerarii present. In addition, eriogoni normally possesses almost twice as many dorsal oral rim tubulars, particularly on the fifth and sixth abdominal segments, as compared to atriplicis. In view of this development, the author believes Ferris' opinion as expressed in his 1953 key to species, where he actually separated atriplicis and eriogoni, is sounder than his statement under the discussion of atriplicis that the two are identical.

\section{Spilococcus keiferi McKenzie, new species}

(Figure 27)

Suggested common name. Keifer mealybug.

Hosts and distribution. Type and paratype examples from Artemisia vulgaris var. heterophylla (Compositae), South Sacramento, Sacramento County, October 25, 1945, H. H. Keifer, collector (Calif. State Dept. Agr. \#45J162), this representing the only known collection of the mealybug in the state.

Type material. Holotype female ( 1 specimen on 1 slide), will be deposited in the University of California, Department of Entomology and Parasitology Museum collection at Davis; and a paratype has been placed in the California State Department of Agriculture, Bureau of Entomology collection at Sacramento.

Habit. No available information.

Recognition characters. The length of the largest specimen is approximately $2.80 \mathrm{~mm}$. On the dorsum the number of cerarii are reduced, there being normally 6 to 7 recognizable pairs on abdomen counting forward from the anal lobes. Anal lobe cerarius with 2 rather small and slender conical setae, usually 3 to 5 slender auxiliary setae and a few scattered trilocular pores. Remaining cerarii along abdominal margin with but 2 slender setae, these progressively smaller, more slender, and usually with 1 or 2 of the pairs more widely separated than in anal lobe pair, no auxiliary setae and with scarcely any concentration of trilocular pores. No cerarii present on thorax. 


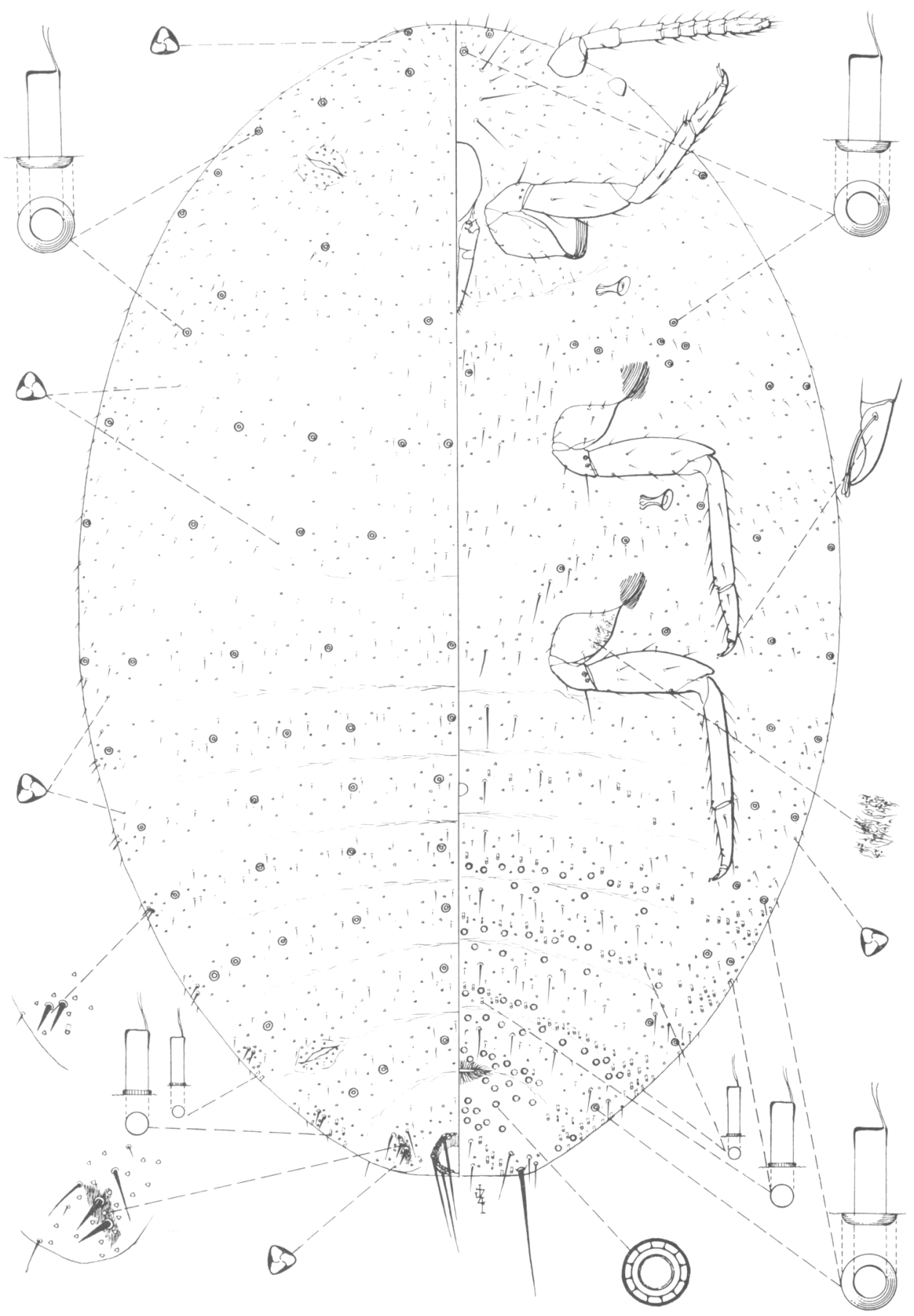

Fig. 28. Spilococcus parvicirculus McKenzie, new species, collected on Franseria acanthicarpa (Compositae), Ontario, San Bernardino County, California. 
Dorsal body setae all small and slender. Dorsum with oral rim tubular ducts quite numerous, as many as from 8 to 10 per segment, except the last, and scattered over the thoracic segments and the head. Oral collar ducts of two sizes present, the larger ones occurring predominantly along body margins, the smaller ones rather generally distributed on abdomen, thorax and head. Trilocular pores situated over entire dorsum. Anal ring of normal form and size for the genus, with its 6 setae about twice as long as greatest diameter of ring.

On the ventral surface, multilocular disk pores are present in considerable numbers, predominantly in the mid-region of abdomen from apical to fourth segments. Two sizes of tubular ducts of the oral collar type are present, the larger ones more numerous, represented in groups in lateral areas of the ninth to fourth abdominal segments, and on thorax approximately opposite anterior spiracle, a few smaller ones also present on thorax. A limited number of oral rim ducts present submarginally on thorax only. Ventral body setae slender and generally longer than those on dorsum. Trilocular pores rather numerous and generally distributed over venter.

Circulus lacking. Antennae slender, normally 8-segmented. Legs moderately slender in relation to their length, femora quite stout. Hind coxae with cluster of pores at base. Denticle or tooth on claws lacking.

NOTES. This species is perhaps most closely related to Spilococcus pressus Ferris, and will run to that species in the key presented in Ferris' Atlas, Volumes $\mathrm{V}$ and VI. It differs from pressus mainly in the possession of more numerous ventral multilocular disk pores on abdomen; greater number of the larger-sized ventral oral collar ducts on ninth abdominal segment and submarginally on thorax opposite anterior spiracles; fewer dorsal cerarii; and a greater number of dorsal oral rim ducts.

\section{Spilococcus parvicirculus McKenzie, new species}

(Figure 28)

Suggested common name. Franseria mealybug.

Hosts and distribution. Holotype female on Franseria acanthicarpa (Compositae), Ontario, San Bernardino County, California, June 22, 1959, G. M. Harper, collector. This single example represents the only collection of this mealybug known to date.

Type material. Holotype female has been deposited in the University of California, Department of Entomology and Parasitology Museum collection at Davis.

Habit. No information available.

Recognition characters. Length of single specimen is approximately 2.50 $\mathrm{mm}$, body form broadly oval when mounted. On the dorsum the cerarii appear to be rather poorly developed, there being 7 to 8 recognizable pairs on abdomen, lacking on thorax and head; anal lobe cerarius with 2 rather slender conical spines, 2 or 3 slender auxiliary setae, and a few scattered trilocular pores; remaining cerarii along abdominal margin with 2 slender cerarian spines, these progressively smaller, no auxiliary setae and with scarcely any concentration of trilocular pores; no cerarii present on thorax. 
Dorsal body setae all small and slender. Dorsum with oral rim tubular ducts quite numerous, as many as from 6 to 10 per segment, except the last, and scattered over the thoracic segments and the head. A very few oral collar ducts of two sizes present, occurring predominantly along margin of last two or three abdominal segments. Trilocular pores situated over entire dorsum. Anal ring of normal form and size for the genus, its 6 setae about twice as long as greatest diameter of ring.

On the ventral surface, multilocular disk pores are present in considerable numbers predominantly in mid-region of abdomen from apical to posterior margin of fifth abdominal segment. Oral collar ducts of two sizes are present on abdomen from apical to fourth segments, the larger ones more numerous. Oral rim tubular ducts of the same size as those of the dorsum occur in small numbers in the lateral areas of most all segments from the eighth abdominal segment forward to the head, in the sternal areas, and about the spiracles of the thorax. Ventral body setae slender and generally longer than those on dorsum. Trilocular pores rather numerous and generally distributed over venter.

Circulus present, small and transversely oval (from whence the specific name was derived). Antennae slender, 8-segmented, second and third segments from base longest. Legs moderately slender in relation to their length. Hind coxae with cluster of translucent dots or pores at base. Denticle or tooth lacking on claws.

NOTES. This species appears quite closely related to Spilococcus cactearum McKenzie, herein described as new, but differs chiefly in the noticeably smaller, transversely oval circulus, and the apparent absence of marginal cerarii on head and thorax.

\section{Genus Trionymus Berg}

One new species of Trionymus is described in this study. In addition, 6 species previously placed by Ferris (1953) in Trionymus have been referred to other genera as follows: Trionymus peregrinus Green (= Trionymus lounsburyi Brain), as a misidentification, Trionymus rostellum Hoke (= Trionymus vallis Ferris), and Trionymus shaferi (Hollinger), have been placed in Chorizococcus McKenzie; Trionymus junceus (McConnell) and Trionymus merrilli Ferris, have been transferred to Dysmicoccus Ferris ; and Trionymus hypolithus Shotwell has been transferred to Cryptoripersia Cockerell. Those species transferred to Chorizococcus were done so primarily on the basis of possessing oral rim tubular ducts, these structures lacking on Trionymus, as here understood; those transferred to Dysmicoccus were done so on the basis of having 6 or more dorsal cerarii, including the frontal ones, whereas Trionymus, as here interpreted, has but 5 or fewer pairs of cerarii, including frontal ones; and Trionymus hypolithus was referred to Cryptoripersia because of absence of recognizable cerarii, these present in typical Trionymus.

Dysmicoccus modocensis Ferris has been transferred into Trionymus (see discussion under Trionymus modocensis (Ferris)).

The addition of the new species, together with changes in generic status of above-mentioned pseudococcid forms, has necessitated a modification of Ferris' (1953) key to Trionymus. The revised key is here presented. 


\section{Key to Trionymus Species of North America}

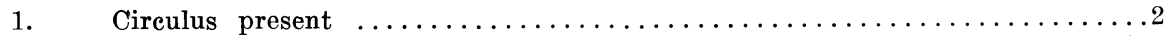

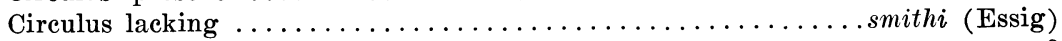

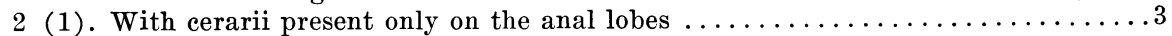

With more than one pair of cerarii present . . . . . . . . . . . . . . . . 6

3 (2). Multilocular disk pores of dorsum confined to last 3 abdominal segments

Multilocular disk pores scattered over entire dorsum ..................4

4 (3). Multilocular disk pores of abdominal venter unusually numerous, those of segments 5 to 7 , medially, arranged in broad bands which are as many as 4

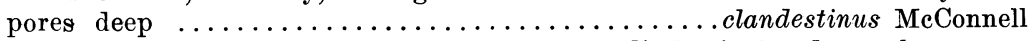

Multilocular disk pores of abdominal venter, medially, in bands nowhere more

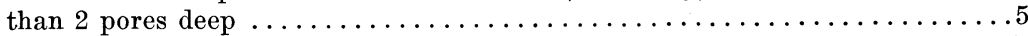

5 (4). Body form of adult female narrowly oval .................caricis MeConnell Body form of adult female broadly pyriform..magnus (Cockerell and Cockerell)

6 (2). Cerarii definitely recognizable only on last 2 abdominal segments...........7 Cerarii definitely recognizable on more than last 2 abdominal segments.....13

7 (6). Anal lobe cerarius with a distinct surrounding sclerotized area............ 8 Anal lobe cerarius definitely without a surrounding sclerotized area........11

8 (7). Multilocular disk pores present over entire dorsum..claviger (King and Tinsley) Multilocular disk pores, if present on dorsum at all, confined to abdominal seg-

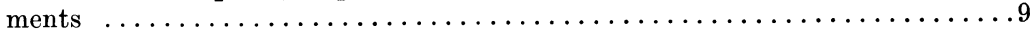

9 (8). Circulus quite small, normally quadrate-shaped, often divided by segmental lino of segments between which it lies; ventral multilocular disk pores lacking on

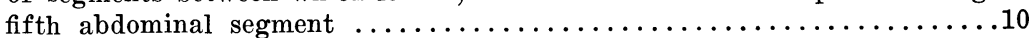

Circulus small, circular or oval, not divided by segmental line of segments between which it lies; ventral multilocular disk pores normally present on fifth abdominal segment ...........................mericanus (Cockerell)

10 (9). Dorsal multilocular disk pores present on last three or four abdominal segments haancheni McKenzie

Dorsal multilocular disk pores lacking on abdomen .........modocensis Ferris

11 (7). Multilocular disk pores in the lateral areas of both thorax and abdomen very

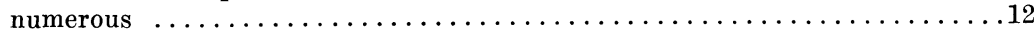

Multilocular disk pores very few or lacking in the lateral areas of both abdomen and thorax $\ldots \ldots \ldots \ldots \ldots \ldots \ldots \ldots \ldots \ldots \ldots \ldots \ldots$ violascens Cockerell

12 (11). Paired setae of anal lobe cerarius short and stout, more or less acorn-shaped; known only from Phormium ...................diminutus (Leonardi)

Paired setae of anal lobe cerarius slenderly conical.........festucae (Kuwana)

13 (6). Anal lobe cerarius surrounded by a distinet, sclerotized area....... dolus Ferris

Anal lobe cerarius without a surrounding, sclerotized area....... mocus Ferris

\section{Trionymus haancheni McKenzie, new species}

(Figure 29)

Synonymy. Dysmicoccus modocensis Ferris, Trionymus modocensis (Ferris), at least in part as a misidentification (see notes).

Suggested common name. Haanchen barley mealybug.

Hosts and distribution. Type and paratypes (adult females) collected on Haanchen barley, Hordeum vulgare (Gramineae), Tulelake, Siskiyou County, California, September 4, 1951, by H. T. Osborn and W. E. Huse (\#51129). Additional paratypes were found in the same area and habit as above, collected August 15, 1951, by W. E. Huse (\#51H107), and on barley 


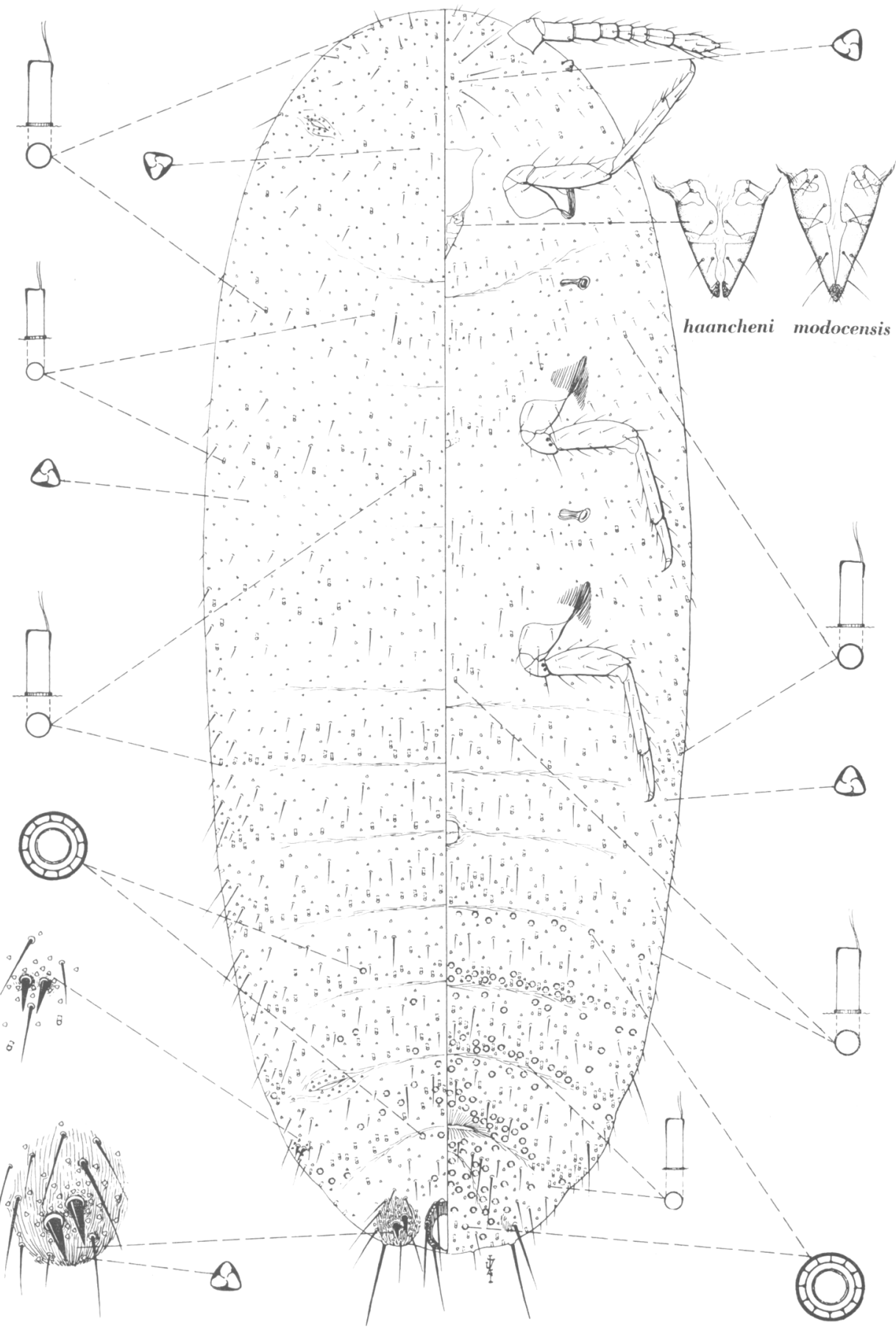

Fig. 29. Trionymus haancheni McKenzie, new species, collected on Haanchen barley, Hordeum vulgare (Gramineae), Tulelake, Siskiyou County, California. 
(culms), Tulelake, June 15, 1954, collected by Joe Schuh (U.S.D.A. \#54-888). ${ }^{7}$

Type material. Holotype female mounted on 1 slide, and paratypes of this species have been deposited in the University of California, Department of Entomology collection at Sacramento; and in the United States National been placed in the California State Department of Agriculture, Bureau of Entomology collection at Sacramento; and in the United States National Collection of Coccoidea at Washington, D.C.

Habit. According to H. T. Osborn (1951) this species is found along the stems under the leaf sheaths of its host. Cottony egg clusters, and accumulations of thick, sticky honeydew secretions are produced by the mealybug.

Recognition characters. Length of largest available mounted specimen is approximately $4.50 \mathrm{~mm}$. Body shape elongate and rather slender. On the dorsum the number of cerarii are reduced, there being only the anal lobe and penultimate pairs present; anal lobe cerarii with 2 moderately stout, conical setae, these accompanied by scattered trilocular pores and slender setae of various lengths, all contained within an oval area that is normally quite well sclerotized. Penultimate cerarii with 2 slightly smaller, conical setae, 3 to 4 slender setae, and a small cluster of trilocular pores; no indication of cerarii appears anterior to these, even on the head. Dorsal body setae narrow and slender. Oral collar ducts of two sizes present on abdomen, thorax and head. Trilocular pores situated over entire dorsum. Multilocular disk pores appear scattered on posterior 3 or 4 abdominal segments. Anal ring of normal form and size for the genus, with its 6 setae about twice as long as greatest diameter of ring.

On the ventral surface, multilocular disk pores present in considerable numbers predominantly in the mid-region of the abdomen, a few reaching lateral margin, from segment 10 to segment 6 . Oral collar ducts of two sizes present, the larger ones more numerous, scattered over entire venter although perhaps more numerous on abdomen. Trilocular pores rather numerous and generally distributed over venter.

Circulus present, rather small, normally quadrate-shaped, and, in some specimens, very definitely crossing the intersegmental line between segments 4 and 5 and divided by this line. Antennae 8-segmented. Legs moderately slender in relation to their length. Denticle or tooth lacking on claws.

NOTES. This species was included on the type slides of the species here recognized as Dysmicoccus modocensis Ferris (= Trionymus modocensis (Ferris)), and has been entangled with it ever since. It is, however, very evidently distinct from modocensis in possessing but 2 pairs of cerarii ; presence of dorsal multilocular disk pores on last 3 or 4 abdominal segments; and a comparatively short, stout, and blunt-type beak. In contrast, specimens of modocensis show a strong tendency toward the development of an antepenultimate pair of cerarii, this usually present, but may not be developed, lack of dorsal multiloculars, and a definitely longer and quite acute beak (see drawing on mouthparts on figure 29).

\footnotetext{
${ }^{7}$ Since this manuscript was submitted for publication, specimens have become available that for the present may be placed with this species collected under leaf sheaths of Elymus sp. (Gramineae), at Ojai, Ventura County, California, July 22, 1959, by H. L. Wilson. (Calif. State Dept. Agr. \#59J13-6). Additional study material is needed, however, to positively ascertain the true identity of this mealybug.
} 
Trionymus haancheni McKenzie is probably most closely related to Trionymus americanus (Cockerell), differing from it mainly in having a comparatively larger, normally quadrate-shaped circulus, this often divided by segmental line of the segments between which it lies, and in the apparent absence of ventral multilocular disk pores on fifth abdominal segment. The circulus of americanus, on the other hand, is quite small, circular or oval, not folding along intersegmental line of the segments between which it lies, and the ventral multilocular disk pores are normally present on fifth abdominal segment.

H. T. Osborn (1951) reports the species as of some economic concern as follows: "On August 15th, the Siskiyou County Agricultural Commissioner's office at Tulelake submitted specimens of a mealybug reported to be so abundant in Haanchen barley in some fields that combines were being gummed up and clogged at harvest. When visited early in September harvesting had been completed in the infested fields but large numbers of dead and dried up mealybugs were present on the stubble. Large numbers of cottony egg clusters contained unhatched eggs. Broken straws on the ground and some standing uncut at the edge of the field showed evidence of feeding by mealybugs along the stems under the leaf sheaths. Accumulations of thick sticky honeydew secretions were still present. Approximately 15,000 acres of Haanchen barley are planted in this district located south and west of Tulelake. Gumming of combines at harvest was said to have involved approximately 350 acres."

\section{SUMMARY}

The objective of this taxonomic study has been to describe and delineate new California species of mealybugs, and to comment briefly, when necessary, on the synonymy of other named forms. A complete revision has been made of the key to genera of North American Pseudococcidae. Keys to North American species have been prepared to include new California mealybugs.

Two new California pseudococcid genera, Chorizococcus and Pygmaeococcus, have been described in this study.

Twenty-eight new California species of mealybugs have been described as follows: Chorizococcus abroniae, $C$. brevicruris, $C$. microporus, $C$. psoraleae, C. wilkeyi, Heliococcus adenostomae, Humococcus caritus, H. inornatus, Phenacoccus echeveriae, $P$. graminosus, $P$. lotearum, $P$. tibiaegracilis, Pseudococcus importatus, $P$. microcirculus, Puto acirculus, $P$. nulliporus, $P$. pricei, $P$. profusus, Pygmaeococcus morrisoni, Rhizoecus bituberculatus, $R$. eluminatus, $R$. pritchardi, $R$. sonomae, $R$. spinosus, Spilococcus cactearum, S. keiferi, S. parvicirculus, and Trionymus haancheni.

New synonymy includes transfer of the following species to Chorizococcus : Distichlicoccus alkalinus (Cockerell), Spilococcus aphyllonis (Cockerell), S. irishii (Cockerell), S. neomexicanus (Tinsley), S. reducta Ferris, Trionymus peregrinus (Green), T. rostellum Hoke and T. shaferi Hollinger. Other synonymy includes Chorizococcus peregrinus (Green) (= Trionymus lounsburyi (Brain), misidentification); transfer of Trionymus hypolithus Shotwell to Cryptoripersia Cockerell ; transfer of Trionymus junceus (McConnell) and T. merrilli Ferris to Dysmicoccus Ferris ; and Dysmicoccus modocensis Ferris to Trionymus Berg. 


\section{ACKNOWLEDGMENTS}

During the spring of 1958 , and shortly after the author's appointment to the staff of the University of California, Professor G. F. Ferris of Stanford University kindly offered to delineate any new Coccoidea which needed illustration. At that time the author was aware of the many undescribed species of mealybugs in California, and in order to take advantage of Professor Ferris' unselfish proposal, it was decided to proceed in that direction. Ten mealybug illustrations were prepared by him before his untimely death May 21,1958 . Eight of these drawings are used in this publication; the remaining two proving to represent extreme variants of forms already described were temporarily set aside. The author acknowledges the assistance Professor Ferris gave, not only in preparing these illustrations, but also in constructive suggestions he made regarding the classification of some of these Pseudococcid forms.

The writer is particularly indebted to Dr. Harold Morrison, Coccidologist, United States Department of Agriculture, Agricultural Research Service, Entomology Research Division, Washington, D.C., who critically examined and supplied copious notes about many of the species considered in this publication. His ideas and comments on generic and specific status of most of the species have been unanimously accepted and are here incorporated. $\mathrm{He}$ also read the manuscript, offering remarks and criticisms which have proved to be most helpful. His unselfish expenditure of time and energy on this project is certainly most appreciated.

Dr. A. Balachowsky, Director, Pasteur Institute at Paris, France, coöperated in making available a certain cactus-infesting mealybug which helped to clarify the status of one described as new in this publication. To him the author expresses his deep gratitude.

Miss Helen M. Brookes, Coccidologist of the University of Adelaide, Waite Agricultural Research Institute, South Australia, sent specimens of a mealybug from that area which proved to be identical with a new grass-infesting species found in California. Records of her collections are included in the description of this mealybug. The author is grateful to Miss Brookes for her kind coöperation.

Professor R. Takahashi, Coccidologist in Japan, has kindly made available cotype specimens of Allotrionymus elongatus, recently described by him, which appear very closely related to a California pseudococcid genus here described as new. The author gratefully acknowledges the assistance of Professor Takahashi in this regard.

Mr. R. F. Wilkey, Entomologist with the California State Department of Agriculture, Department of Entomology, has been particularly helpful in assisting the author in reviewing certain mealybug species deposited in their collection. He also shared his ability as an excellent technician in preparing on microscope slides certain, little known pseudococcid forms. His help with this work is gratefully acknowledged.

The University of California Committee on Research at Davis, provided a liberal research grant making available money for assistance in preparing some of the scientific illustrations. To this committee and its various mem- 
bers who played such an important part in getting the grant approved, a sincere acknowledgment is here expressed.

Gratitude is also expressed to Mrs. Julia Z. Iltis, Scientific Illustrator, for preparing 10 of the excellent mealybug illustrations included in this publivation.

\section{BoRkHSENIUS, N. S. ${ }^{9}$}

\section{REFERENCES}

1947. On the taxonomic significance of morphological characters of mealybugs (Coccoidea, Pseudococcus) Doklady Akademii Nauk U.S.S.R. 58(9) :2109, paragraph 3 (in Russian).

1948. Notes on Pseudococcus comstocki (Kuw.) and some allied species (Homoptera: Coccoidea), with descriptions of three new species. Bul. Ent. Res. 39(3):417-21 (in English).

1949. Fauna U.S.S.R. Volume VII. Zool. Inst. Acad. Sci., U.S.S.R. New Series, No. 38:237-41, illus. Moseow-Leningrad (in Russian).

BouChÉ, P. F.

1844. Beiträge zur Naturgeschichte der Scharlachlaüse (Coceina). Ent. Ztschr. v, p. 302. BRAIN, C. K.

1912. Contribution to the knowledge of mealybugs, genus Pseudococcus, in the vicinity of Cape Town, South Africa. Ent. Soc. Amer. Ann. 5(2):177-89, illus.

BüNZLI, G. H.

1935. Untersuchungen über coccidophile Ameisen aus den Kaffeefeldern von Surinam. Mitt. Schweiz. Ent. Ges. 16(6-7) :455-593.

DELOTTO, G.

1958. The Pseudococcidae (Hom.: Coccoidea) described by C. K. Brain from South Africa. Bul. British Mus. (Nat. Hist.) Ent. 7:79-120, illus.

EzzAT, Y. M., and H. S. MCConNELL

1956. The mealybug tribe Planococcini (Pseudococcidae, Homoptera). University of Maryland, Agr. Exp. Sta. Bul. A-84:1-108, illus.

FERRIS, G. F.

1950-53. Atlas of the Scale Insects of North America. Ser. V-VI, The Pseudococcidae, I-II. Stanford Univ. Press, Stanford University, Calif. Illus.

Goux, L.

1941. Contribution à l'étude d'un faisceau d'espèces constituant un sous-genre nouveau du genre Pseudococcus (Hem. Coccidae) (1). Bul. Mus. Hist. Marseille 1(1):6683 , illus.

GREEN, E. E.

1925. Observations on British Coccidae, IX. Ent. Monthly Mag. 61:40-41. Illus.

HAMBLETON, E. J.

1946. Studies of hypogeic mealybugs. Rev. de Entomologia 17(1-2):1-77, illus.

OsBoRN, H. T.

1951. Insect pest survey. Thirty-second annual report, period ending December 31, 1951. California Department of Agriculture Bul. 40(4):154.

TAKAHASHI, $R$.

1958. Key to the genera of Pseudococcidae in Japan, with descriptions of three new genera and two new species (Homoptera). University Osaka Prefecture Bul. Ser.

WEBER, N. A. B, vol. 7, 1957 (actually 1958), p. 4 (separate).

1944. The neotropical coccid-tending ants of the genus Acropyga Roger. Ent. Soc. Amer. Ann. 37(1): 89-122.

Zimmerman, E. C.

1948. Insects of Hawaii, Homoptera: Sternorhyncha, Volume 5, University of Hawaii Press, Honolulu. Pp. 1-464, illus.

${ }^{9}$ According to British Museum System of Transliteration. 
The journal Hilgardia is published at irregular intervals, in volumes of about 600 pages. The number of issues per volume varies. Subscriptions are not sold. The periodical is sent as published only to libraries, or to institutions in foreign countries having publications to offer in exchange.

You may obtain a single copy of any issue free, as long as the supply lasts; please request by volume and issue number from:

\section{Agricultural Publications \\ 207 University Hall \\ 2200 University Avenue \\ Berkeley 4, California}

The limit to nonresidents of California is 10 separate issues on a single order. A list of the issues still available will be sent on request. 